\title{
Postulated Weather Modification Effects of Large Energy Releases
}

February 1977

Prepared for The Nuclear

Regulatory Commission 


\title{
NOTICE
}

This report was prepared as an account of work sponsored by the United States Government. Neither the United States nor the United States Nuclear Regulatory Commission, nor any of their employees, nor any of their contractors, subcontractors, or their employees, makes any warranty, express or implied, or assumes any legal liability or responsibility for the accuracy, completeness or usefulness of any information, apparatus, product or process disclosed, or represents that its use would not infringe privately owned rights.

\author{
PACIFIC NORTHWEST LABORATORY \\ operated by \\ BATTELLE \\ for the \\ ENERGY RESEARCH AND DEVELOPMENT ADMINISTRATION \\ Under Contract EY-76-C-06-1830
}

\author{
Printed in the United States of America \\ Available from \\ National Technical information Service \\ U.S. Department of Commerce \\ 5285 Port Royal Road \\ Springfield, Virginia 22151
}

Price: Printed Copy $\$ \_*$; Microfiche $\$ 3.00$

$\begin{array}{lc}\text { *Pages } & \begin{array}{c}\text { NTIS } \\ \text { Selling Price }\end{array} \\ 001-025 & \$ 4.50 \\ 026-050 & \$ 5.00 \\ 05 i-075 & \$ 5.50 \\ 076-100 & \$ 6.00 \\ 101-125 & \$ 6.50 \\ 126-150 & \$ 7.00 \\ 151-175 & \$ 7.75 \\ 176-200 & \$ 8.50 \\ 201-225 & \$ 8.75 \\ 226-250 & \$ 9.00 \\ 251-275 & \$ 10.00 \\ 275-300 & \$ 10.25\end{array}$


BNWL -2162

33679000627291

POSTULATED WEATHER MODIFICATION

EFFECTS OF LARGE ENERGY RELEASES

by

J.V. Ramsdell

B.C. Scott

M.M. Orgil1

D.S. Renné

J.E. Hubbard

K.A. McGinnis

February 1977

Battelle

Pacific Northwest Laboratories

Richland, Washington 99352 
$\bullet$

$\checkmark$

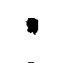

$-$

$\vdots$

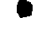

4

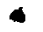

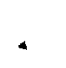

$-$

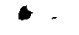


Postulated impacts of large energy releases have been examined in the light of existing technical information. The magnitudes of direct atmospheric modifications have been estimated, and the ecological and economic implications of the modifications have been explored.

Energy releases from energy centers (10 to 40 power plants at a single site) and individual power plant clusters ( 1 to 4 power plants) have been considered. In the atmosphere the energy will exist initially as increased temperature (sensible heat), moisture (latent heat), and air motion (kinetic energy). Addition of energy could result in increased cloudiness and fog, and changed precipitation patterns. Potential secondary atmospheric impacts include decreased daytime and increased nighttime temperatures, early initiation of convective clouds, and increased frequency of hail, lightening and convective vortices.

Large energy releases may increase the temperature of the air by a Celcius degree or more. The magnitude of the increase and the volume of air affected would be functions of the cooling systems used. A large energy center may produce a heat island that is capable of influencing airflow and precipitation patterns; but it is unlikely that a single cluster of power plants would significantly effect either. The moisture released by evaporative cooling systems could result in increased cloudiness and fog. A large energy center might increase precipitation amounts by up to $30 \%$, depending upon cooling systems used and the region of the country. These increases might occur as far as 30 to $50 \mathrm{~km}$ from the energy center. In general, the predicted atmospheric modifications would be difficult to identify statisticaliy because of dispersion and the natural variability of atmospheric phenomena.

Alteration of the atmospheric energy balance by addition of heat and moisture has ecological implications. Changes in atmospheric temperature, humidity and direct solar radiation may result in changes in species diversity and productivity within natural ecosystems and in changes in agricultural productivity. In natural ecosystems, the responses to the various 


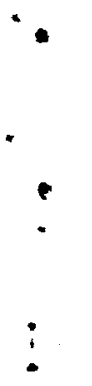

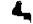


postulated atmospheric modifications tend to be offsetting. The response to an increase in temperature would be countered by the response to a decrease in direct solar radiation, etc. As a result, the net ecosystems response to large energy releases would be highly site specific. Similar conclusions have been reached for agricultural responses. Specific responses would be governed by species, region of the country and the form in which the energy is released. They could be either positive or negative. The direct physiological effects of the postulated atmospheric changes on human and animal populations would be minimal. Humans would, more probably, be affected by impacts restricting their activities.

A framework for economic analysis of the impacts of the postulated atmospheric modifications was established on the basis of costs and benefits. Willingness-to-pay was selected as the appropriate measure for valuing each impact. The primary and secondary atmospheric modifications may affect recreation, transporation, and aesthetics as well as agriculture and forestry. Economic values can be placed on some of the effects. However, the willingness of people to pay to gain benefits and avoid damages in many cases can only be determined through extensive surveys. The economic consequences of a given energy release would be highly site specific. 


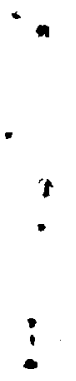

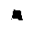

4

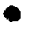

$+$

$\therefore$ 


\section{CONTENTS}

SUMMARY . . . . . . . . . . . . . . . . . . . . . 1 . .

1.0 INTRODUCTION . . . . . . . . . . . . . . . . . . . . . 1

1.1 NECESSITY FOR ENERGY RELEASES. . . . . . . . . . . . 2

1.2 MAGNITUDE OF LARGE ENERGY RELEASES . • . . . . . • . . . 2

1.3 TRANSFER OF ENERGY TO THE ATMOSPHERE . . . . . . . . . . 4

1.4 ATMOSPHERIC EFFECTS OF ENERGY RELEASES. . . . . . . . . 4

1.5 TIMING AND LOCATION OF ATMOSPHERIC EFFECTS . . . . . . 5

1.6 REPORT ORGANIZATION . . . . . . . . . . . . . . . . 6

2.0 ATMOSPHERIC EFFECTS OF LARGE ENERGY RELEASES . . • . . . . . 9

2.1 POSTULATED ATMOSPHERIC EFFECTS OF ENERGY RELEASES . . . . 9

2.1.1 Magnitude of Energy Center

Induced Temperature Perturbations . . . . . . 10

2.1.2 Formation of a Heat Island . . . . . . . 12

2.1.3 Initiation of Convective Clouds. . . . . . . . 13

2.1.4 Increased Moisture . . . . . . . . . . . 18

2.1.5 Concentration of Vorticity . . . . . . . . . . 23

2.2 CONSEQUENCES OF THE POSTULATED EFFECTS. . . . . • . . 26

2.2.1 Enhancement of Cloudiness and Precipitation. . . . 26

2.2.2 Enhancement of Fog and Stratus . . . . . . . 35

2.2.3 Concentration of Vorticity . . . . . . . . . 36

3.0 EFFECTS OF HEAT AND MOISTURE RELEASES ON THE BIOSPHERE . . . . 39

3.1 ENVIRONMENTAL CHANGES AND THEIR RELATION TO THE BIOSPHERE . 39

3.1.1 Radiation and Heat Balance . . . . . . . . . 39 
3.1 .2 Moisture Budget. . . . . . . . . . . . . . . 42

3.1 .3 Other Atmospheric Effects . . . . . . . . . . . 44

3.2 EFFECTS ON PLANTS AND PLANT COMMUNITIES . . . . . . . . . 44

3.2.1 Temperature and Moisture. . . . . . . . . . . 47

3.2.2 Radiation and Photosynthesis . . . . . . . . 52

3.2.3 Fog and Dew. . . . . . . . . . . . . . 53

3.2.4 Summary of Ecosystems Effects . . . . . . . . . . 54

3.3 EFFECTS ON AGRICULTURE AND AGRICULTURAL PRODUCTIVITY. . . . . 54

3.3.1 Response of Individual Agricultural Products
to Climatic Changes from Energy Centers. . . . . . . 55

3.3.2 Summary of Agricultural Effects . . . . . . . . . 59

3.4 EFFECTS ON ANIMALS AND ANIMAL POPULATIONS . • • • • . • . 61

3.4.1 Temperature . . . . . . . . . . . . . . . . 62

3.4.2 Precipitation and Moisture . . . . . . . . . 62

3.4.3 Fog, Dew and Hail . . . . . . . . . . . 63

3.4.4 Effects on Livestock Animals and Their
Agricultural Implications . . . . . . . . . . . . 63

3.5 EFFECTS ON HUMANS AND HUMAN ACTIVITIES . . . . . . . . . . 64

3.5.1 Human Comfort Indices. . . . . . . . . . . . . 65

3.5.2 Summary of Human Effects. . . . . . . . . . . 66

4.0 ECONOMIC ANALYSIS. . . . . . . . . . . . . . . . . . . . . 67

4.1 ENVIRONMENTAL ECONOMICS THEORY . . . . . . . . . . . 67

4.2 EFFECTS OF FOG . . . . . . . . . . . . . . . . 72

4.2.1 Effects of Fogging on Air Traffic. . . . . . . . . 72

4.2.2 Effects of Fogging on Ground Trave1 . . . . . . . . 74

4.2.3 Aesthetic Effect of Fog . . . . . . . . . . . 76 
4.3 VALUES OF PRECIPITATION, HUMIDITY, TEMPERATURE . . . . . . 79 4.3.1 Agricultural Effects. . . . . . . . . . . 79 4.3.2 Recreational Effects... . . . . . . . 79 4.3.3 Health Effects . . . . . . . . . . . . 80 4.3.4 General Quality of Life Effects. . . . . . . . 80 4.3.5 Effects of Tornado Damage. . . . . . . . . . . 81 4.4 SUMMARY OF ECONOMIC EFFECTS . . . . . . . . . . . . . 82 REFERENCES . . . • . . . . . . . . . . . . . . . . 83

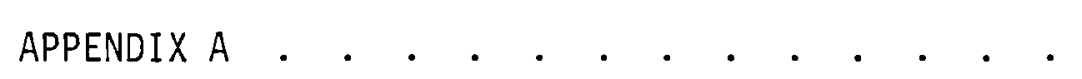
APPENDIX B APPENDIX C 
1-1 A Qualitative Plot of Power Dissipated by Various Natural and Anthropogenic Activities as a Function of Their Scale Size .

2-2 Change in Relative Humidity with Temperature for 36,000 MWe Energy Center and an Initial Relative Humidity of $40 \%$. . . . . 19

2-3 Convective Precipitation Enhancement from a Large (36,000 MWe) Energy Center. The isopleths can be used to estimate annual precipitation increases $(\mathrm{mm})$ at a particular site if an energy center is located at that site... . . . . . . . 29

2-4 Spring (March, Apri1, May) Convective Precipitation Increases (mm) from a Large $(36,000$ MWe) Energy Center. . . . . . . . 29

2-5 Summer (June, July, August) Convective Precipitation Increases (mm) From a Large (36,000 MWe) Energy Center . . . . . . . . . 30

2-6 Autumn (September, October, November) Convective Precipitation Increases $(\mathrm{mm})$ from a Large $(36,000 \mathrm{MWe})$ Energy Center . . . . 30

2-7 Winter (December, January, February) Convective Precipitation Increases $(\mathrm{mm})$ from a Large (36,000 MWe) Energy Center . . . . 31

2-8 Percentage Increase in Total Annual Precipitation Due to Convective Precipitation Enhancement from a Large $(36,000$ MWe) Energy Center.

2-9 Precipitation Rate Increase Produced by Allowing Precipitation Initially Falling at Rate $R_{0}$ to Pass Through a Plume of a Given Thickness. The plume water content was assumed to be $0.5 \mathrm{~mm}^{-3}$. . . . . . . . . . . . . . . . 34

2-10 Geographical Distribution of Potential Fog Increases From Cooling Tower Effluents (EG\&G, 1971) . . . . . . . . . . . . . 36

3-1a Schematic Representation of the Daytime Radiation Balance After Tanner (1968)

3-1b Schematic Representation of the Daytime Energy Balance After Tanner (1968).

3-1c Schematic Representation of the Nighttime Energy Balance After Tanner (1968)

3-2a Suggested Change in Vegetation Zones for North America in Response to a $-7^{\circ} \mathrm{C}$ Change in Mean Annual Temperature (From Fareed and Caldwe11 in CIAP-5, 1975) 
3-2b Suggested Change in Vegetation Zones for North America in Response to a $\pm 20 \%$ Change in Precipitation (From Fareed and Caldwell in CIAP-5, 1975) . . . . . . . . . . 50

3-3 The Streams of Energy Flow to and from an Organism in Its Natural Environment(Figure from Gates (1963)) . . . . . 61

4-1 Components Used in Valuing Private Market Goods . . . . . 69

4-2 Incorporation by External Effects . . . . . . . . . . 71

\section{TABLES}

3-1 Summary of Environmental Considerations and the Potential Impact of Wet Cooling Systems . . . . . . . . . . . 45

3-2 Summary of Impacts of Climatic Change on Agricultural Yields. . . . . . . . . . . . . . . 57

3-3 Summary of Estimates of Impacts on Agricultural Yields Due to a Postulated Change in Mean Temperature of $+2^{\circ} \mathrm{C}$ and Annual Precipitation Increase of 10 to $20 \%$ (From CIAP-5, 1975) . . . . . . . . . . . . . . . . 60

4-2 Average Bids in Dollars for Emission Control Levels . . . . 78 


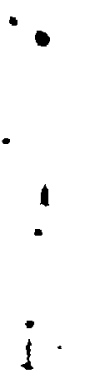




\section{POSTULTED WEATHER MODIFICATION EFFECTS \\ OF LARGE ENERGY RELEASES}

\subsection{INTRODUCTION J.V. Ramsde11}

A11 forms of thermal power production and many industrial precesses release energy to the environment. Inevitably this energy makes ts way into the atmosphere. It is appropriate to examine the direct impacts on the atmosphere and the indirect impacts on ecosystems and economics a:s the magnitudes of individual releases become larger. The purpose of this report is to place the impacts that have been postulated in the literature, (e.g., Rotty, 1974; Hanna and Gifford, 1975), for large energy releases in perspective consistent with existing technical information. Changes in atmospheric characteristics (temperature, moisture, wind, etc.) may or may not actually occur. Assuming that they will occur, this report estimates the magnitude of possible atmospheric impacts and their ecological and economic implications.

The impetus for this study was the exploration of the Nuclear Energy Center concept as an alternative to dispersed power plant siting. The energy center concept generally involves grouping 10 to 40 power plants on a common site. The center may contain supporting fuel cycle facilities; however, the major energy releases and atmospheric effects are expected to be associated directly with power generation. Where models are used to estimate the magnitude of the atmospheric effects of energy centers, a 36 power plant center producing 36,000 $\mathrm{MW}_{\mathrm{e}}$ is assumed. The problems examined are independent of origin of the energy. Energy releases of similar magnitude are associated with large urban areas and many natural phenomena.

On a smaller scale, there is interest in the potential impacts of energy releases from a single cluster of 1 to 4 power plants. The potential impacts of these smaller energy releases have been estimated by linearly scaling down the energy center impact estimates. 


\subsection{Necess ity For Energy Releases}

As lorg as thermal power plants are used for the production of electrical energy, a significant portion of the thermal energy produced will be released to the environment rather than converted to electrical energy. The laws of the -modynamics which govern the thermal to electrical energy conversion indici: :e that $100 \%$ conversion efficiency is not possible or even approachable. Wit ti current conversion technology, fossil-fuel power plants can attain abou: 40\% efficiency; nuclear plant efficiencies are 1 imited to about $33 \%$. Advances in technology are not likely to significantly improve these efficiencies. For example, the advanced design, high temperature, gas-cooled nuclear pows $r$ plants would only be expected to increase overall efficiency to about $36 \%$, The remaining energy, almost $2 / 3$ of the total produced, would still be rel sased to the environment.

The the mal energy which remains following thermal-electrical conversion is generally low grade (represented by small temperature differences). This energy may ive some economic value, but it cannot efficiently be converted to another energy form. Thus even if a use is found for the-energy, a large portion will still be released to the environment; however, the energy release will be spread over a wider area. Considering the cost of transporting low grade energy and the large residual amount of this energy following thermalelectrical conversion, it is improbable that much of it can be used.

\subsection{Magnitude of Large Energy Releases}

The magnitude of energy releases under consideration can be placed in perspective using Figure 1.1 (Slinn, 1975) in which power (energy release rate) is shown as a functicl of area of release. Further perspective is provided by considering the power used by an oven, the household appliance with the largest energy use. I: has horizontal area of about $10^{-1} \mathrm{~m}^{2}$ and uses about $10^{-2} \mathrm{MW}_{e}$; t therefore vould be located off the lower left-hand corner of Figure 1.1. In contrast, the smallest energy release considered in this study is that from a sin:le $1000 \mathrm{MW}_{e}$ power plant which is about 100,000 times larger than from an oven. The areal extent of the release is approximately $1000 \mathrm{~m}^{2}$; is represented in Figure 1.1 by the single cooling tower. 


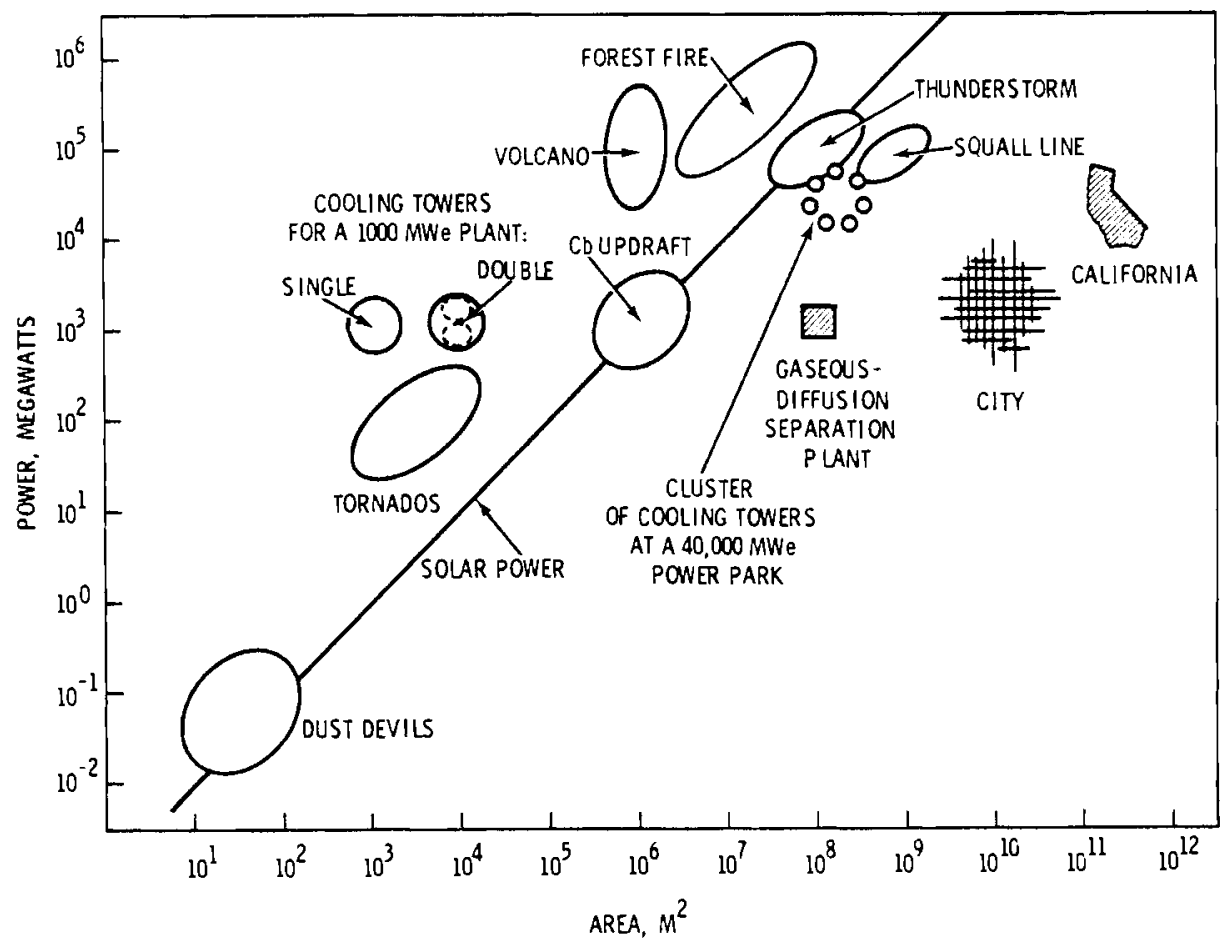

FIGURE 1.1. A Qualitative Plot of Power Dissipated by Various Natural and Anthropogenic Activities as a Function of Their Scale Size

The largest energy release considered is for an energy center or power park comprised of 40 power plants each rated at $1000 \mathrm{MW}_{3}$. The areal extent of the energy releases in an energy center is more than 40 times that for a single power plant because of the spacing required between cooling systems to maintain their efficiency.

The ratio of energy released to areal extent of the release is frequently used to describe energy releases. Since the information on the actual magnitudes of the release and the area is lost in these ratios, the ratios must be evaluated by comparison with a standard. The standard chosen most frequently is the solar energy flux at the earth's surface. For a latitude of $45^{\circ} \mathrm{N}$ at the summer solstice, the noon solar flux on a clear day is about $10^{-3} \mathrm{MW} / \mathrm{m}^{2}$. This flux is represented in Figure 1.1 by the line labeled Solar Power. Those processes that have energy releases with higher density than the solar flux would be located above the line; those with lower density below it. Thus the energy density of the smallest release under consideration is greater than that of incoming solar radiation, while the largest releases have densities less than incident solar radiation. 


\subsection{Transfer of Energy To The Atmosphere}

Energy released from power plants is transfered to the atmosphere by three mechanisms; conduction, convection and thermal radiation. Conduction and convection involve contact between the atmosphere and the power piant cooling system; the energy transfer is accomplished by increases in air temperature and moisture content at the cooling system. The dominant mechanism depends upon atmospheric conditions and cooling system type. Thermal radiation occurs as a result of the temperature of the cooling system. In radiative transfer, the energy lost by the cooling system may be absorbed by the atmosphere. This may occur in moist air near the earth's surface, or in an upper level cloud layer. Or, the radiant energy may not be absorbed in the atmosphere and therefore may be lost to space.

\subsection{Atmospheric Effects of Energy Releases}

The energy released by power plants may take several forms in the atmosphere; increased temperature of the air (sensible heat); increased moisture content (latent heat); increased atmospheric kinetic energy (wind); and increased noise. The changes in the first three energy forms are generally considered to be the most important atmospheric effects of large energy releases; these and secondary effects resulting from them are discussed in detail in this report. Noise is not considered, but it may have some local secondary effects.

The three direct atmospheric effects of energy release under consideration can produce secondary atmospheric effects that may be more noticeable than the direct effects. Among these secondary effects is an increase in the frequency of cloudiness and fog, a direct result of increasing atmospheric moisture. An increase in cloudiness could also be caused by warming the atmosphere and initiating convective processes which lead to cloud formation. An increase in cloudiness or fog will, in turn, alter the radiation balance between the earth and the atmosphere resulting in decreased daytime temperatures and increased nighttime temperatures. Large energy releases could affect precipitation in several ways. An increase in the total amount of precipitation might occur, but in many cases the precipitation would be simply redistributed. If large energy releases initiate or enhance significant 
convective activity, increased precipitation may be accompanied by hail and lightning. Large energy releases may also contribute to formation of concentrated convective vortices.

\subsection{Timing and Location of Atmospheric Effects}

The specific atmospheric effects resulting from large energy releases depend upon the natural climate of the region, the direction and distance from the release, and the cooling system type and configuration. Many postulated atmospheric effects would be difficult to distinguish from naturally occurring phenomena, because they would occur under similar conditions and would be lost within normal atmospheric variability. For example, increases in fog might occur as earlier formation and later dissipation of fog rather than increases in the total number of occurrences. Similarly, additional convective activity might occur as earlier appearance of cumulus clouds on those days on which they would naturally appear. In these cases actual verification of predicted effects would be difficult, if not impossible.

Many atmospheric conditions that are susceptible to modification by large energy releases are seasonal in nature. Both fog and the initiation of cloud formations might be in this category in some regions of the country. As a result both the type and timing of weather modifications tend to be specific to the location of the energy release.

The effects discussed in this report are based on the assumption that weather modifications are associated with particular wind directions. As a result they tend toward maximum values. Lower values are likely, because of wind direction variability. The effects are initially evaluated for a maximum energy release from a large energy center or power park; when appropriate scaled down estimates are given for energy releases from isolated clusters of 1 to 4 power plants.

The magnitudes of the postulated effects will vary with distance from the point of energy release. Some are a maximum at the release point and decrease rapidly with increasing distance. Fog near a cooling pond is an example of this. In other cases, such as increased precipitation from convective storms, the maximum effect would occur well downwind of the energy source. 
Weather is the state of the atmosphere at a specific time. Climate refers to a statistical description of weather. Climate involves long term averages, seasonal and diurnal cycles, and random variability. Postulated individual atmospheric impacts of large energy release are weather modifications. These may be readily observable such as a visible plume from a cooling tower. Climate modification may occur if weather modification occurs; the spatial and temporal distribution of the potential weather modifications makes the magnitude of the accompanying climate modifications small. The naturally occurring random variability of weather would make identification of climate modifications resulting from large energy releases difficult. Possible exceptions to this would be found near ground level release points.

\subsection{Report Organization}

The primary and secondary effects of energy releases are examined in detail in Section 2, Atmospheric Effects of Large Energy Releases. Models ranging from sophisticated cloud models to elementary box models are used to provide semi-quantitative estimates of the potential atmospheric effects. These models do not treat cooling system types explicitly. Therefore some interpretation of the results is required to account for the variations of effects resulting from the variation of cooling system types. Where fogging increases are predicted, they are generally associated with low level evaporative cooling systems (i.e., cooling ponds and spray ponds). If natural draft cooling systems are used the fogging increase should generally be interpreted as an increase in cloudiness. Increases in convective activity are more properly associated with cooling towers than with cooling ponds. The release of energy from all cooling systems will tend to produce a heat island but the heat island may not be observable at ground level beyond the immediate vicinity of the cooling system.

Section 3, Effects of Heat and Moisture Releases on the Biosphere, considers the potential ecological impacts of potential weather modifications due to large energy releases. These ecological effects discussed will not be widespread, but will occur in relatively small areas downwind of release point. Some of the postulated weather modifications would be expected to be associated with specific wind directions, others would not. 
Evaluation of the ecological effects of weather modification is complicated by regional variations in the response of a single species to the same modification and differing responses of various species within a region. With this variability it is difficult to describe potential atmospheric modifications as either beneficial or adverse. The approach taken in this report is to provide estimates of the ecological effects for representative species for a variety of regions throughout the country.

In Section 4, Economic Effects of Large Energy Releases, several aspects of the economic consequences of large releases of energy to the atmosphere are discussed in theoretical and methodological terms. The section also discusses means for obtaining the additional information required for complete analysis. However, complete economic analys is of the consequences of large energy releases cannot be made until specific energy release sites are known or cross-sectional data are developed, and detailed atmospheric and ecological evaluations are completed.

The evaluation of economic consequences requires not only that all the ecological consequences of the weather modification be known, but also that monetary values be placed on the human responses to the modifications. However, a substantial body of environmental theory exists that provides the rationale to address this. These evaluations must be completed and combined before economical consequences can be termed either beneficial or adverse for society. 


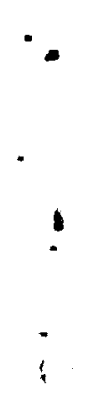




\subsection{ATMOSPHERIC EFFECTS OF LARGE ENERGY RELEASES}

\section{B.C. Scott and M.M. Orgili}

The atmosphere can transform, transfer, and dispose of excess energy through mechanisms extending from global scale circulations and radiative transfer through convection and latent heat release to molecular scale turbulent transport. When attempting to evaluate the local and regional consequences of vast quantities of energy rejected from large energy centers, it quickly becomes apparent that the dissipation mechanisms will interact over several scales of motion, from synoptic scale extratropical cyclones to molecular scale turbulent transport. Previous authors (e.g., Slinn, 1975; Hanna and Gifford, 1975; Rotty, 1974) have sought to establish analogies between natural dissipation mechanisms and proposed energy center configurations in order to predict the impact of energy released from an energy center. Such analogies are presently the only feasible way to forecast the consequences of releasing the massive quantities of heat and moisture into the atmosphere. Current numerical models are, in general, inadequate for detailed prediction of contributions to cloudiness (with the possible exception of fog), precipitation and atmospheric motions that result from large energy releases.

\subsection{Postulated Atmospheric Effects of Energy Releases}

If we envision a large 30,000 to $40,000 \mathrm{MW}_{\mathrm{e}}$ energy center, occupying an area between $35 \mathrm{~km}^{2}$ and $400 \mathrm{~km}^{2}$, composed of clusters of 3 to $41000 \mathrm{MW}$ reactors and separated from neighboring clusters by a few kilometers, then we can begin to estimate the magnitudes of the induced perturbations. The total energy rejected from such a site is comparable to the energy emitted by large cities (Hanna and Gifford, 1975). However, the energy emitted per unit area is far greater for a large energy center than for a large city. A 40,000 $\mathrm{MW}_{\mathrm{e}}$ energy center may occupy roughly the same area as Washington, DC, but will require the dissipation of approximately eight times as much energy (Koenig and Bhumralkar, 1974). Cities, however, expel most of their energy in sensible heat form (Koenig and Bhumralkar, 1974), while an energy center using evaporative cooling systems extensively may release as much as $80 \%$ of its rejected energy by evaporation of water (Ramsde11, 1977). Even so, the 
sensible heat flux from large cities and large energy centers will be compar$a b l e$ in magnitude. The meteorological consequences of sensible heat flux from a large energy center can be expected to be similar to those produced by a large city. The additional energy emitted as latent heat from a large energy center will only amplify the expected consequences.

Estimation of the meteorological effects of energy releases through analogy between power generating facilities and cities is not valid when the facility consists of a single cluster of a few ( 1 to 4) $1000 \mathrm{MW}_{e}$ power plants. Compared with a large energy center, the area impacted by a cluster of 1 to 4 power plants will be vastly reduced and the heat flux will be greater. The potential modification of meteorological phenomena will be limited to an occasional cloud or long plume and to fogging.

Aithough the energy fluxes of a city and a large energy center are comparable, differences between the two make direct comparisons dubious. The most notable difference is in surface roughness. Frictionaliy-induced regions of convergence and divergence can be as important in producing the observed meteorological anomalies near large cities as other factors. It is not at all obvious that a large energy center will present a barrier to the prevailing winds as do cities. Certainiy a cluster of one to four power plants will have insignificant effects on the prevailing air flow patterns.

A second major difference between energy centers and cities involves land use, and in particular the discharge of aerosol and gaseous poliutants. Large cities tend to produce increases in precipitation downwind from the city (for example, see Changnon and Huff, 1973). Just how this precipitation increase is related to the aerosol loading of the city atmosphere is uncertain. The energy center is not expected to discharge large quantities of aerosol into the atmosphere.

\subsubsection{Magnitude of the Energy Center Induced Temperature Perturbations}

The air above an energy center can be expected to consist of plumes of warm air which eventually tilt in the direction of the prevailing wind and may merge with each other to produce a volume of air heated above the surrounding undisturbed environment. We can estimate the heating by appiying the first law of thermodynamics in the form 


$$
\dot{h}=\mathrm{mC}_{\mathrm{p}} \frac{\Delta \mathrm{T}}{\Delta \mathrm{t}} \text {. }
$$

Here $m$ is the mass of air heated by the energy center $(a)$ and is defined as the product of air density times the volume of air heated in time $\Delta t$. For these estimates, we assume that the volume of heated air can be represented by the box illustrated in Figure 2.1. The depth, $\Delta h$, of the heated volume is represented by the approximate depth of the mixing layer, and the width, $\Delta y$, is represented by the dimension of the energy center normal to the wind. The length, $u \Delta t$, of the heated volume is variable and depends upon the wind speed. With this configuration in mind, the mass of the air heated by an energy center can then be defined as $m=\rho \Delta h \Delta y(u \Delta t)$. Thus,

$$
\Delta T=\frac{\dot{h}}{u C_{p} \rho \Delta h \Delta y} .
$$

By assuming the depth of the heated volume is $1 \mathrm{~km}$, the width of the center is $10 \mathrm{~km}$, the wind speed is $5 \mathrm{~m} \mathrm{~s}^{-1}$, for 36 plants of $1000 \mathrm{MW}$ each, $0.3<\Delta \mathrm{T}<1.14 C^{\circ}$. The variation in $\Delta \mathrm{T}$ comes from assuming that the sensible heat release may vary between 20 and $80 \%$ of the total rejected energy output. If a cluster of 4 power plants on $4 \mathrm{~km}^{2}$ of land is assumed, the above for mula yields temperature changes of $0.2<\Delta T<0.6 C^{\circ}$. Naturally these values of $\Delta T$ are only estimates; the product $u \Delta h \Delta y$ can easily vary by a factor of two. This simple box model assumes uniform, instantaneous mixing of the air receiving the exhaust. In reality regions of warmer and cooler air would exist in the box.

Temperature perturbations as smal1 as $10^{\circ}$ can initiate both moist and dry convection. Thus we find that the predicted temperature variation for the large $\left(36,000 \mathrm{MW}_{e}\right)$ energy center is meteorologically significant. However, as the number of $1000 \mathrm{Ml}$ e power units is reduced to four, the induced temperature perturbation decreases to the point where it becomes smaller than natural fluctuations.

\footnotetext{
(a) Other symbols are defined in Appendix A.
} 


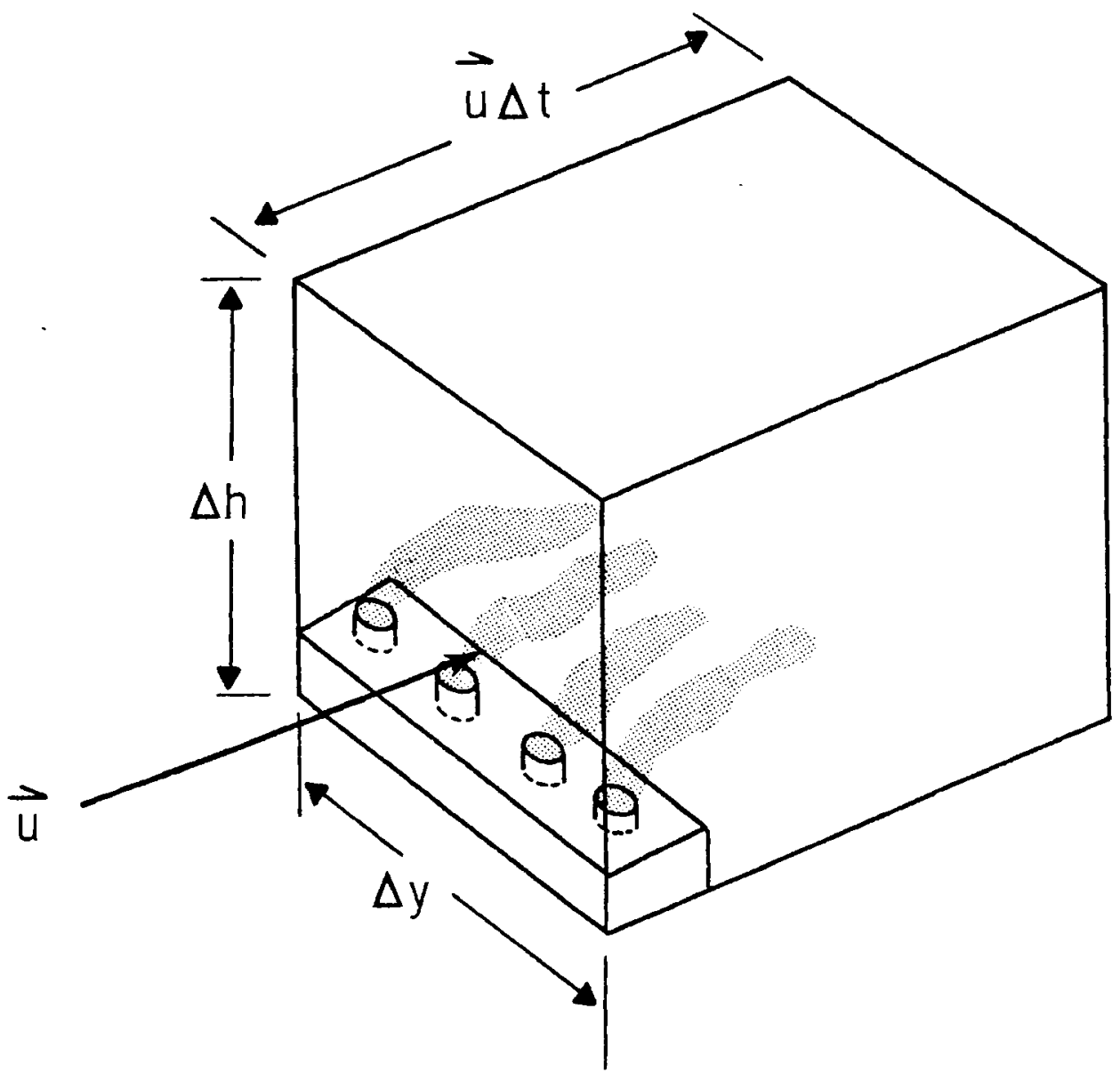

FIGURE 2.1. Geometry of the Volume Heated by an Energy Center

\subsubsection{Formation of a Heat Island}

The energy released from a large energy center will likely produce what is commonly called a heat island or thermal mountain (Malkus, 1963) where the upward heat flux causes motions that closely resemble flow over a mountain ridge. Malkus and Stern (1952) have used a linear model to predict that the crest of this "thermal mountain" is located slightly downwind from the downwind edge of the heat source and that the magnitude of the "mountain" depends upon the magnitude of the surface temperature perturbation and the undisturbed a tmospheric lapse rate. In general, their analysis predicts the mountain height to be approximately one half as high in kilometers as the surface 
perturbation is in degrees Celcius. Thus, if this linear theory is appropriate, a large energy center could produce a thermal mountain ranging in height from 200 to $1000 \mathrm{~m}$.

The more recent numerical modeling of Vukovich et al., (1976) applied a complete set of dynamic equations to synoptic conditions frequently encountered at St. Louis. They found that for a surface temperature perturbation of approximately $2^{\circ} \mathrm{C}$, the top of the positive thermal perturbation was near $300 \mathrm{~m}$ and that vertical velocity perturbations extended to about $1.2 \mathrm{~km}$. Their study also illustrated that as the wind speed increased, the intensity of the heat island circulation decreased and the heat plume associated with the heat is land extended further downwind.

The observations presented by Dettwiller and Changnon (1976) support both of the above studies. They found that for midday surface perturbations of 1 to $3 \mathrm{C}^{\circ}$, the heat island of St. Louis often extended 500 to $1500 \mathrm{~m}$ above the city.

The above theoretical and observational studies imply that a large energy center will have a detectable impact on a local scale. At the very least, the "thermal mountain" produced by a large energy center can deflect air up, over and around the sides of the "mountain" resulting in low level convergence, upward vertical motion and enhanced cloudiness and precipitation. Enhanced precipitation will result either from stimulated convective activity or from increased frontal precipitation. By contrast, a cluster of one to four reactors would not produce a heat island of any consequence because the initial extent of the heat island is small and the temperature perturbation decreases rapidly as the area increases.

\subsubsection{Initiation of Convective Clouds}

Cumulus clouds associated with individual cooling tower plumes in an energy center will be readily detectable by the general public. Such clouds are occasionally observed now from existing 1000 and 2000 MWe facilities (Spurr, 1974; Oak Ridge Staff, 1974) and can, in general, be predicted on a daily basis with simple one-dimensional cloud models. More complex models 
show that under certain conditions, the heat and moisture source from an entire energy center will also readily produce convective clouds (e.g., see Hane and Drake, 1976). However it is not clear that the formation of a cloud through enhanced low level buoyancy or forced lifting will result in increased precipitation. The actual formation of a cloud depends roughly on the height of the lifting condensation level ( $L C L$ ), and whether or not there is positive buoyancy when the LCL is reached. For example, a $3.1 \mathrm{~km} \mathrm{LCL}$ is not likely to be reached by a buoyant element originating at the surface and mixing with the environment as it ascends; particularly if there is any horizontal wind or if the ambient atmosphere is even slightly stable. Given the necessary input conditions, existing one-dimensional Lagrangian cumulus models (e.g., Weinstein, 1970) appear to predict the initial cloud formation stage adequately. Their prediction of subsequent cloud growth and precipitation formation are considerably more suspect (Scott, 1976) because of the parameterization of cloud microphysics. By adjusting constants in the parameterization, signficantly different results can be predicted.

Other factors are important in determining convective cloud and precipitation formation. The temperature of cloud base (and therefore its height) are related to the probability of precipitation. At colder temperatures less water is available to be condensed. If the same number of cloud condensation nuclei are available at the cloud bases of two different clouds, then in the cloud with the colder base the droplets will be smaller and will take longer to grow to precipitation size (if other conditions are equal). Thus, there is an implied seasonal and latitudinal dependence on convective cloud formation; such a dependence will be apparent at most power parks.

The ambient aerosol number concentration and size distribution are also important in precipitation formation. A continental aerosol size distribution will enable a prolific production of cloud droplets compared to a maritime size distribution. However, large numbers of cloud droplets are detrimental to precipitation production because the time required to grow precipitationsized drops is greatly increased. Subsequently, in order for precipitation to form, continental clouds must extend much higher than maritime clouds to allow time for the greater in-cloud growth. For example, Petterson (1956) presents 
results indicating convective clouds in England had to reach $4.6 \mathrm{~km}$ to have a $50 \%$ precipitation probability, while Battan and Braham (1956) found that convective continental clouds over the central United States had to extend to $7.6 \mathrm{~km}$ before they had the same probability.

Malkus (1963) emphasizes that an important feature in precipitation development is how long a precipitation particle has to develop in a cloud. Thus, precipitation could theoretically develop from a sufficiently long plume. However, in the absence of any vertical ascent, cloud supersaturation with respect to water would be near zero and all but ice particles would be unable to grow large enough to fall (maximum ice particle growth would occur at temperatures near $-12^{\circ} \mathrm{C}$ ).

An important feature implicit in these "cloud depth" discussions is the preexistence of an unstable or conditionally unstable atmosphere. No measurable amounts of liquid precipitation will be produced until the plumes from cooling devices trigger (or release) the natural instability in the atmosphere. Natural cloud initiation mechanisms such as turbulent eddies have size scales and temperature/moisture perturbations similair to the perturbations expected from a cluster of cooling devices (see for example, Kaimel and Businger, 1970). Thus, it is probable that convective activity will only be initiated on days when there are (or will be) naturally occurring convective clouds. The energy center may produce convection sooner in the day and prolong it into the nighttime hours. Indeed, such effects have already been documented at 2000 MWe sites in England (Spurr, 1974).

The recent modeling efforts of Hane and Drake (1976) have also indicated that convective precipitation can be enhanced by up to $10 \%$ if the clouds happen to advect over a large $(40,000 \mathrm{MWe})$ energy center. As in the above discussions, we would expect the magnitude of the enhancement to depend strongly upon atmospheric stability, temperature at cloud base and cloud top, and the colloidal stability of the cloud (input aerosol size distribution). 


\subsubsection{Prediction of Convective Activity with Existing Cloud Models}

A major difficulty in predicting the frequency and intensity of convective activity initiated by an energy center with simple cloud models is the current inability of such models to describe how individual plumes will interact downwind from their origin. Existing one-dimensional models (e.g., Weinstein and Davis, 1968; Simpson and Wiggert, 1969) require the initial cloud radius as input data. Such data is simply not available. The resultant calculations from models are also extremely sensitive to the magnitude of the initial temperature and moisture perturbations, and to the time-dependent radial dimensions of the cloud (Soong, 1974; Lopez, 1973). Again if plume merging is not described, such information is not available.

The results from one-dimensional models depend on the choice of atmospheric temperature and moisture profiles. For example, Boyack and Kearney (1973) claim to have selected atmospheric profiles typical of stability and moisture conditions in which natural convective showers and thunderstorms occur. Based upon these profiles, and using the one-dimensional WeinsteinDavis (1968) model, they concluded that plumes from a 1000 MWe dry cooling tower were not likely to produce large clouds. Unfortunately of the twelve profiles selected, only one truly represented an air mass in which surfaceinitiated convective activity was occurring. Their model predicted cloud formation for only this one situation. Thus, their choice of eleven unrepresentative profiles may have seriously biased their conclusions.

The formulas of Briggs (1969) and Hanna (1972) are among the simpler and more popular quasi-empirical relationships used to predict plume rise from cooling towers. Recently, however, evidence has begun to appear suggesting that these formulas are not adequate to describe the behavior of merged plumes from larger power facilities. Brennan et al. (1976a), for example, report that at the Amos plant near Charleston, W. Virgina (power output between 1000 and 2900 MWe) no relationships were found between heat release and plume rise, or wind speed and plume rise despite the theoretically predicted relationships in the Briggs and Hanna formulas. 
Once a power plant has triggered convective clouds, additional features should be considered when trying to predict subsequent cloud growth. Hill (1974) found that certain larger, randomly positioned clouds developed circulation patterns which were able to draw in surrounding smaller clouds, which ultimately merged with the larger clouds. Wind shear also is part of convective cloud development. Schlesinger (1972) stressed the importance of vertical shear of the horizontal wind in determining the intensity of convective activity. In general, he found that shallow convection is suppressed by vertical shears in the horizontal wind, and as the magnitude of the wind shear increases, the intensity and duration of deep convection varies according to moisture supply. No simple convective cloud model can adequately handle any of these features.

A few final points must be considered in our discussion of potential cumulus cloud development. First, if a heat island is formed, it is likely that the induced air flow patterns will produce lines of convergence which will be intensified by local topographical features. Such convergence lines are produced in the three-dimensional mesoscale model of St. Louis by Vukovich et al., (1976). Convective clouds need not have their origins directly associated with clusters of (or individual) cooling devices. The clouds will form in confluent zones determined by the rejected energy output, the local topography and the prevailing wind velocity. Trying to predict frequency of enhanced convective cloud development due to a large energy center with simple one-dimensional cumulus cloud or plume rise models is futile. Similarily, the prediction of enhanced convective activity at sites containing only a few power units will be meaningless if plume merging possibilities are not adequately incorporated.

\subsubsection{Potential Precipitation Reduction}

It is possible that a large energy center could reduce regional precipitation. Conservation of mass requires compensating subsidence in the areas surrounding convective activity. It is possible that this subsidence will suppress the convection and precipitation that would have developed naturally. Additionally, if the energy center acts as a mountain barrier then the enhanced precipitation at the local power park site could result in 
detectable precipitation decreases at points well downwind. The ratio of observed precipitation to that potentially available has been estimated to be about 0.2 for natural orographic systems (Elliot and Hovind, 1964; Young, 1974). Thus, if the downwind sites were sufficiently close so that lateral and vertical mixing and convergence of moisture could not replenish the moisture lost on the energy center "thermal mountain" then downwind decreases of precipitation of up to $20 \%$ would be detectable. Small energy center sites containing one to four reactors are not likely to produce any barrier effect; thus, downwind decreases in precipitation should not occur.

\subsubsection{Increased Moisture}

An increase in moisture resulting from energy production would have many effects, which are separated and discussed below.

\subsubsection{Magnitude of the Moisture Perturbation}

By again applying the first law of thermodynamics, we find that if the energy released by a power plant is used to evaporate water, then the change in water content of the air $(\Delta w)$ is given by

$$
\Delta \mathrm{w}=\frac{\dot{\mathrm{h}}}{\mathrm{uL} \rho \mathrm{h} \Delta \mathrm{y}} \text {. }
$$

For example, if we let $\dot{h}$ vary between $20 \%$ and $80 \%$ of the total rejected energy output of a 36,000 MWe energy center, we find that for $\Delta h=1 \mathrm{~km}$, $\Delta y=10 \mathrm{~km}$ and $u=5 \mathrm{~m} \mathrm{~s}^{-1}$,

$$
0.1 \times 10^{-3}<\Delta \mathrm{w}<0.4 \times 10^{-3} \mathrm{~g} \mathrm{~g}^{-1}
$$

\subsubsection{Moisture Effect on Human Comfort}

A postulated effect of some concern is the potential increase in human discomfort due to moisture increases. Relative humidity, RH, combined with temperature, is often assumed to be a measure of comfort. For the definition of relative humidity $\left(R H=100 \mathrm{w} / \mathrm{w}_{\mathrm{S}}\right)$ we can show that deviations in relative humidity are given by

$$
\Delta R H=\frac{100 \Delta W p}{.622 e_{S}}-\frac{R H m_{V} L \Delta T}{R^{*} T^{2}} .
$$


That is, deviations in humidity depend upon both temperature and moisture perturbations. The above expression for $\triangle R H$ is used to obtain Figure 2.2 which illustrates typical RH changes expected for a 36,000 MWe energy center rejecting heat into the hypothetical box discussed in Section 2.1.1.

For those cooling systems where most of the rejected heat is in sensible heat form, the $\Delta T$ term dominates for $T>0^{\circ} \mathrm{C}$, and the humidity drops. At colder temperatures even the addition of small quantities of water is sufficient to increase the humidity in spite of a concurrent temperature increase. However, the most notable feature of Figure 2.2 is that the total humidity variation is small (less than $2 \%$ for $-10^{\circ}<\mathrm{T}<35^{\circ} \mathrm{C}$ ) when most of the rejected heat is in sensible heat form.

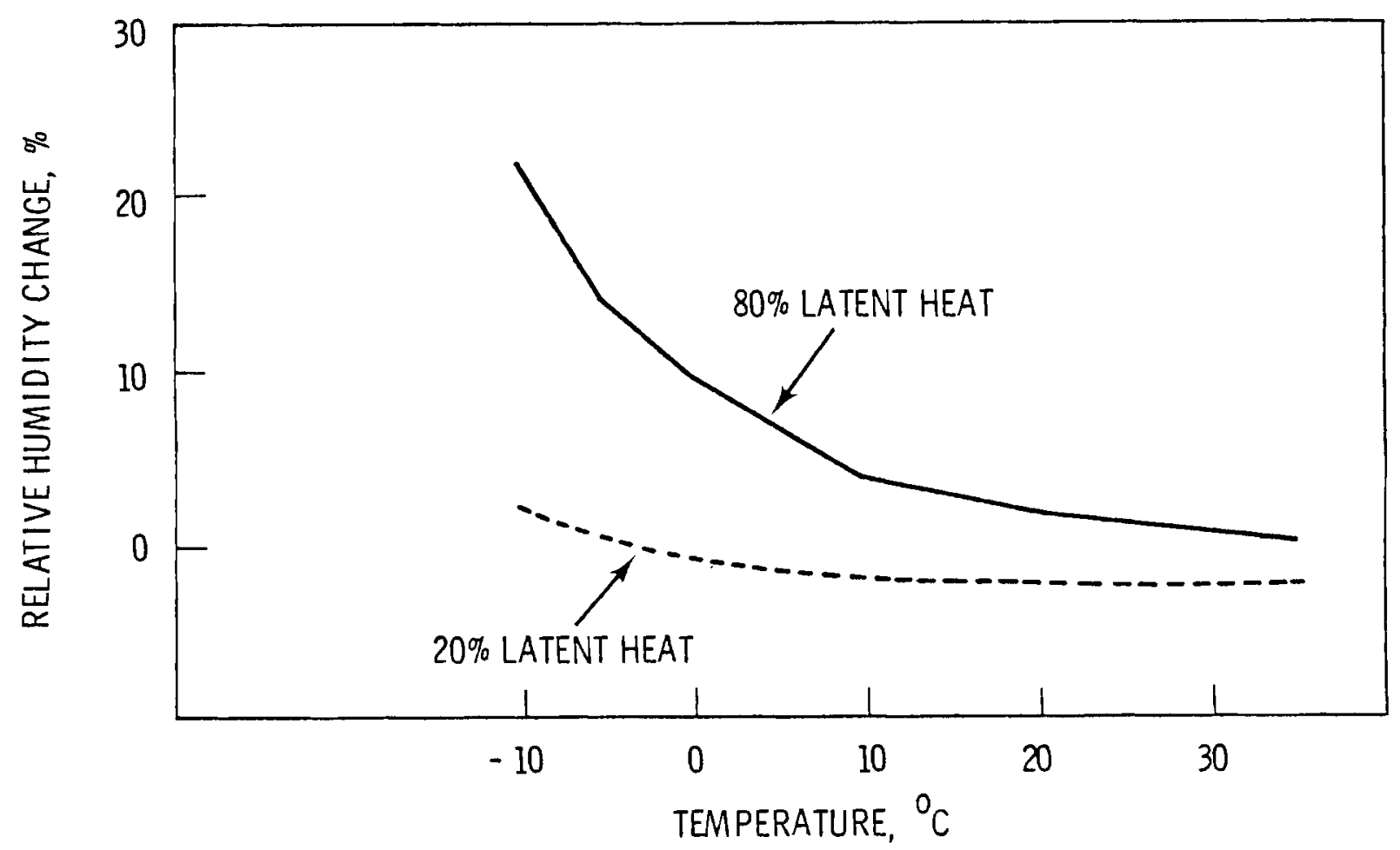

FIGURE 2.2. Change in Relative Humidity with Temperature for a 36,000 MWe Energy Center and an Initial Relative Humidity of $40 \%$. 
When the cooling system releases most of the rejected heat in latent form, the large quantity of water vapor enables the $\Delta \mathrm{w}$ term to dominate for a $11 \mathrm{~T}<35^{\circ} \mathrm{C}$, and humidity increases. However, for moderate temperatures, relative humidity variations are still quite small and amount to less than $5 \%$ for $\mathrm{T}>10^{\circ} \mathrm{C}$.

When a cluster of four 1000 Mwe power plants is considered (occupying a $2 \mathrm{~km} \times 2 \mathrm{~km}$ area) humidity variations are about half the values obtained from the large energy center. However, the area affected by this four unit cluster is considerabiy smaller than the area perturbed by the 36 unit center. Under most conditions, and in the absence of clouds, the humidity "plume" from the four unit cluster would be difficult to detect downwind from the sources.

Since both heat and moisture are being added to the atmosphere there will be a potential for some increase in human discomfort, particularly when the temperature is greater than $20^{\circ} \mathrm{C}$. A widely used discomfort formula for hot, humid weather (the temperature-humidity index or THI) indicates minor increases in discomfort; the THI increases by less than $1.0 \mathrm{~F}^{\circ}$ as a result of energy discharge from the large energy center. Even smaller changes in THI occur when the energy center is scaled down to four or fewer power plants. The THI increase also varies by a few tenths of a degree depending on the type of cooling system; i.e., whether the rejected heat is in sensible or latent form.

\subsubsection{Solar and Terrestrial Radiative Effects}

Another postulated effect of enhancing the moisture content of the boundary layer is the potential modification of the local balance between solar and terrestrial radiation. Rotty (1974), for example, quotes Landsberg (1962) in claiming urban decreases of $20 \%$ in the total radiation reaching the surface. It is probable that the majority of this reduction can be attributed to the urban aerosol, but other factors may contribute. Several simulations were performed with a long wave radiative flux model developed by Scott (1970) to determine the consequences of adding water vapor to the lowest $\mathrm{km}$ of the atmosphere. Adding $1 \mathrm{~g} \mathrm{~kg}^{-1}$ to the lowest $\mathrm{km}$ of a cloud-free atmosphere caused insignificant changes in the cooling rate $\left(<0.2^{\circ} \mathrm{Cday}^{-1}\right)$. 
It is likely, however, that more significant changes in radiative flux would be produced if the moisture addition resulted in appreciable cloudiness. Should the plumes from a large energy center rise into a stable atmosphere, merge, and then be confined to a limited area by, say, topographical features, an extensive stratiform layer could form. In such instances, the cloud layer could actualily emit sufficient longwave radiation to increase temperatures at the surface during hours of darkness. Such an effect could occur even with an individual power unit if the unit was located at a site where natural ventilation was poor (e.g., a deep valley).

\subsubsection{Generation of Clouds and Plumes}

Extensive cloudiness need not be produced by the merging of visible plumes from individual sources. To illustrate, turbulent mixing can often transform the lower layers of a stable atmosphere into a neutral atmosphere. The subsequent cooling and increased moisture content aloft often result in a layer of stratiform clouds (LeBlanc and Brundidge, 1969). Whether such a process can occur because of energy releases at a large energy center remains to be demonstrated.

It is not immediately obvious what effect additional moisture input will have on the initiation of convective clouds. If the total output energy is fixed, increased contributions from latent energy reduces the intial updraft velocity but lowers the LCL. Thus, if a power plant plume has positive buoyancy at the LCL or sufficient momentum to penetrate a capping inversion, the resultant cloud will have a lower, warmer cloud base (more water available to be condensed) and will be potentially thicker (more time for hydrometeor growth) than a plume generated entirely from sensible heat output. However, the question of buoyancy at the LCL depends strongly on plume radius which is dependent upon how the neighboring plumes interact. Additional insight to the effects of moisture and heat on plume rise awaits an adequate plume merging theory.

The persistency of plumes from cooling towers has been found to be directly related to the saturation deficit at the height of the plumes (Brennan et a1., 1976b; Barber et a1., 1974). In genera1, plumes can be expected to be short in the summer and more persistent in the winter. Martin 
(1974) found that plume lengths at Ratcliffe, England, a 2000 MWe site, extended less than $1 \mathrm{~km}$ from the source on about $80 \%$ of the occasions, while Brennan et al. (1976b) noted that if the saturation deficits at the Amos site (1000-2900 MWe) were $\leq 1.0 \mathrm{~g} \mathrm{~m}^{-3}$, plumes could extend out to distances of $10 \mathrm{~km}$ and occasionally to $30 \mathrm{~km}$.

\subsubsection{Fog Production}

Probably the most certain result of increased moisture content in the lower atmosphere is the enhanced probability of fog. Fog is a local problem; its duration, intensity, extent and frequency depend upon local topography, nearness to natural moisture sources, depth of mixing, and time of year. If an energy center is located in a region where natural fogs frequently occur during some period of the year, increases in fog frequency and intensity will be virtually assured if low-level evaporative cooling mechanisms (e.g., cooling ponds, mechanical draft cooling towers) are used (Spurr, 1974). Ramsdell et al. (1976), for example, predict a doubling in the total fog hours and a four-fold increase in hours with visibility $1 / 16$ mile for certain combinations of cooling devices in a conceptual study of a Nuclear Energy Center at Hanford, WA. Where natural draft cooling towers are used, relatively little additional fog will result because the cooling tower plumes will nearly always remain above the surface (Spurr, 1974; McVehil, 1971; Brennan et al., 1976b).

Studies evaluating the impact of fog formation and enhancement at local sites should be approached with great caution. The most favorable conditions for natural fog formation are when the winds are light and the nights are clear and long. If emissions by cooling mechanisms do increase the fog impact, it will most likely be during these periods. Enhanced fog impact will occur because the fog forms sooner, dissipates later and is denser than the natural fog. Climatological studies trying to pinpoint "downwind" regions of impact should restrict their wind data sample so that it represents periods when natural fog is likely to occur. Also, the influence of local terrain on regional flow patterns becomes important because fog is likely to form during periods of light winds and high stability. Gaussian plume models which neglect the probable channeling of local air flow during the meterorological conditions will likely generate fictitious predictions of regions of impact. 


\subsubsection{Concentration of Vorticity}

Vorticity is the tendency of a fluid to rotate. Hanna and Gifford (1975), Briggs (1975), Koenig and Bhumralkar (1974), and Czapski (1968) have suggested that the release of large quantities of energy to the atmosphere may be sufficient to concentrate natural atmospheric vorticity into organized convective vortices. Dust devils, waterspouts and tornadoes are examples of natural convective vortices. Certain basic atmospheric conditions are usually necessary for vortex formation, but the physical mechanisms for their generation vary; the following sections examine those atmospheric characteristics associated with the formation of convective vortices.

\subsubsection{Atmospheric Conditions Favoring Vorticity Concentration}

Concentrated vortices cannot form in a vorticity-free fluid (Leslie, et a1., 1970); they must be generated locally or be produced by amplification of natural atmospheric vorticity. Bergman (1970), Bode, et a1., (1975) and others have indicated that buoyancy and ambient rotation are prerequisitites but not sufficient conditions for concentrated vortex formation. A more extensive list of environmental factors important in vortex formation is given by Morton (1966 and 1969).

Convective vortices may be sustained only if the buoyancy and natural ambient vorticity lie within certain limits. If the buoyancy is too large, rotation plays a minor role in the flow behavior. If it is too small, the motion is strongly inhibited by rotation except near the source of the buoyancy. Briggs (1975) and Bergman (1970) have developed criteria for formation of convective vortices based on the ratio between the vertical velocity of the rising fluid and the tangential velocity of surrounding fluid, but these criteria are too general and do not consider important factors in vortex formation. Factors considered important by Morton and not considered in the criteria of Briggs and Bergman include atmospheric turbulence and the wind profile.

The probability of severe concentrated vortex development increases with enhanced development of large convective clouds and thunderstorms. Morton (1969) indicates that unobserved incipient or weak convective 
vortices may be present in many thunderstorms. Large sensible and latent heat releases could combine with atmospheric conditions associated with thunderstorms to augment or trigger this vortex development.

\subsubsection{Vorticity Concentration by Natural and Industrial Energy Releases}

It is common to compare the energy releases projected for large electrical energy production facilities with natural and other man-made heat releases, including those from urban areas; the amount of energy released from these sources is similar. Concentrated convective vortices have been associated with both volcanoes and forest fires, though the release of large amounts of energy does not imply the formation of convective vortices. Each analogy must be examined carefully to determine the degree of applicability to large energy releases in power production.

In some respects a plume of sensible and latent heat from an energy center is similar to a volcanic plume. Both plumes interact with the wind and have the potential to initiate convective cloud formation. However, volcanic plumes have internal sources of buoyancy and energy such as high velocity steam jets ( $\geq 100 \mathrm{~m}^{-1} \mathrm{~s}$ ) not found in an energy center plume. These volcanic energy sources are not symmetrical and probably account, in large measure, for the development of the convective vortices associated with volcanoes. To the extent that the internal energy sources of volcanic plumes are responsible for convective vortices this analogy is inappropriate.

Estimated energy release rates in large forest fires are approximately the same magnitude as potential energy release rates from large energy centers. Forest fires are known to trigger convective activity which results in well-developed cumulus clouds. These fires are often associated with convective vortices during unstable atmospheric conditions (Morton, 1969; Graham, 1955; Taylor and Williams, 1968; Glaser, 1957; Lee and Hellman, 1974). As a result an analogy is frequently made between forest fires and energy centers to indicate potential vorticity concentration by energy releases from energy centers.

The physical environment of a fire contains pronounced asymmetries in the energy release that apparently favor vortex formation. The convective column can be so concentrated that entrainment or mixing with surrounding air does not disturb the plume significantly (Taylor, et al., 1973). 
Many aspects of thermal plumes from large fires differ from plumes which might come from an energy center, although the total energy may be similar. First, a fire is an intense source of sensible heat which develops an extremely strong convective column and is fed by a significant converging air flow from surrounding areas. Under normal ambient wind conditions, it is doubtful that cooling systems associated with an energy center could develop an organized large scale convergence of the air flow. Studies of air flow in the vicinity of isolated cooling towers (Boyack and Kearney, 1973) indicate that induced air flow during calm ambient winds may have inward velocities of about $2 \mathrm{~m} \mathrm{~s}^{-1}$ at a distance of $21 \mathrm{~m}$ from the towers. At distances of more than $150 \mathrm{~m}$ air movement at ground level may be undetectable.

The analogy between energy releases from urban areas and energy centers has already been described. Generally urban areas have been credited with triggering increased convective activity including thunderstorms and hail. This increased convective activity may be associated with some increase in severe winds, but it has not been explicitiy associated with increases in the frequency or magnitude of convective vortices. In two instances (Hoddinott, 1960 and Stout, 1961), however, industrial activity including large heat releases has been associated with isolated convective clouds and convective vortices.

The analyses described all have a common weakness, in that each of the energy releases compared with the energy center release is accompanied by a release of particulates which can act as condensation nuclei. Huff and Changnon (1973) indicate that in urban areas there is a slightly more evidence to link the energy release with the observed modifications than there is to link the particulate releases. However, they also indicate that the relative importance of the two releases cannot be quantitatively defined from their studies.

\subsubsection{Experience at Existing Power Plants}

Although energy centers do not exist and individual clusters do not release energy at the upper end of the range we are considering, energy is released at lower levels. Often the energy releases are distributed 
over wide areas using large bodies of water; thus, the density of the energy releases is low enough that induced vertical motions in the atmosphere are small and concentration of vorticity is negligible. However, in many instances cooling towers are used. In these cases the energy release density is relatively high and significant atmospheric vertical motions may be induced. If the induced vertical motions are of an appropriate magnitude relative to existing atmospheric vorticity the energy release may contribute to the concentration of the vorticity.

Experience with single and small clusters of cooling towers shows that the plumes have not generated signifcant concentrated convective vortices. In England the Central Electricity Generating Board (Spurr, 1974; Spurr and Scriven, 1975) has approximately 50 years of cooling tower operating experience with no reported instances of significant vortex development. Experience in the Federal Republic of Germany (Bartels and Casper, 1975) is similar to that in England. No concentrated vortex development has been reported in cooling tower studies conducted in the United States.

\subsection{Consequences of the Postulated Impacts}

In Section 2.1 the nature of various postulated atmospheric impacts of large energy release was examined. This examination included estimation of typical magnitudes for the potential atmospheric modifications. In Section 2.2 the implications of these modifications will be examined in more details.

\subsubsection{Enhancement of Cloudiness and Precipitation}

A large energy center occupying approximately $100 \mathrm{~km}^{2}$ or less and generating approximately 36,000 MWe of power is expected to have a measurable impact on the surrounding environment. At the very least a heat island or thermal mountain will be produced which will increase cloudiness and precipitation by triggering convective activity and enhancing existing cloud systems. Individual clusters of reactors are expected to produce continuous plumes which will generally evaporate within a few $\mathrm{km}$ of the source, but may occasionaliy extend to $15 \mathrm{~km}$ downwind from the source. Long strings or streets of convective clouds similar to those discussed by Malkus (1963) 
and LeMone (1973) may also originate from the power park. Malkus (1963) observed such cloud streets to extend greater than $12 \mathrm{~km}$ from a small $\left(50 \mathrm{~km}^{2}\right)$, natural heat island source.

Although daily and even hourly variations in the lateral and longitudinal extent will occur because of the strong dependence on environment conditions, both the cloud plumes and street will generally be about $0.5 \mathrm{~km}$ wide. The increased cloudiness will produce some surface shadowing. Rain or snow showers will occasionally fall from these clouds and plumes, with the timing and intensity closely related to atmospheric stability, wind speed (and shear), temperature, and saturation deficit at cloud base levels. Because of the ability of ice crystals to grow rapidly, even in an atmosphere subsaturated with respect to water, snow should be more likely particularly when the temperature approaches $-12^{\circ} \mathrm{C}$. Indeed, snow accumulations of one inch have been observed from cooling tower plumes by Brennan et al. (1976b).

Statistically significant daily precipitation increases exceeding $19 \%$ have been observed in urban areas which produce sensible heat fluxes equivalent to proposed large energy center sites (Dettwiller and Changnon, 1976). Changnon and Huff (1973) found that thunderstorm frequencies have increased from 25 to $40 \%, 15$ to $30 \mathrm{~km}$ downwind from urban heat islands. In addition to being estimates of increased rainfall, such figures are also initial estimates of increased damage due to hail, wind, and flooding. Large energy centers can be expected to similarly increase precipitation and thunderstorms. However, because of the considerably smaller energy output and area of influence, a cluster of one to four power plants should have little effect on the regional precipitation patterns.

\subsubsection{Enhancement of Convective Precipitation}

Basing our impact forecasts on the observed characteristics of urban heat islands, we predict that the maximum increases in rain volume from convective storms would be 10 to $20 \mathrm{~km}$ downwind from a large energy center. This estimate is also consistent with the expected horizontal transport of a growing raindrop during the 15 to 20 min it takes to produce precipitation in

a typical convective cloud. Maximum increases in hail volume are predicted 25 to $35 \mathrm{~km}$ downwind from a large energy center. 
As stated in Section 2.1.3.1, it is currently impossible to predict the number and intensity of the individual convective clouds that might be initiated by an energy center. However, it is possible to estimate increases in convective precipitation through enhancement of existing convection. Estimates of enhanced convective activity are based primarily on the modeling work of Hane and Drake (1975), who determined that a precipitation increase of $10 \%$ could be produced when moisture and heat from a large energy center were drawn into existing storms. To translate this local enhancement into an estimate of precipitation increase over a regional area we use the convective storm observations of Austin and Houze (1972). Their results indicate that typical convective cells average $8 \mathrm{~km}$ high ( $5 \mathrm{~km}$ deep), with lifetimes of about $15 \mathrm{~min}$, and rainfall intensities of about $25 \mathrm{~mm} \mathrm{hr}^{-1}\left(1.0 \mathrm{in} . \mathrm{hr}^{-1}\right)$. This translates to a total rainfall of $6 \mathrm{~mm} \mathrm{cell} 1^{-1}$. Half of their observations of convective storm areas contained three or less cells. Thus, taking a convective storm to be composed typically of two cells, we can expect about $12 \mathrm{~mm}$ of rain per storm. Using the number of thunderstorm days given in the U.S. Weather Bureąu Technical Paper No. 19 (1952) the total precipitation originating from thunderstorms was computed. An estimate of enhanced convective precipitation due to a large energy center is $10 \%$ of this total.

Figure 2.3 shows the predicted annual increase in local precipitation due to enhancement of existing convection by a 36,000 MWe energy center. In general, annual precipitation increases of $50 \mathrm{~mm}$ or more can be expected near most large power park sites in the southern two-thirds of the country. Maximum increases would be near sites located in northeast New Mexico and in the Gulf Coast States. Up to $114 \mathrm{~mm}$ of additional rain could be expected in central Florida.

On a seasonal basis, Figures 2.4 - 2.7 illustrate that the greatest precipitation increases should occur during June, July and August. March, April and May contribute most of the remaining portion of the total annual increase. 


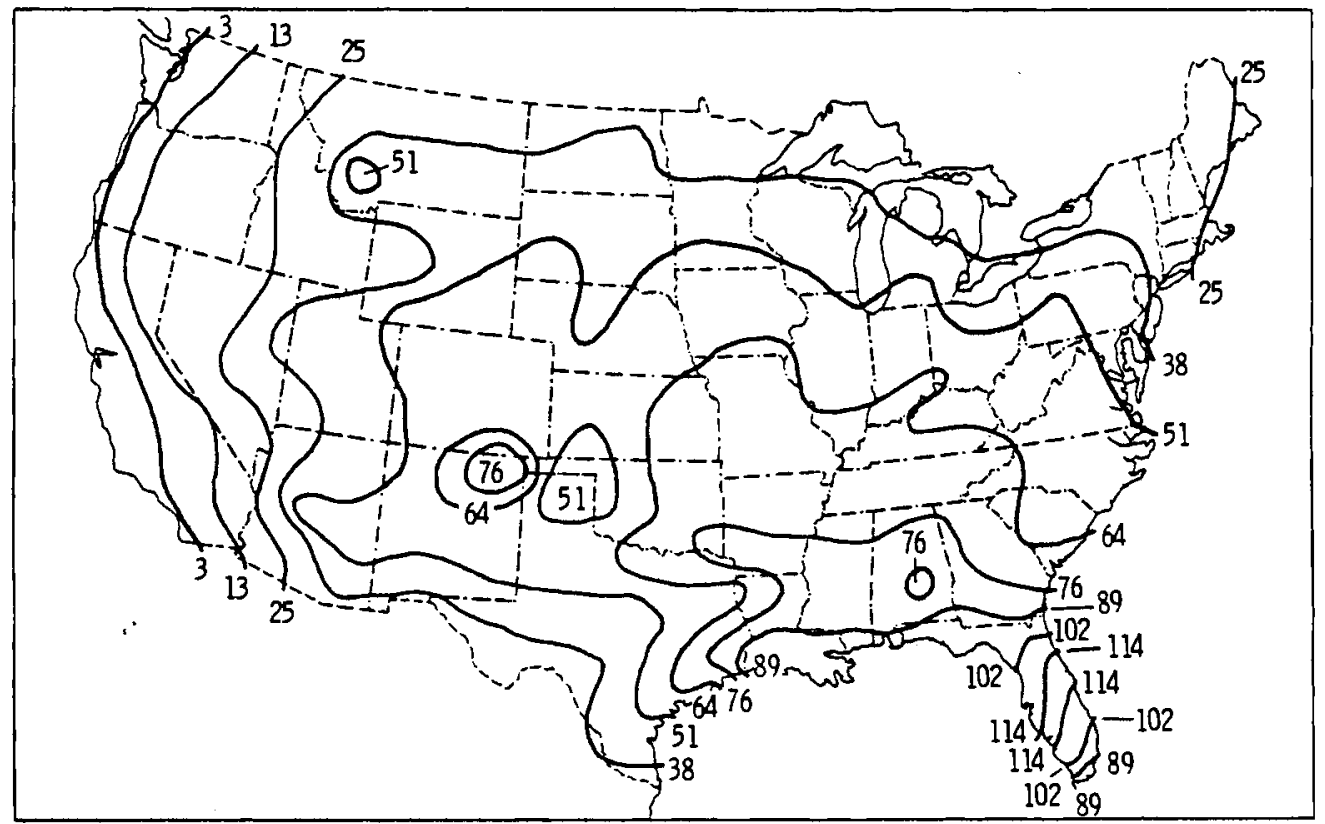

FIGURE 2.3. Convective Precipitation Enhancement from a Large (36,000 MWe) Energy Center. The isopleths can be used to estimate annual precipitation increases (mm) at a particular site if an energy center is located at that site.

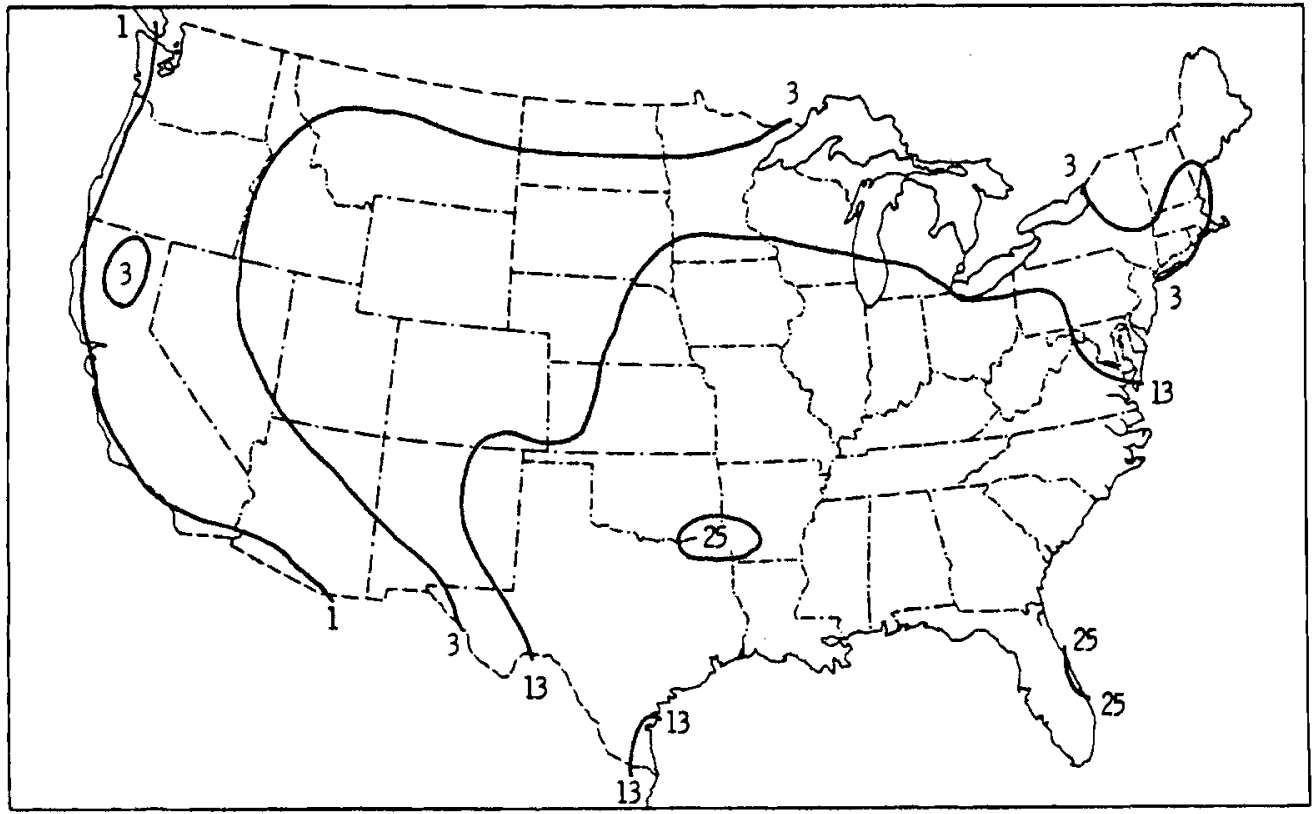

FIGURE 2.4. Spring (March, April, May) Convective Precipitation Increases (mm) from a Large $(36,000$ MWe) Energy Center. 


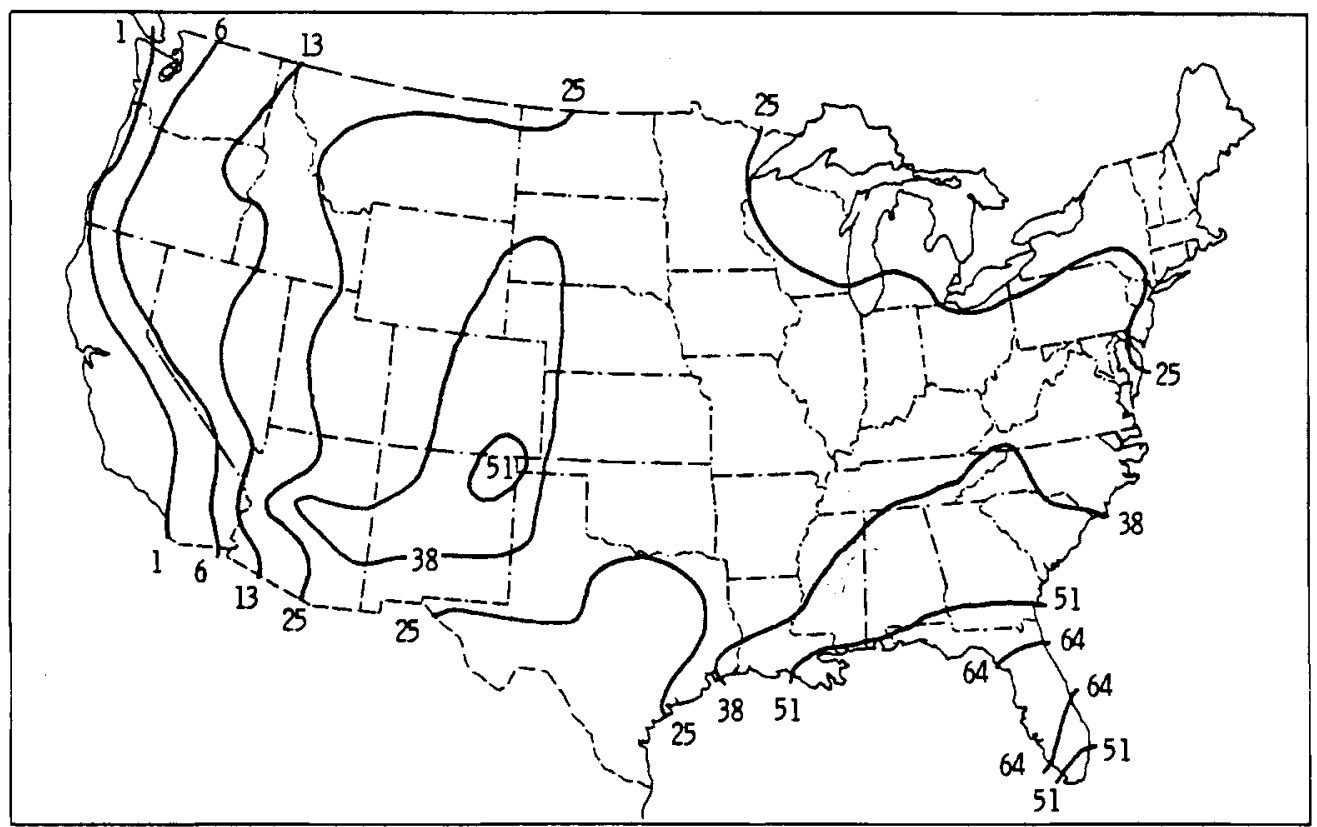

FIGURE 2.5. Summer (June, July, August) Convective Precipitation Increases (mm) from a Large (36,000 MWe) Energy Center.

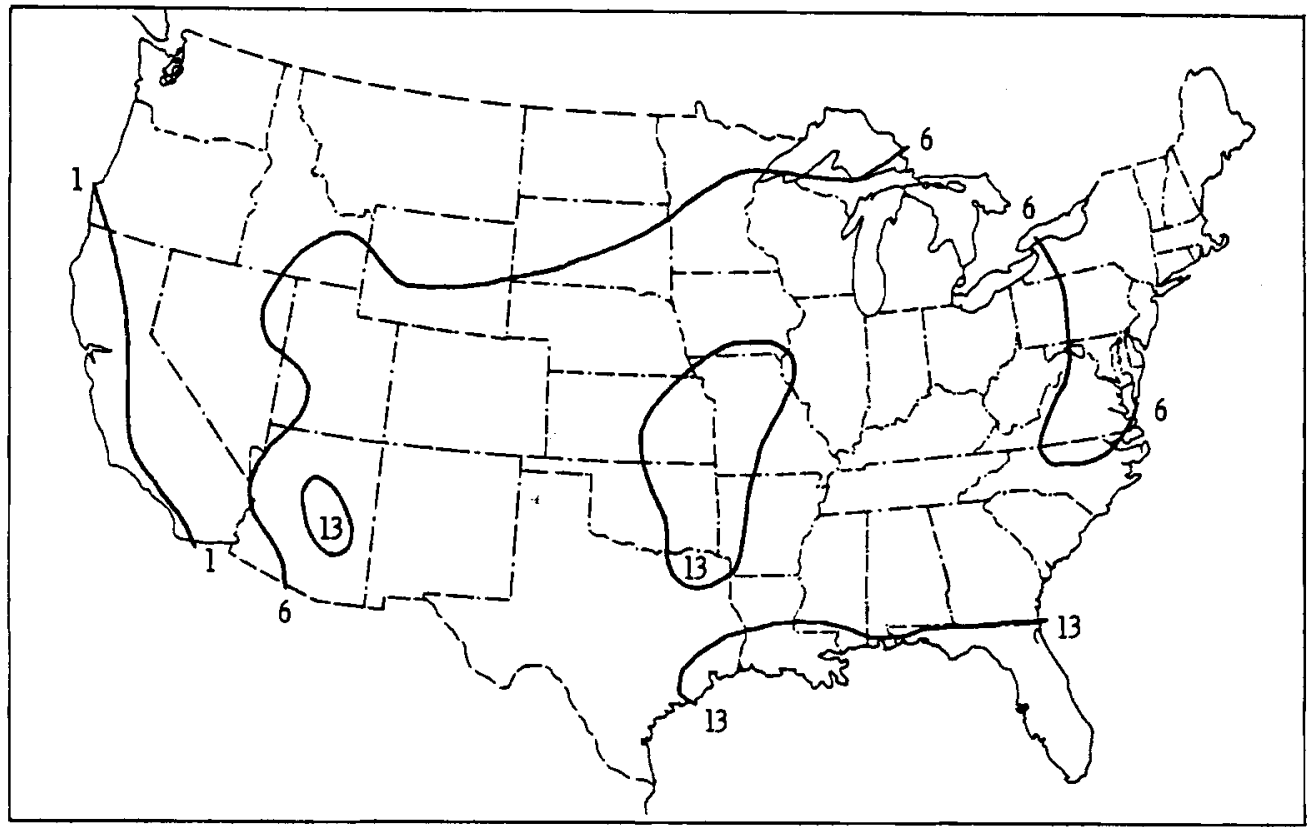

FIGURE 2.6. Autumn (September, October, November) Convective Precipitation Increases (mm) from a Large $(36,000$ MWe) Energy Center. 


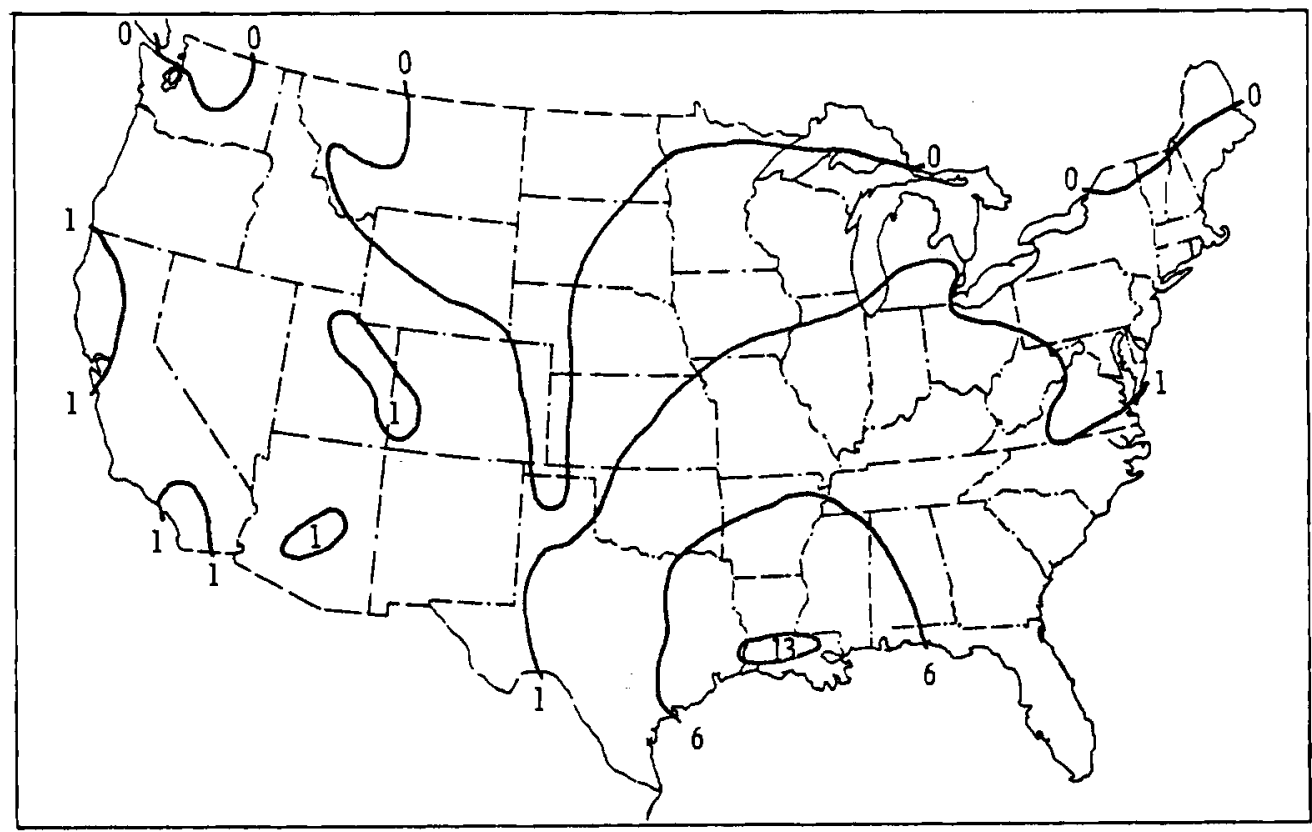

FIGURE 2.7. Winter (December, January, February) Convective Precipitation Increases (mm) From a Large $(36,000$ MWe) Energy Center.

Because much of the projected precipitation increase would occur in regions of the country where rainfall is already abundant, it is helpful to examine the predicted percentage increase of precipitation on a regional scale. Figure 2.8 presents these results. In general, a large energy center located in the eastern half of the country would be expected to increase local precipitation volumes 5 to $10 \%$ if convective enhancement was the only operating mechanism. Precipitation could increase as much as $25 \%$ near some sites in the Rocky Mountain states although local topographical features have probably biased this estimate. That is, thunderstorms in these states are likely to form over ridges and mountain tops and then dissipate before they are able to move over the lower regions where a large energy center would probably be located. The thunderstorm frequency chart therefore predicts many thunderstorms, but most of them may never be directly influenced by an energy center. Sti11, much of the total precipitation in these plateau and mountain states originates from convective showers so that any energy center would be expected to have greater effects there (on a percentage basis) than in the eastern half of the country. 


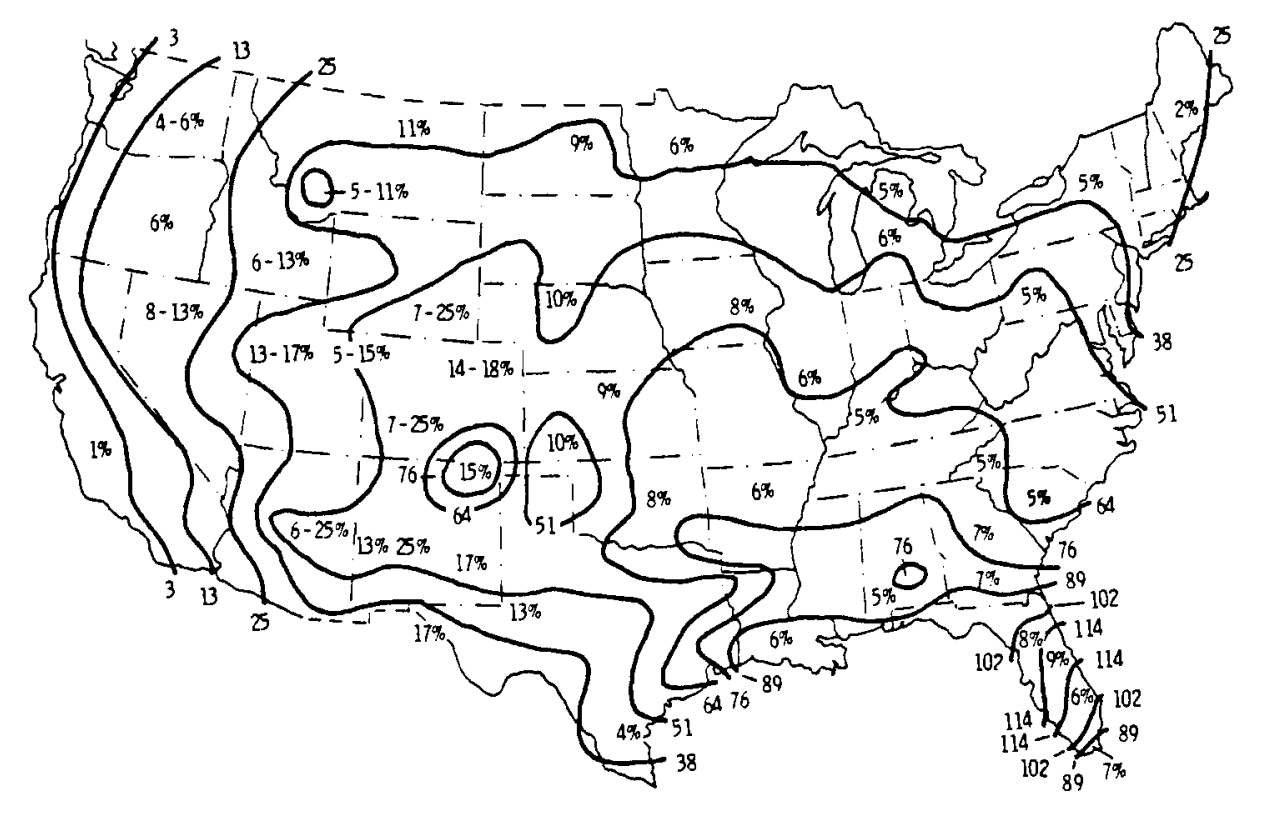

FIGURE 2.8. Percentage Increase in Total Annual Precipitation Due to Convective Precipitation Enhancement from a Large $(36,000$ MWe) Energy Center

A point of interest is the extremely low frequency of thunderstorm occurrence observed in the coastal sections of the West Coast States. Cool, moisture-laden air flows from the Pacific over the land producing a stable atmosphere not conducive to deep convection. A climatologically analogous situation occurs in Great Britain and in other portions of Northern Europe. The lack of any significant changes in total rainfall or cloudiness noted for a 2000 MWe site at Ratcliffe, England (Martin, 1974) can perhaps be attributed to a discharge of heat into a cool, stable atmosphere.

We emphasize that these results apply just to enhancement of previously existing natural convection. Certainly, though, a large energy center will be able to initiate convective activity. The total precipitation increases shown in Figures 2.3-2.7 could easily be doubled by such an effect. Because the isopleths presented in Figures 2.3-2.7 were derived for a 36,000 MWe energy center, they represent upper bounds for smaller generation sites. 
A cluster of 1 to 4 units, for example, would be expected to increase precipitation considerably less than those sites represented in Figure 2.3.

The term "downwind" has been used extensively in the preceeding paragraphs. The occurrence of enhanced convective activity will depend strongly on atmospheric stability and moisture content. The greatest effects will occur during unstable spring or summer conditions where the surface airflow would be transporting convectively unstable air northward. Such conditions are generally associated with particular synoptic situations so that "downwind" is likely to always be in the same general direction.

\subsubsection{Enhancement of Frontal Precipitation}

Another possible effect will be the enhancement of synoptic scale (frontal) precipitation due to precipitation falling through a plume from an energy center. Appendix B presents the equations for determining increases in precipitation rate caused by existing precipitation falling through a plume of given thickness. The results of our calculations appear in Figure 2.9. Plume thicknesses of $300 \mathrm{~m}$ are frequently observed (e.g., Brennan et al., 1976b); even larger plume thicknesses could be expected from an energy center if the plumes merged. Based upon our calculations, precipitation rates would be expected to increase by 10 to $25 \%$ for typical rain situations. For a synoptic scale storm with a precipitation rate of $2.5 \mathrm{~mm} \mathrm{hr}^{-1}$ and lasting 6 hours, the increase in precipitation below the centerline of a stationary plume would be about $2.5 \mathrm{~mm}$. However, the centerline of the plume could be expected to meander and slowly change orientation as the spatial orientations of fronts varied. Additionally, natural fluctuations within the storm (e.g., convective bands and local topographic features) produce equivalent variations in precipitation. Thus, the change in precipitation intensity or amount would be nearly undetectable, both from plumes generated within a large energy center and from single power units.

\subsubsection{Enhanced Orographic Precipitation}

The possible enhancement of orographic precipitation can be illustrated using a conceptual power park at Hanford, Washington. During frontal induced precipitation, the Hanford site is generally just downwind 


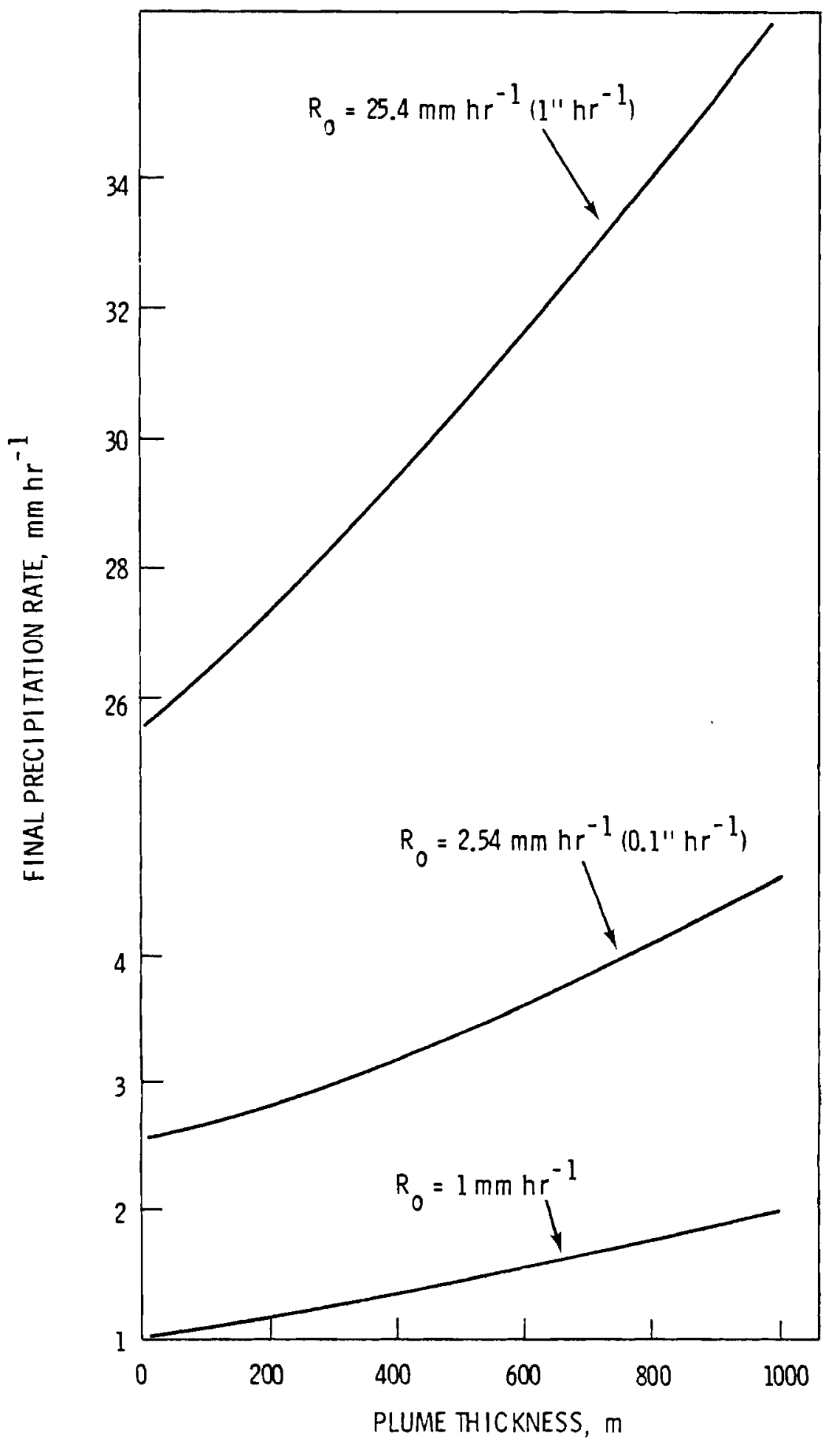

FIGURE 2.9. Precipitation Rate Increase Produced by Allowing Precipitation Initially Falling at Rate $R_{0}$ to Pass Through a Plume of a Given Thickness. The plume water content was assumed to be $0.5 \mathrm{~mm}-3$. 
of a $1000 \mathrm{~m}$ high ridge which receives, on an annual basis, about twice as much precipitation as Hanford. Normally, the mesoscale flow patterns induce subsidence to the lee of the natural ridge and suppress precipitation at Hanford. Should a thermal mountain be established at Hanford, it could be adequate to enable continued forced uplifting in the lee of the natural ridge and over the Hanford site. Such a mechanism could cause substantial (up to 100\%) precipitation increases at Hanford. Other proposed power parks located in hilly terrain could similarly increase rainfall.

\subsubsection{Enhancement of Fog and Stratus}

The consequences of increased fog density and duration on surface and air transportation is obvious. However, more subtle changes can occur in the climate of an area. Increasing the persistency of low level clouds and fog will tend to moderate surface temperature fluctuations. Warmer nights and cooler days will be a direct consequence. A longer frost-free season could be an added benefit provided fogging occurred in the fall and spring. Since the frequency of radiational fog formation is based upon the length of night and rate of surface cooling, the most important time is therefore fall through spring; the hours of maximum fog occurrence are midnight through 10:00 a.m. (McVehi1, 1971).

On a regional basis, mechanical draft cooling towers and cooling ponds will be the most detrimental in terms of fog occurrence in areas where natural heavy fog occurs often, where low level inversions are frequent, and where the October through March mixing depths are low. Figure 2.10 presents regional estimates of fog potential based upon such criteria (EG\&G, 1971). In the areas of high potential, heavy fog is observed on more than 45 days of the year, the October through March mixing depths are $600 \mathrm{~m}$ or less, and low-level inversions occur $20-30 \%$ of the time. In the low potential regions heavy fog is observed less than 20 days per year, and the October to March mixing depths generally exceed $600 \mathrm{~m}$. In general, fogging will be a problem in all of the Gulf Coast, Atlantic Coast, and Great Lakes states as well as in the Pacific Coast states. Fogging becomes less of a problem as distance fram a major water surface increases. 


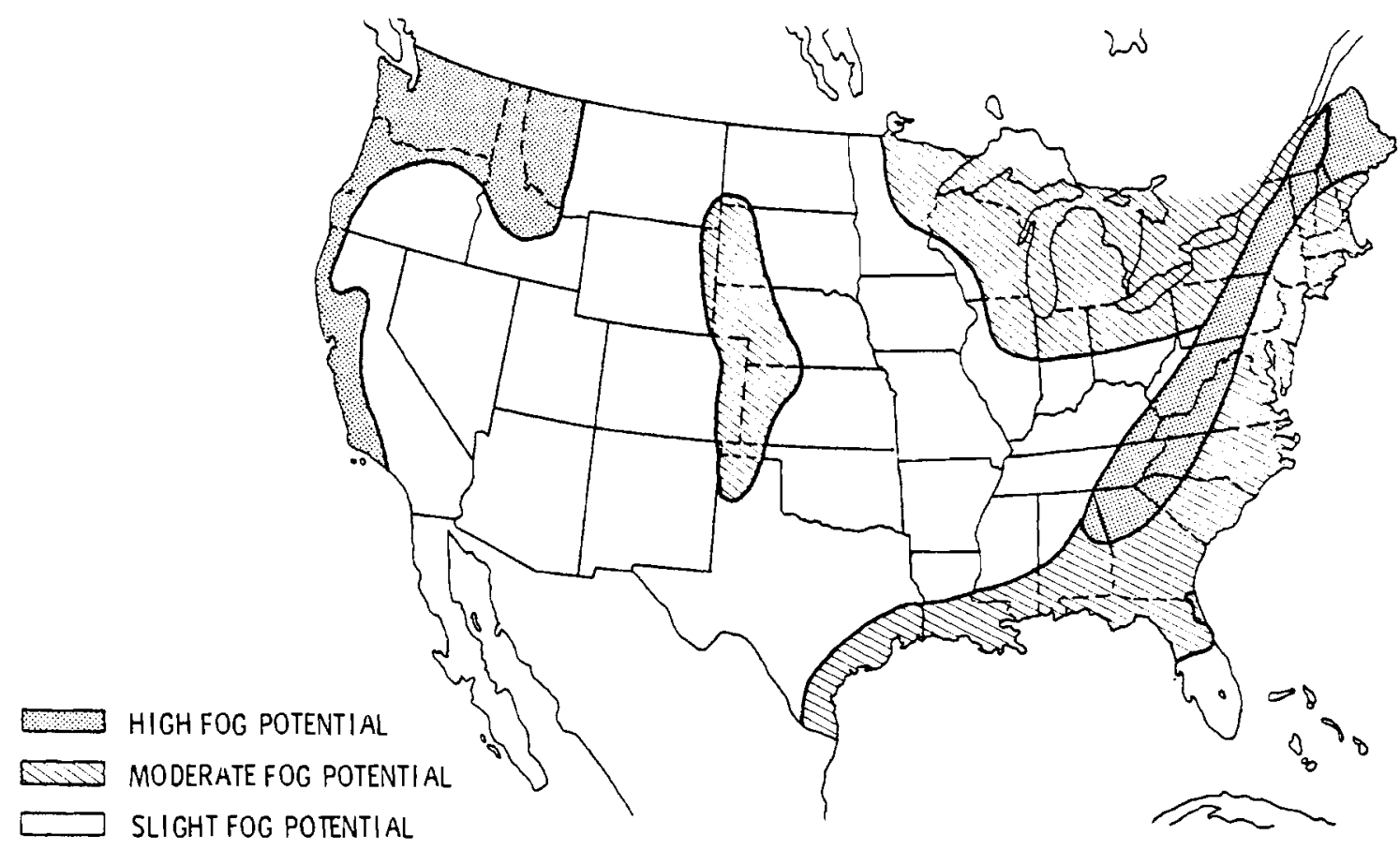

FIGURE 2.10. Geographical Distribution of Potential Fog Increases from Cooling Tower Effluents (EG\&G, .1971)

\subsubsection{Concentration of Vorticity}

In Section 2.1.5 we considered the effects of large energy releases on the postulated concentration of vorticity, discussed the atmospheric conditions favorable to vorticity concentrations and examined several analogies between natural, industrial and urban energy releases and energy releases in power production. We also discussed the current experience with energy releases at the lower end of the range under consideration. This section will consider the potential effects of energy releases at the upper end of the range.

\subsubsection{Energy Releases from Power Parks}

The release of large amounts of energy is associated with, but not sufficient for, concentration of atmospheric vorticity in convective vortices such as dust devils, waterspouts and tornadoes. The energy released from one or two power plants through single or small clusters of cooling towers is insufficient to trigger the development of convective vortices. However, buoyant plumes from several clusters of cooling towers may combine and significantly effect concentration of vorticity. 
The intensity of the thermal and moisture plume from an energy center will depend on the energy rejection rate, the number of cooling towers, and the separation between towers. The separation between cooling towers is especially significant because it is related directly to possible merging between the individual plumes. If the individual plumes merge, the size of the combined plume may become sufficient to interact with the atmospheric vorticity fields produced by natural convection, topography and synoptic scale weather systems. Hanna and Gifford (1974) suggest that cooling tower clusters in a large energy center be separated by a distance equal to the plume rise from a single tower to reduce plume merger during the most active phases of plume rise.

\subsubsection{Location and Timing of Convective Vortex Information}

To the extent that large energy releases initate the formation of concentrated convective vortices by enhancement of convective clouds, the vortices will occur at distances downwind of the release that are consistent with the time required for the clouds to develop fully. To the extent that they are initiated directly by the energy release, convective vortices will occur immediately downwind of the release. The more important or probable of these processes has not been determined, thus it is assumed that concentrated convective vortices might be generated from an energy center to 25 to $50 \mathrm{~km}$ downwind of the center.

On a large scale the probability of initiating convective vortices depends on climate. If the ambient atmospheric conditions are not suitable, an energy release cannot initiate vorticity concentration. The frequency of natural convective vortices indicates climatological susceptability to vorticity concentration by large energy releases. Those regions that experience frequent natural convective vortices are also regions where convective vortices initiated by large energy releases would be most probable.

The convective vortices for which the most complete climatological records are readily available are tornadoes. The records indicate that while tornadoes occur in all parts of the country, they are most frequent in the Midwest with a maximum in the area of OKlahoma and Kansas (Markee et al., 1974). Large energy releases are deemed to be most likely to trigger convective vortices in 
this region. Tornadoes are relatively frequent in the Southeast; thus this region is also susceptible to an increase in convective vortices. The likelihood that large energy releases will trigger vorticity concentration is relatively low in the Northeast, and is very low west of the Rocky Mountains.

The timing of increased convective vortices can also be estimated from cl imatological records of tornado activity (Skaggs, 1969). Tornado statistics for the Gulf Coast and the Southeastern states indicate that increases in convective vortices would be most likely during the winter; the preferred time of day would be afternoon and early evening. In the spring and early summer the probability decreases and the preferred time shifts to late morning. In the late summer and early fall the probability of an increase in convective vortices is a minimum with no preferred time of day.

The tornado statistics of states further north indicate that the probability of an increase in concentrated convective vortices is low in all seasons except summer. During the summer, convective vortices would be triggered most frequently during the late afternoon. Seasonal variation of tornado activity west of the Rocky Mountains is erratic, thus prediction of timing of increased frequency of vortices is questionable. The works of Idso (1974) and Ingram (1973) indicate that the maximum potential for increased activity in Arizona occurs during the summer, while Stone et al., (1972) indicates the maximum potential for increased frequency of vortices for Pacific Northwest is in the spring.

\subsubsection{Minimum Energy Release Needed to Initiate Concentration of Vorticity}

The energy release from one or two power plants generally appears not to be sufficient to initiate concentration of vorticity. However, we cannot determine when energy releases become sufficiently large to produce this effect. The various criteria and analysis used to support the postulated concentration of vorticity are not adequate to permit scaling of the impact with confidence. 


\subsection{EFFECTS OF HEAT AND MOISTURE RELEASES ON THE BIOSPHERE}

\section{D.S. Renne and J.E. Hubbard}

We have been discussing the types of impacts large energy sources have on the climate surrounding them: average increase in temperature, higher atmospheric humidity, possible convective and frontal storm precipitation enhancement, increased cloudiness and fog. We now need to relate these changes to the biosphere--that zone between the earth's surface and atmosphere in which all living things reside. The biosphere offers many reaction pathways to energy and moisture changes. Some general theory and a limited literature review are presented here to identify biotic responses to postulated atmospheric effects of heat and moisture releases.

\subsection{Environmental Changes and Their Relation to the Biosphere}

According to Hanna and Swisher (1971) three scales of climatic change exist: large scale (horizontal distances $>50 \mathrm{~km}$ ), mesocale ( 1 to $50 \mathrm{~km}$ ) and microscale $(<\mathrm{km})$. In addition Marlatt (1967) utilized an "ecoscale" which might include a tree or bush, a leaf, or someone's skin. Based on statements in literature on cooling tower impacts, and previous discussions of atmospheric impacts due to large heat releases in this report, the impacts on the biosphere will generally be on the order of mesoscale or smaller. More specifically, convective storms triggered by large heat releases could have an effect as far as $50 \mathrm{~km}$ downwind of the source, but atmospheric temperature and humidity changes will be noticed for only a few kilometers from the source. For a single cooling tower, although the visible plume may be observed as far as $30 \mathrm{~km}$ from the source (Kramer, et a1., 1976), temperature and humidity changes will occur only on the microscale, or perhaps only the ecoscale.

\subsubsection{Radiation and Heat Balance}

Assessing effects of large heat releases to the atmosphere on a biological system can be approached by a description of the energy budget which considers the net heat gain or loss to the system. The streams of radiant energy at the earth's surface have been depicted by Tanner (1968) in Figure 3.1a. The radiant energy balance of the system can be given by: 


$$
Q_{N}=Q_{I}(1-a)+\left(Q_{L} \downarrow-Q_{L} \uparrow\right)
$$

where:

$$
\begin{aligned}
Q_{N}= & \text { net radiant energy balance } \\
Q_{I}= & \text { incoming shortwave solar and sky radiation } \\
a= & \text { albedo of the surface (shortwave reflectivity) } \\
Q_{L^{\downarrow}}= & \text { downward flux of longwave infrared "thermal" radiation } \\
Q_{L}= & \text { upward flux of longwave infrared "thermal" radiation from the } \\
& \text { surface }
\end{aligned}
$$

The imbalance of net radiation at the surface specified by $Q_{N}$ requires that, when $Q_{N}$ is positive, the excess heat be dissipated to the atmosphere or subsurface, or converted to food energy by the vegetation, lest the system experience continued warming. This generally occurs in the tropics and summer mid-latitudes during most daylight hours. Excess heat energy is typically dissipated by sensible heat transfer to the atmosphere and subsurface layers, and by the evaporation and transpiration of water. A small fraction $(<2 \%)$ is utilized in gross photosynthesis. When $Q_{N}$ is negative, a net transfer of heat to the system from the atmosphere or subsurface layer is required lest the system experience continued cooling. The different heat transfer processes are shown in Figures $3.1 \mathrm{~b}$ and 3.1c, as depicted by Tanner (1968).

Large releases of heat and moisture can effect the terms in equation (1) in the following manner:

$Q_{I}$ : If clouds are generated by the heat and moisture releases, less incoming solar radiation will be received at the surface. Reifsnyder and Lull (1965) estimate that with a stratus cloud layer (similar to a thick cooling tower plume) the solar energy received is approximately $25 \%$ of the clear sky value; in a fog, the radiation would be only $17 \%$ of the clear sky value. However, clouds scatter as well as reduce the solar beam; thus increased cloudiness would provide more scattered "sky" radiation with respect to the direct solar beam, and reduce the importance of land slope and aspect on the reception of shortwave energy by biological systems. 

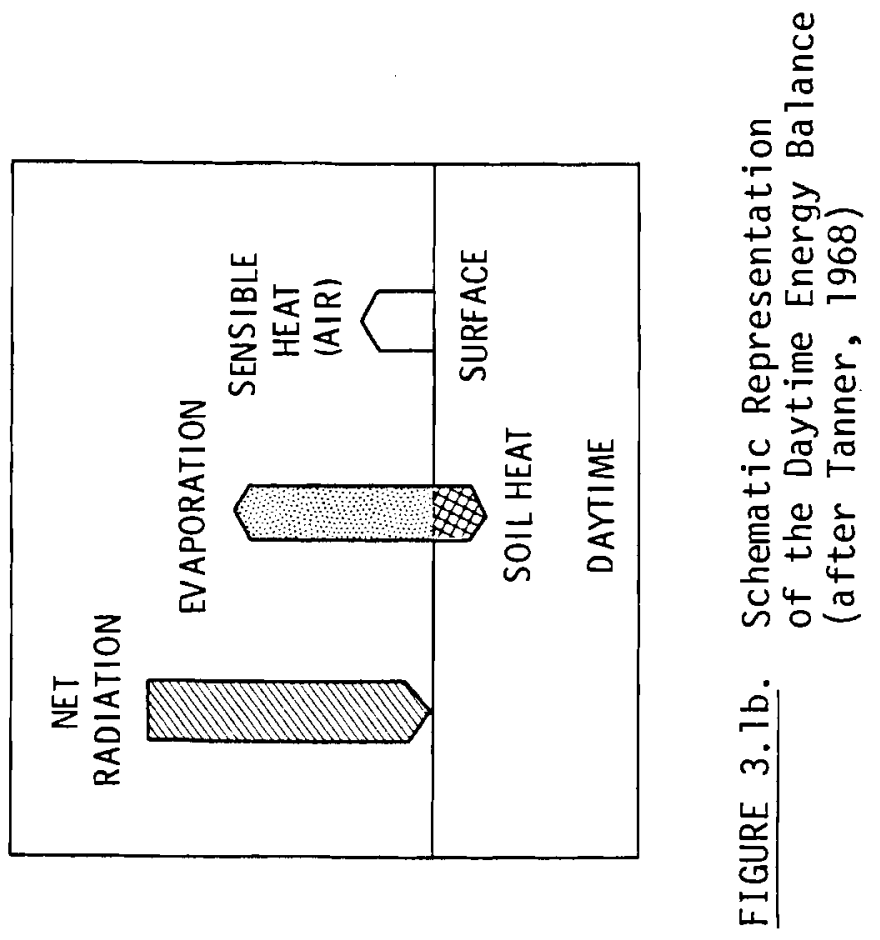

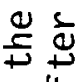

峞造

ธ워

든

Tृ

c

जे

过嵌

$\simeq$ Ш

늘

至.

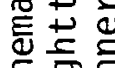

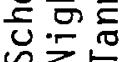

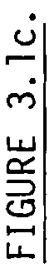

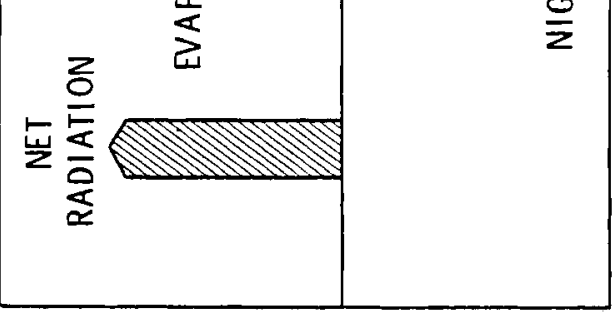

क

ธะ

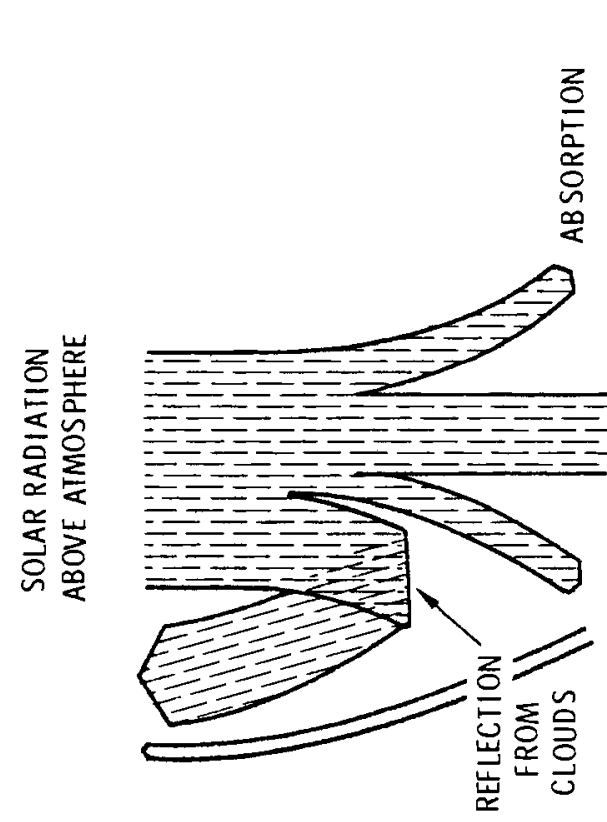

z气
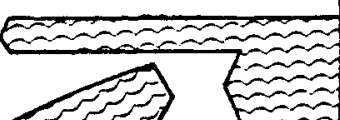

平方

징

둥

纸

约㝴

언

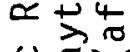

융

实旁

禹

낸용

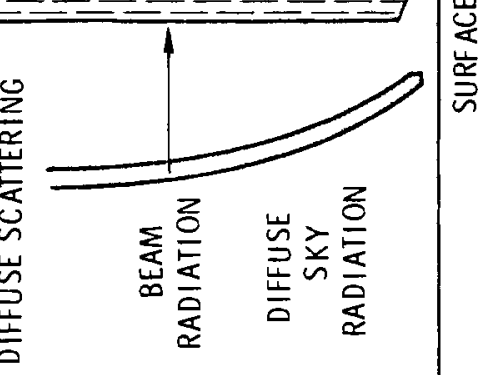

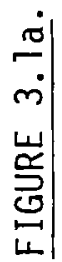


a: The albedo of natural surfaces also can change near large heat and moisture releases. In general, the altedo ranges from $7 \%$ for evergreen forests to $11 \%$ for green fields and 19\% for dry pastures (Mather, 1974). If a dry pasture adjacent to an energy source experiences an increase in precipitation, the shortwave energy balance will increase because of the reduction in albedo as the pasture changes from brown to green.

$Q_{L}+$ : The downward long wave radiation will be increased near a large heat and moisture supply to the atmosphere. The effective temperature of the low clouds and fog is usually greater than the sky temperature, and therefore the longwave "thermal" radiation emitted toward the surface is greater.

$Q_{L} \uparrow:$ Since the upward thermal radiation at the surface is a function of the surface temperature, changes in this parameter caused by heat and moisture released to the atmosphere are a function of the changes in the surface temperature from these releases. Because of the increased cloudiness, the surface temperature will generally be cooler than normal during the day, decreasing $Q_{L} \uparrow$, and warmer than normal at night, increasing $Q_{L} \uparrow$. The net effect of changes in the net infrared radiation would be cooler daytime and warmer nighttime air temperatures than would otherwise have occurred.

\subsubsection{Moisture Budget}

A description of the moisture budget within biotic systems such as field plots or watersheds can also provide insight: into the effects large heat and moisture releases to the atmosphere can have on these systems. The moisture budget may be expressed:

$$
\Delta W=P-E-T-R
$$

where

$$
\begin{aligned}
\Delta W= & \text { change of moisture within the system } \\
P= & \text { precipitation and other inputs, such as fog drip, dew, and } \\
& \text { groundwater seepage }
\end{aligned}
$$




$$
\begin{aligned}
& E=\text { evaporation from the system } \\
& T=\text { transpiration from the system } \\
& R=\text { losses from the system due to runoff and groundwater seepage. }
\end{aligned}
$$

A11 of the factors in equation (3.2) can be affected either directly or indirectly by large heat and moisture releases to the atmosphere in the following manner:

P: The increased precipitation postulated from large heat and moisture releases to the atmosphere will provide additional moisture to biological systems at various rates and locations, and in different forms including snow and ice. Direct condensation of water, such as fog and dew, could also increase.

E: Evaporation is a function of solar radiation and atmospheric temperature and moisture. With a decrease in solar radiation and increase in humidity, evaporation of water from the soil surface and of intercepted moisture from plant surfaces would decrease near large energy centers.

$T$ : Transpiration from plants is a physiological response to the radiant heat loading on the plant, atmospheric temperature and humidity, soil moisture, and the characteristics of the plant itself. Thus, the increase in atmospheric temperature and humidity and decrease in solar radiation will trigger a number of complex physiological responses that could either increase or decrease transpiration.

R: An increase in short, intense convective storms can cause runoff and flooding on small watersheds and provide major erosion of soil, particularly in semi-arid regions. In moist regions, an increase in precipitation will show up almost entirely as an increase in runoff.

Thus, a general increase in total moisture within the biological system will result from a large increase of heat and moisture to the atmosphere. Depending on the location and type of plant communities, some of this 
moisture will be utilized by the species for growth and transpiration, while the remainder will run off through surface or groundwater flow.

\subsubsection{Other Atmospheric Effects}

The chemical quality of the emissions from energy centers also requires consideration with respect to biotic systems. Cooling tower plumes can interact with material in the atmosphere from other sources.

The potential impact of wet cooling systems on aquatic and terrestrial environments has been summarized by Roffman (1975). Moser (1975) is studying the effects of vegetation of high salinity drift. In his investigations the coolant is brackish water. Parr et al. (1976) measured the effects of chromium and zinc in the cooling water drift on tobacco plants. Within 200 meters of the source, the drift resulted in a great reduction in leaf size.

Moore (1975) has observed no serious environmental effects produced by wet natural draft cooling towers in England. However, he reports the interaction of cooling tower plume droplets (normal pH 3.2) from natural draft towers with low-level sources of $\mathrm{SO}_{2}$. As a result, "some droplets collected at $400 \mathrm{~m}$ downwind in light winds have $\mathrm{pH} 3.5 . "$

Table 3.1, taken from Roffman (1975) summarizes the potential environmental effects of cooling towers. Some of the effects he identifies, such as noise levels and the external appearance of structures and plumes, are beyond the scope of this report and not considered here.

\subsection{Effects on Plants and Plant Communities}

Any biotic species occurs where it does because under natural conditions the environment is optimal for its survival. Broacl-leaf plants in tropical rain forests maximize the reception of sunlight and transpire the water that is readily available. Needle-leaf plants in cold climates minimize the transpiration process where and when water is scarce; the needles reradiate thermal energy to adjacent needles to maximize the available heat within the canopy. Light-colored plants found in the desert reflect much of the incoming solar radiation to minimize the heat loading on the plant. Dark-colored plants found in colder and cloudier climates absort more solar radiation, maximizing the use of the available heat. 


\section{TABLE 3.1. Summary of Environmental Considerations and the Potential Impact of Wet Cooling Systems (from Roffman, 1975)}

\section{Atmospheric Effects}

Visible Plume: Visual intrusion, ground shading, and reduction in visibility to various means of transportation.

Ground Fog: Potential hazard to ground and water transportation and nuisance to nearby communities.

Icing: Potential hazard to ground transportation and ice accumulation on nearby structures and utility wires.

Orift Deposition: Potential damage to biota, acceleration of corrosion of nearby structures, and contamination of soil and water bodies.

Cloud Formation: Visual intrusion and potential local weather modifications.

Precipitation and Snow Augmentation: Potential local weather modifications and nuisance to nearby communities and drivers on adjacent roads.
Hydrologic and Aquatic Effects

Net Water Consumptive Use: Potential depletion of surfacewater and groundwater resources and degradation of water quality.

Blowdown Discharge: Potential contamination of surface-water and groundwater supplies, potential increase of soil salinity, and increase of water temperature near discharge point.

Seepage and Leakage Water: Same effects as blowdown discharges.

Intake Screen Devices:

Impingement or entrapment of aquatic life.

Transport Through Condenser and Circulation Pumps: Damage to aquatic organisms.

Discharge Systems: Disturbance to benthic and nonbenthic aquatic communities due to mechanical forces and turbulence.
Land Effects

Land Use: Type of land acquired and the amount of area required for each of the cooling systems.

Terrestrial Impact: Potential damage to plant communities and wildlife due to excavation, grading and construction, effects of drift deposition; and excess moisture on the biota.

Land Characteristics: Effects of seismic risks, soil permeability, and type of foundation or construction required.

Other Effects

Sound Levels: Nuisance to nearby residents and transient observers.

Aesthetics: Nuisance to nearby residents and transient observers. 
Most ecological research has dealt with responses of individual organisms or populations of a single species to their environment. Much of this research is summarized in Daubenmire's (1974) treatise on autecology. However, biologists, ecologists, botanists and agronomists are increasingly researching the effects on biotic species if their natural environment is suddenly altered. These alterations can occur from human activities such as transplanting or introducing a species to a strange environment, agricultural and urbanization practices, and intentional and inadvertent weather modification. Alterations can also be caused by natural phenomena such as floods, fire, and climatic change. Several recent noteworthy studies have summarized present knowledge of ecological implications of weather modification due to cloud seeding (Cooper and Jolly, 1969) and due to alterations of the radiation balance of the earth's stratosphere (C1 imatic Impact Assessment Program, Chapter 5, 1975) ${ }^{(a)}$; these studies provide much of the infornation used in this survey of the ecological implications of large heat and moisture releases.

An attempt is made here to separate these implications to natural ecosystems from those to agricultural production. In general, modern agricultural practices are such that adjustment can be made to changes in the environment, provided they are not too severe; in fact, many beneficial uses of heat released from energy sources have been identified and proposed (Campbe11, 1968; Bea11, 1969; Johns, et a1, 1971, Witherspoon, 1972). However, in natural ecosystems, species diversity and plant community characteristics will slowly evolve as the environment changes, and eventually a new climax ecosystem community will stabilize. During this change the opportunity for pathogens to enter the system can increase. In certain marginal regions some species could become extinct while other dormant species could suddenly flourish. However, no actual field data exists for this process. We must rely on observational evidence from experiments that may be only remotely related to the problem of heat and moisture releases from energy sources.

(a) This document will hereafter be referred to as CIAP-5. 
Furthermore, the types of environmental modifications caused by large heat and moisture releases described in previous sections are generally much smaller than the natural climatic variations that have occurred on earth, even since the last ice age. They are only applicable to microscale or mesoscale area, in contrast to the macroscale considered in CIAP-5.

\subsubsection{Temperature and Mois ture}

In general there are optimal diurnal and seasonal temperature and moisture environments for plants, and an increase or decrease in either of these parameters will affect plant productivity, and under extreme conditions cause wilting and death. The environment in the vicinity of a large energy center will be modified by increasing atmospheric temperature and moisture. Gates (1965) shows that if the leaf temperature, which is a function not only of the air temperature but of the radiant energy loading on the leaf, increases by more than $5 \mathrm{C}^{\circ}$ above its natural level photosynthetic activity will drop dramatically. Whittaker (1967) notes that an "increase of internal temperature beyond a certain point can subject that plant to a thermal avalanche of mutually aggravating effects which overwhelms its physiology." The responses are such that a positive feedback occurs--an increase in leaf temperature triggers physiological responses that can further increase the temperature. Whittaker states that even modest increases in temperature can have abrupt lethal effects.

However, the air temperature increases shown in Section 2, even from large energy centers, are smal1 compared to normal diurnal and seasonal variations. Other offsetting factors, such as an increase in cloudiness and reduction in solar radiation loading, could actually decrease leaf temperatures. No evidence at this point indicates that these catastrophic temperature effects on ecosystem productivity will occur, even in the vicinity of a heat and moisture source as large as that expected from a nuclear energy center. 
Cooper, in CIAP-5 (1975) states that annual yields of air-dry herbage in native perennial grasslands correlate primarily with precipitation. In the same monograph, Fritts also shows a direct relationship between forest growth and changes in precipitation, such that an increase in precipitation would cause higher yields. Reversing the results in a table he provides (showing yield effects from a decrease in temperature) to show the effects of an increase in temperature on forest yields indicates that an arid forest border in Arizona and an arid forest site in Washington state would experience an increase in radial growth of Ponderosa pine from an increase in temperature; radial growth of Ponderosa pine in a forest interior in Arizona and an arid continental site in Colorado, and of Douglas fir in an arid north-facing slope in Colorado would decrease.

Cooper in CIAP-5 (1975) applies simulation models to several types of ecosystems to determine their response to climatic change. He shows that an increase in temperature will increase total matter production for grassland, tundra, coniferous forest and deciduous forest ecosystems, but decrease production in desert ecosystems. He warns that parts of the model results deviate from observations; careful scrutiny of the results and conclusions are needed.

Fareed and Caldwell in CIAP-5 (1975) use climatic diagrams to determine the effect of climatic change on natural ecosystems. Figure $3.2 \mathrm{a}$ shows only small changes in vegetation zones in the U.S. for a $10^{\circ}$ difference in temperature. Changes are greater for a $\pm 20 \%$ change in precipitation, particularly in the northern latitudes and eastern U.S. (Figure 3.2b). Except for Australia, his charts generally show that precipitation changes have a greater effect on vegetation zones than do temperature changes. For a $1^{\circ} \mathrm{C}$ increase in temperature he shows productivity to increase in the $20^{\circ}-40^{\circ} \mathrm{N}$ latitude belt by 4 to $7 \%$. 

2a SOUTHWESTERN SEMI-EVERGREEN AND DECIDUOUS FORESTS
2b SOUTHEASTERN SEMI-EVERGREEN AND DECIDUOUS FORESTS
$3 a$
$3 b$
WESTERN SCLEROPHYLLOUS WOODLANDS WITH WINTER RAIN
5 SOUTHEASTERN MOIST WARM TEMPERATE WOODLANDS
$6 a$ (NEMORAL) FORESTS
6b NORTHWESTERN DECIDUOUS (NEMORAL) FORESTS
7 WESTERN TEMPERATE STEPPES SEMI-DESERTS AND DESERTS WITH COLD WINTERS
8 NORTHERN BOREAL CONIFEROUS ZONE
9 NORTHERN TUNDRA
10a WESTERN MOUNTAINS INORTHERN ROCKY MOUNTAINS)
$10 \mathrm{D}$ WESTERN MOUNTAINS (CENTRAL ROCKYMOUNTAINS)
IOC WESTERN MOUNTAINS (SOUTHERN ROCKY MOUNTAINS)

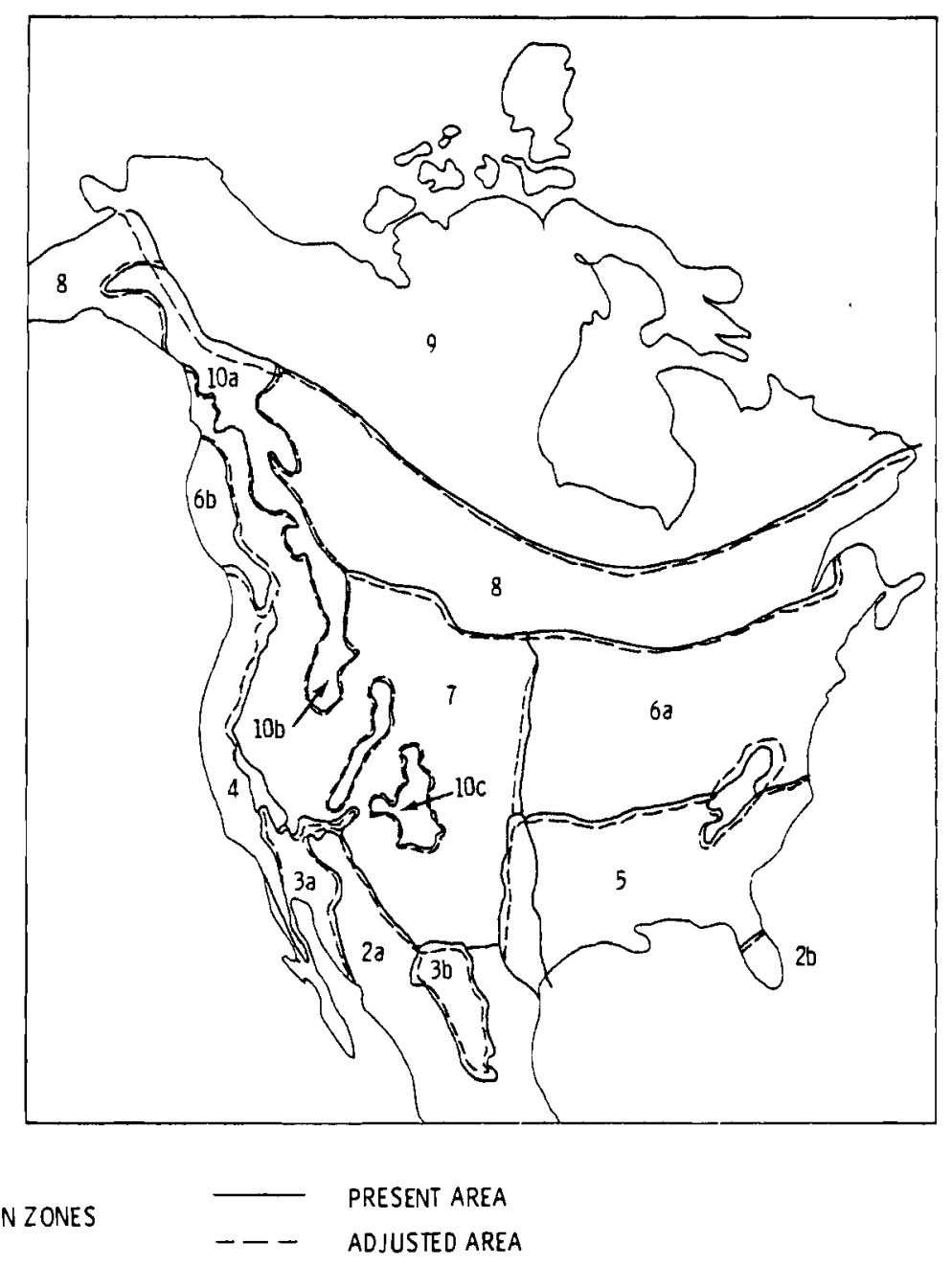

FIGURE 3.2a. Suggested Change in Vegetation Zones for North America in Response to a $-10^{\circ}$ Change in Mean Annual Temperature (from Fareed and Caldwell in CIAP-5, 1975) 
2a SOUTHWESTERN SEMI-EVERGREEN AND DECIDUOUS FORESTS

2b SOUTHEASTERN SEMI-EVERGREEN AND DECIDUOUS FORESTS

3a SOUTHWESTERN HOT SEMI- DESERTS AND DESERTS

3b SOUTHCENTRAL HOT SEMI-DESERTS AND DESERTS

4 WESTERN SCLEROPH YLLOUS WOODLANDS WITH WINTER RAIN

5 SOUTHEASTERN MOIST WARM TEMPERATE WOODLANDS

6a NORTHEASTERN DECIDUOUS (NEMORAL) FORESTS

6b NORTHWESTERN DECIDUOUS (NEMORAL) FORESTS

7 WESTERN TEMPERATE STEPPES, SEMI-DESERTS AND DESERTS WITH COLOWINTERS

8 NORTHERN BOREAL CONIFEROUS ZONE

9 NORTHERN TUNDRA

10a WESTERN MOUNTAINS INORTHERN ROCKY MOUNTAINSI

IOb WESTERN MOUNTAINS (CENTRAL ROCKY MOUNTAINSI

IOC WESTERN MOUNTAINS ISOUTHERN ROCKY MOUNTAINS)

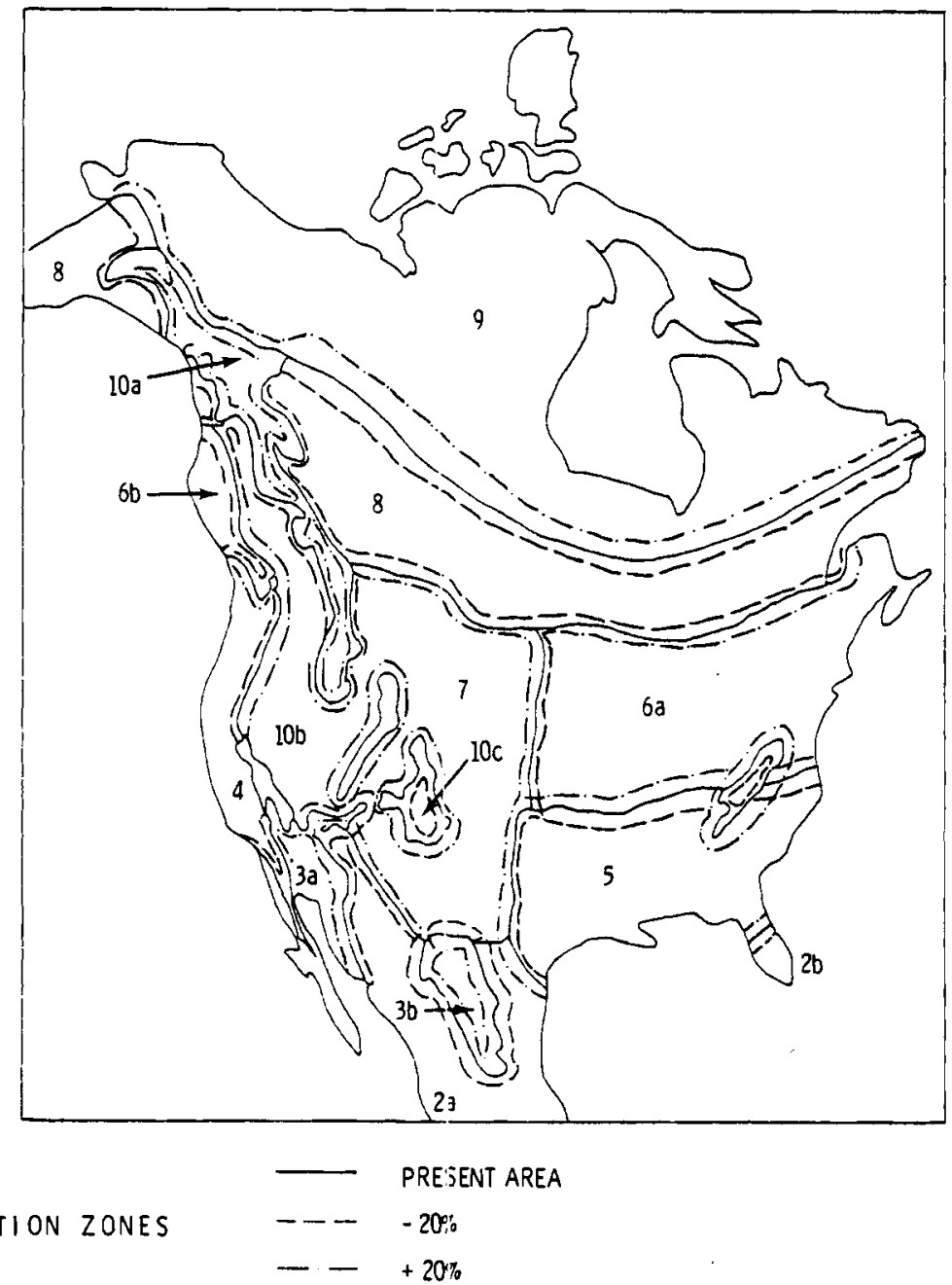

FIGURE 3.2b. Suggested Change in Vegetation Zones for North America in Response to a $\pm 20 \%$ Change in Precipitation (from Fareed and Caldwell in CIAP-5, 1975). 
Dorrenwend and Harris in CIAP-5 (1975) examine the effect of climatic change on peninsular Florida life zones. Using the Holdridge system of delineating natural vegetation formation based on precipitation, potential evapotranspiration, average frost-free period, and a synthetic variable termed biotemperature, they show that with a warmer and wetter climate in Florida, postulated to result from large releases of heat and moisture, almost the entire peninsula would be dominated by a subtropical moist forest life zone.

Linacre (1964) has studied the complex temperature-humidity-wind speed effects on plant evapotranspiration. He shows that in a moist climate, a combination of increased wind speed and humidity will decrease evapotranspiration more than an increase in humidity alone. However in arid climates an increase in humidity will decrease evapotranspiration less if an increase in wind speed occurs.

In general the literature identifies moisture stress as a more important variable than temperature for ecosystem diversity and productivity. Whittaker (1967) and Cooper and Jolly (1969) say much about the impacts on ecosystems that would occur from an increase in precipitation due to weather modification. Whittaker notes that population positions will shift along a moisture gradient to account for this change. Some species will disappear for lack of a tolerable environment. Al though these community changes will occur rather slowly (Cooper and Jolly 1969) there could eventually be an extensive alteration in the impacted area. Cooper further states that these adjustments will normally be slower in regions of high weather variability than in uniform climates.

Cooper discusses extensively the effects of an increase in precipitation on a variety of ecosystems for different climatic zones. In general, community structures in semi-arid zones would change most if precipitation increased. In arid regions, only a small increase in vegetation would be likely, while in moist climates an increase in rainfall would most likely increase surface runoff. Semi-arid regions would be most efficient in 
converting increased precipitation into increased bioproductivity, and species that may be lying dormant in the ground could suddenly bloom in these areas.

Whittaker notes that forests could utilize an increase in precipitation for increased productivity up to a certain point. However, he writes: "There is an apparent plateau beyond which increased moisture available to stable or climax forests does not increase their production."

The effects of increasing both temperature and moisture could increase plant disease due to insects and pathogens, both of which are directly affected more by temperature and humidity than by precipitation. Thus an increase in precipitation could improve plant vigor, ecosystem productivity and diversity, but this could be offset somewhat by an increase in the possibility of disease entering or increasing its attack on plants in the community.

\subsubsection{Radiation and Photosynthesis}

An increase in temperature will not necessarily increase the photosynthetic process in plants. In fact photosynthesis decreases during the midday heat, with bimodal maximums in photochemical reactions occurring in mid-morning and late afternoon (Gates, 1963). An increase in cloudiness will reduce the direct beam incoming solar radiation. However, unless the clouds are exceptionally thick the reduction in direct beam radiation will be partially offset by an increase in the diffuse sky radiation; this type of shortwave radiation penetrates plant canopies more readily, allowing the photosynthetic process to continue.

Gates (1965) has examined extensively the response of plants to various radiation loadings and environmental factors. He shows that the photosynthetic process depends on both light and temperature, as stated above, and that leaf temperature results from a complex interaction of solar radiation loading, ambient temperature and wind speed, moisture availability, and 
atmospheric humidity--all factors which could be altered by heat and moisture releases from energy centers.

McCree and Keener (1974) examined the effect of atmospheric turbidity on the photosynthetic rate of leaves. Turbidity, due to natural or humancaused dust and haze, strongly affects the absolute magnitude and spectral quality of the solar beam, but does not affect the total global irradiance on a horizontal surface due to the increase in the diffuse component. They show, therefore, that photosynthetic rates of crops would only be changed by a factor of $5 \%$ or so if atmospheric turbidity increased.

\subsubsection{Fog and Dew}

An increase in atmospheric moisture could increase the occurrence of fog and dew in the immediate vicinity of an energy facility rejecting heat and moisture to the atmosphere. Both fog and dew have an impact on ecosystems besides the obvious radiational effects of fog or low stratus discussed above. In some ecosystems, such as the California coastal forests, fog can influence species composition, and the vegetation and soil characteristics of these coastal forests reflect the persistence of fog (Azevedo and Morgan, 1974). In those regions, an increase in the occurrence of fog would stimulate this ecosystem even further, although it is questionable if such an ecosystem would become established in other regions should increases in fog occur.

Dew has been identified as a significant component of the hydrologic balance in a Douglas Fir stand in the Pacific Northwest (Fritschen and Doraiswamy, 1973). An increase in this moisture source could benefit other ecosystems, particularly in arid and semi-arid environments. However, dew duration is of major importance in the pathology of fungus diseases (Rosenberg, 1974). Some pathogens are only able to penetrate the stomata of leaves if enveloped in liquid water, while others require free water long enough for the cells to germinate and divide. 


\subsubsection{Summary of Ecosystems Effects}

In general, changes in temperature will alter the geographical distribution of ecosystems, while changes in precipitation will alter both the distribution and productivity. A reduction in solar radiation due to cloudiness is usually offset by an increase in the diffuse radiation which although weaker than the solar beam, penetrates the plant canopy more efficiently. This factor combines with photosynthes is (which works more efficiently when leaf temperatures are not abnormally warm) to keep net photosynthetic production at a fairly high level even on cloudy or hazy days. Fog and dew can also be source of additional moisture to increase productivity, but the increase in temperature and moisture, particularly liquid water droplets on the plant leaves, can also increase the opportunity for pathogenetic and insect diseases to enter the community. Furthermore, the increase in moisture possible from releases of large energy centers is most efficient in increasing plant productivity only in semi-arid regions.

\subsection{Effects on Agriculture and Agricultural Productivity}

Many arguments presented on the impacts of climatic modification on ecosystems are also valid for agricultural productivity. However, an important factor called human technology enters here. Technology permits agricultural production to respond quickly to environmental changes; in fact, productivity is a function of factors other than the local climate. These factors include economics and the availability of irrigation water, fertilizer and frost protection. As these factors become more significant, the study of the relation of climatic factors to agricultural production, either through multiple regression models utilizing long-term data on yields and climate, or through dynamic simulation models that estimate productivity in time steps as short as a day or less becomes increasingly less reliable.

Edmonds et a1. (1974) note that certain crops such as alfalfa, oats, clover, wheat, Indian rice grass, and ponderosa pine could be seriously damaged by cooling tower emissions during the germination and young leaf stages of development. However, a general body of 1iterature shows that agricultural production could be improved by increasing atmospheric temperature and precipitation, such as likely will occur in the vicinity of 
facilities rejecting large amounts of heat and moisture to the atmosphere. For example, Hegarty (1972) notes that a warming of the climate in Scotiand can benefit agriculture since a plant is most efficient when it attains its maximum leaf area index at the same time that seasonal conditions are most favorable for photosynthesis--a condition that would occur if the growing season was lengthened. The types of impacts associated with the release of heat and moisture to the atmosphere will indeed lengthen the growing season, by increasing atmospheric temperature and delaying the occurrence of frost through an increase in cloudiness and a moderation of nocturnal minimum temperatures near the facilities releasing the heat and moisture.

Konstantinov (1974) shows that optimal hydrometeorological and radiation conditions can be identified for all vegetative species. For food crops, these optimal conditions usually occur in mid latitudes. For example, grain crops produce maximum yields under conditions of $60 \mathrm{~cm}$ mean annual rainfall and net radiation of $44-50 \mathrm{kcal} \mathrm{cm}^{-2} \mathrm{yr}^{-1}$. However, Namken et al. (1974) state that temperature is the one environmental factor that determines which species will grow under which environmental conditions, the time of year it may be grown, and the length of growing season available to it. They note that a plant growing under its most optimal temperature conditions is usually adversely affected by a temperature change, and as a plant adapts towards one temperature extreme it becomes increasingly sensitive to other extremes. However, other authors note that moisture can be more important than temperature, particularly for agricultural products such as wheat (CIAP-5, 1975). Even for natural ecosystems Daubenmeier has identified many ecotones, particularly at lower elevations, to be a function more of moisture availability than temperature conditions (Daubenmeier, 1956).

\subsubsection{Response of Individual Agricultural Products to Climatic Changes From Energy Centers}

Much information is available on yield predictions for individual crops as functions of climatic parameters. The information is generally summarized using multiple regression techniques (Munn, 1970). More recently, dynamic simulation models have been used to estimate crop yields as a 
function of a variety of environmental factors. These regression and simulation relations can be used to determine how yields might vary with change in one or more of the environmental factors. As noted in the previous section, literature reviews are available on the impact of climatic changes due to artificial precipitation augmentation (Cooper and jolly, 1969) and changes in surface temperature due to extensive aircraft operations in the stratosphere (CIAP-5, 1975). In addition, the CIAP-5, perhaps the best overall collection of information yet assembled to assess the impacts of climatic changes on ecosystems, discusses in detail the impacts of climatic change on agricultural productivity for several crops.

CIAP-5 provides tables relating changes in mean temperature and precipitation to changes in yields. In general, these tables were developed by applying regression or simulation models to specific crop species in specific locales; thus they are subject to much uncertainty, including the uncertainty of how human technology would respond to these environmental shifts. These tables generally show impacts on yields for individual crops for both increase and decrease in temperature and precipitation.

It is beyond the scope of this report to reproduce an extensive summary of this extremely relevant document. Instead the major findings in CIAP-5 as well as others are summarized in Table 3.2. In this table, discussions on crop yield changes are oriented toward postulated increases in temperature, humidity, and precipitation (including fog and dew), since one or a11 of these parameters would be expected to increase near a facility releasing large amounts of heat and moisture to the atmosphere.

Corn yields in the midwestern United States in general will increase for both decreasing temperatures, and increasing precipitation (Benci et al., in (IAP-5). Thus, a $1-2 C^{\circ}$ temperature increase and $15 \%$ precipitation increase would offset each other in yield changes, although a net reduction in corn yields would still occur. This shows that although Table 3.2 considers the effect of each environmental factor on crop yields individually, combining two environmental parameters (in particular temperature and 


\author{
precipitation) creates offsetting influences on yield changes. Furthermore, \\ these environmental factors are shown in CIAP-5 to vary considerably from \\ state to state.
}

\title{
TABLE 3.2. Summary of Impacts of Climatic Change on Agricultural Yields
}

\begin{tabular}{|c|c|c|c|c|c|}
\hline \multirow[b]{2}{*}{ Crop } & \multicolumn{5}{|c|}{ Increase In } \\
\hline & Temperature & Hunidity & Precipitation & Solar Radiation & Fog, Dew \\
\hline $\begin{array}{l}\text { General } \\
\text { Biomass }\end{array}$ & $\begin{array}{l}\text { Gross photosynthesis } \\
\text { increases (Campbell. } \\
\text { 1976); yie1d increases } \\
\text { (Hegarty, 1972) }\end{array}$ & $\begin{array}{l}\text { Gross photosynthesis } \\
\text { increases (Campbell, } \\
\text { 1976) }\end{array}$ & & & $\begin{array}{l}\text { Increased chance } \\
\text { for pa thogens to } \\
\text { enter plants } \\
\text { (Rosenburg, } \\
\text { 1974) }\end{array}$ \\
\hline Corn & $\begin{array}{l}\text { Decrease yields (July } \\
\text { and August) (Changnon } \\
\text { and Neili, 1968); number } \\
\text { of leaves increase, time } \\
\text { to tassel initiation } \\
\text { decrease (Coligado and } \\
\text { Brown, 1975); decrease } \\
\text { yields (Chapter } 4 \text { in } \\
\text { CIAP-5, 1975) }\end{array}$ & $r$ & $\begin{array}{l}\text { Beneficial oniy in June } \\
\text { and July (Changnon and } \\
\text { Neil), } 968 \text { ); slight } \\
\text { increase in yields } \\
\text { (Chapter } 4 \text { in CIAP-5, } \\
\text { i975) }\end{array}$ & $\begin{array}{l}\text { Decreasing water } \\
\text { use efficiency } \\
\text { (Lomas, et al., } \\
1974)\end{array}$ & \\
\hline Wheat & $\begin{array}{l}\text { Increased marquis spring } \\
\text { wheat yield up to } 20^{\circ} \mathrm{C} \\
\text { decrease above } 25^{\circ} \mathrm{C} \\
\text { [Friend, 1966 (as quoted } \\
\text { in Namken, et al. } \\
\text { 1974)]; decrease in } \\
\text { yields (Chapter } 4 \text { in } \\
\text { CIAP-5, (975) }\end{array}$ & & $\begin{array}{l}\text { Increase yields dfrectly } \\
\text { (Biscoe et al., 1975; } \\
\text { Hanks, 1974); beneficiai } \\
\text { during sowing and germina- } \\
\text { tion, and in general dur- } \\
\text { ing all weeks of the year } \\
\text { (Screenivasan, ig74); } \\
\text { increase yields in midwest } \\
\text { except IL. IN (Chapter } 4 \\
\text { in CIAP-5, 1975) }\end{array}$ & & \\
\hline Rice & $\begin{array}{l}\text { Beneficial during nur- } \\
\text { sery period, detrimental } \\
\text { during growth and matur- } \\
\text { ity stages (Huda et } \\
\text { al., 1975); beneficial } \\
\text { in northern latitudes } \\
\text { (Arakawa, 1957; Murata, } \\
\text { 1975); general increase } \\
\text { in yields throughout } \\
\text { much of the world (Chap- } \\
\text { ter } 4 \text { in CIAP-5, 1975) }\end{array}$ & $\begin{array}{l}\text { Beneficial during } \\
\text { establistment, } \\
\text { detrimental after- } \\
\text { wards (Huda et al., } \\
1975 \text { ) }\end{array}$ & $\begin{array}{l}\text { Beneficial during nursery } \\
\text { period, detrimental dur- } \\
\text { ing growth and maturity } \\
\text { (Huda et a1., 1975); gen- } \\
\text { eral slight increase in } \\
\text { yields throughout much of } \\
\text { world (Chapter } 4 \text { in } \\
\text { CIAP-5, 1975) }\end{array}$ & $\begin{array}{l}\text { Increase yields in } \\
\text { northern latitudes } \\
\text { (Murata, 1975): } \\
\text { l.8\% reduction in } \\
\text { yield for } 1.0 \% \\
\text { reduction inal } \\
\text { sunlight (Chapter } \\
4 \text {, in CIAP }-5,1975 \text { ) }\end{array}$ & \\
\hline Soybeans & $\begin{array}{l}\text { Decreased yields (Chap- } \\
\text { ter } 4 \text { in CIAP-5, 1975) }\end{array}$ & & $\begin{array}{l}\text { Increase yields (Chapter } \\
4 \text { in CiAP-5, 1975) }\end{array}$ & & \\
\hline Cotton & $\begin{array}{l}\text { Increase yields (Chap- } \\
\text { ter } 4 \text { in CIAP-5, 1975) }\end{array}$ & & $\begin{array}{l}\text { Decrease yields (Chapter } \\
4 \text { in CIAP }-5,1975 \text { ) }\end{array}$ & & \\
\hline Sorghum & $\begin{array}{l}\text { Slight decrease in } \\
\text { yields (Chapter } 4 \text { in } \\
\text { CIAP-5, 1975) }\end{array}$ & & $\begin{array}{l}\text { Increase in yields (Chap- } \\
\text { ter } 4 \text { in CIAP-5, 1975) }\end{array}$ & & \\
\hline $\begin{array}{l}\text { Forage, } \\
\text { Grain } \\
\text { Crops }\end{array}$ & $\begin{array}{l}\text { Decrease yields, par- } \\
\text { ticularly in southern } \\
\text { regions (Chapter } 4 \text { in } \\
\text { CIAP-5, 1975) }\end{array}$ & & $\begin{array}{l}\text { Beneficial to certain } \\
\text { optima? ppt. value, then } \\
\text { detrimental (Konstantinov, } \\
1974 \text { ); increase yields, } \\
\text { but present rangeland } \\
\text { would be diverted to } \\
\text { cereal production (Chap- } \\
\text { ter } 4 \text { in CIAP-5, 1975) }\end{array}$ & $\begin{array}{l}\text { Beneficial to a } \\
\text { certain optimal radi- } \\
\text { ation level, then } \\
\text { detrimental (Konstan- } \\
\text { tinov, 1974) }\end{array}$ & \\
\hline Hops & $\begin{array}{l}\text { Slight decrease in qual- } \\
\text { ity above } 16^{\circ} \mathrm{C} \text { (Smith, } \\
1974 \text { ) }\end{array}$ & & & & \\
\hline $\begin{array}{l}\text { Wood } \\
\text { Storage }\end{array}$ & & & $\begin{array}{l}\text { Beneficial to a certain } \\
\text { ppt. value, then detri- } \\
\text { mental (Konstantinov, } \\
\text { 1974) }\end{array}$ & $\begin{array}{l}\text { Beneficial to a } \\
\text { certain radiation } \\
\text { level, then detri- } \\
\text { (xonstantinov, } \\
1974 \text { ) }\end{array}$ & \\
\hline $\begin{array}{l}\text { Natural } \\
\text { Pasture }\end{array}$ & $\begin{array}{l}\text { Improve growth in con- } \\
\text { junction with increased } \\
\text { soil moisture (Wallach, } \\
1975 \text { ) }\end{array}$ & & & & \\
\hline $\begin{array}{l}\text { Fruit } \\
\text { Crops }\end{array}$ & $\begin{array}{l}\text { Northward (or southward } \\
\text { south of equator) shifts } \\
\text { in production areas } \\
\text { (Chapter } 4 \text { in CiAP-5, } \\
\text { 1975) }\end{array}$ & & $\begin{array}{l}\text { Detrimental if in areas of } \\
\text { marginal light intensity or } \\
\text { heat accumulation (Chapter } \\
4 \text { in CIAP-5, 1975) }\end{array}$ & & \\
\hline
\end{tabular}


Wheat yields also increase with precipitation and decrease with temperature increases (Ramirez et al., CIAP-5). The combined effect is a general decrease in yields for 1 to $20^{\circ}$ temperature increase and $10-20 \%$ increase in precipitation. However, the decrease is much greater in Illinois and Indiana than in North Dakota or Kansas, where in fact yields may increase slightly.

Rice, on the other hand, may be affected more by changes in sunlight availability than temperature, particularly in tropical regions (Stansel and Huke, (IAP-5). A decrease in sunlight will decrease productivity in the tropics. In the mid latitudes of the United States rice yields increase with increasing temperature and decrease with increasing precipitation. This is in direct contrast to wheat and corn. However in the United States an increase of $2 \mathrm{C}^{\circ}$ temperature and $15 \%$ in precipitation produces only a small net increase in rice yields.

The response of soybean productivity to changes in temperature and precipitation is much more complex (Curry and Baker, CIAP-5). In general, a $2^{\circ} \mathrm{C}$ temperature increase and $15 \%$ precipitation increase would result in virtually no change in soybean yields in Ohio, a $12 \%$ decrease in Indiana and a $9 \%$ increase in Iowa.

CIAP-5 shows that photosynthetic production in cotton plants would decrease almost directly with a decrease in solar radiation (Baker, et al., CIAP-5). Cotton yields decrease with temperature but increase with higher precipitation in a fashion similar to rice. The net effect of a $2 \mathrm{C}^{\circ}$ temperature increase and a 30\% precipitation increase is to increase yields somewhat.

In general, productivity of forage crops increases with rainfall and temperature in the northern latitudes (Hart and Carlson, CIAP-5). In the United States, however, based on studies in controlled environments, CIAP-5 shows that yields increase in months when temperatures are cooler and decrease when temperatures are warmer, particularly in southern climates where temperatures are already too warm for optimal crop growth. Thus, large power generating facilities causing an average increase of $2.5 \mathrm{C}^{\circ}$ in air temperature would have a negative effect on forage producitivity, particularly in the southern states. 


\subsubsection{Summary of Agricultural Effects}

Despite human technology which virtuaily masks any but the most severe effects of climatic changes on agricultural yields, some patterns are evident that could result in small changes in yieids near iarge energy centers. However, the yield changes vary from positive to negative depending on the crop and the state in which the estimates were made. In general, wheat and corn would be negatively effected by additions of heat and moisture to the atmosphere, while it is possible that rice, soybeans, cotton, sorghum and alfalfa yields would increase, at least in some regions of the United States.

Table 3.3 summarizes the estimates of changes in yields for various crops as shown in CIAP-5 (1975). These estimates are based on the application of regression and simulation models to the crop under different environmental conditions. Because many uncertainties exist not only about the yield changes shown for a temperature increase of $2 \mathrm{C}^{\circ}$ and a precipitation increase of 10 to $20 \%$, but also about the postulated change in the environmental parameters themselves near large releases of heat and moisture to the atmosphere, these numbers should be considered only rough approximations. Again, the human technology factor (the manner in which agricultural specialists would respond to these environmental changes) has not been included in these estimates. 
TABLE 3.3. Surmary of Estimates of Impacts on Agricultural Yields Due to a Postulated Change in Mean Temperature of $+2 \mathrm{C}^{\circ}$ and Annual Precipitation Increase of 10 to 20\% (from CIAP-5, 1975)

\begin{tabular}{|c|c|}
\hline \multicolumn{2}{|l|}{ Corn } \\
\hline Indiana & $-30 \%$ \\
\hline Iowa & $-11 \%$ \\
\hline Missouri & $-5 \%$ \\
\hline Illinois & $-20 \%$ \\
\hline \multicolumn{2}{|l|}{ Wheat } \\
\hline North Dakota & -0.69 to -0.49 bushels/acre \\
\hline South Dakota & -1.13 to -0.67 bushels/acre \\
\hline Kansas & -0.82 to -0.16 bushels/acre \\
\hline Oklahoma & -3.45 bushels/acre \\
\hline Illinois & -4.10 to -5.71 bushels/acre \\
\hline Indiana & -3.05 to -4.20 bushels/acre \\
\hline \multicolumn{2}{|l|}{ Rice } \\
\hline California & $+20 \%$ of average U.S. production \\
\hline Arkansas & $+4 \%$ of average U.S. production \\
\hline Louisiana & $-5 \%$ of average U.S. production \\
\hline Texas & $-6 \%$ of average U.S. production \\
\hline United States & $+3 \%$ of average U.S. production \\
\hline \multicolumn{2}{|l|}{ Soybeans } \\
\hline Ohio & $+1 \%$ \\
\hline Indiana & $-12 \%$ \\
\hline Iowa & $+9 \%$ \\
\hline Cotton & +0.54 bales/acre ${ }^{(\mathrm{a})}$ \\
\hline \multicolumn{2}{|l|}{ Sorghum } \\
\hline Manhattan, Kansas & $+5.8 \%$ \\
\hline \multicolumn{2}{|l|}{ Alfalfa } \\
\hline Albuquerque, New Mexico & $+18 \%($ Oct $)$ to $-7 \%(\mathrm{Jul})^{(\mathrm{b})}$ \\
\hline Minneapolis, Minnesota & $+18 \%$ (May) to $-2 \%$ (Jul, Aug) \\
\hline St. Louis, Missouri & $+12 \%$ (May) to $-6 \%$ (Jul, Aug) \\
\hline Raleigh, North Carolina & $+16 \%$ (Apr) to $-9 \%$ (Aug) \\
\hline $\begin{array}{l}\text { (a) Interpolated for change } \\
+30 \% \text {. } \\
\text { (b) For } 2.5 \mathrm{C}^{\circ} \text { temperature ir } \\
\text { tation. The extreme va } \\
\text { during the growing seas }\end{array}$ & $\begin{array}{l}\text { in precipitation from } 0 \text { to } \\
\text { crease, no change in precipi- } \\
\text { ues are given for the months } \\
\text { n of April - October. }\end{array}$ \\
\hline
\end{tabular}




\subsection{Effects on Animals and Animal Populations}

Effects of changes in environmental parameters on animals may be examined using the energy balance as in Porter and Gates (1969). Figure 3.3, taken from Gates (1962), shows that the energy streams to the animal are balanced by the energy outflow:

$$
M+Q_{a b s}=Q_{L}+Q_{H}+Q_{e x}+Q_{S W} \pm C \pm W
$$

where:

$$
\begin{aligned}
M= & \text { metabolic rate } \\
Q_{a b s}= & \text { rate of radiant energy (solar and thermal) absorbed by the } \\
& \text { animal } \\
Q_{L}= & \text { thermal radiant energy emitted from the animal's surface } \\
Q_{e x}= & \text { latent energy of moisture loss through respiration } \\
Q_{S W}= & \text { latent energy of moisture loss through sweat } \\
C & =\text { heat conducted into the substrate } \\
W & =\text { work produced by the animal }
\end{aligned}
$$

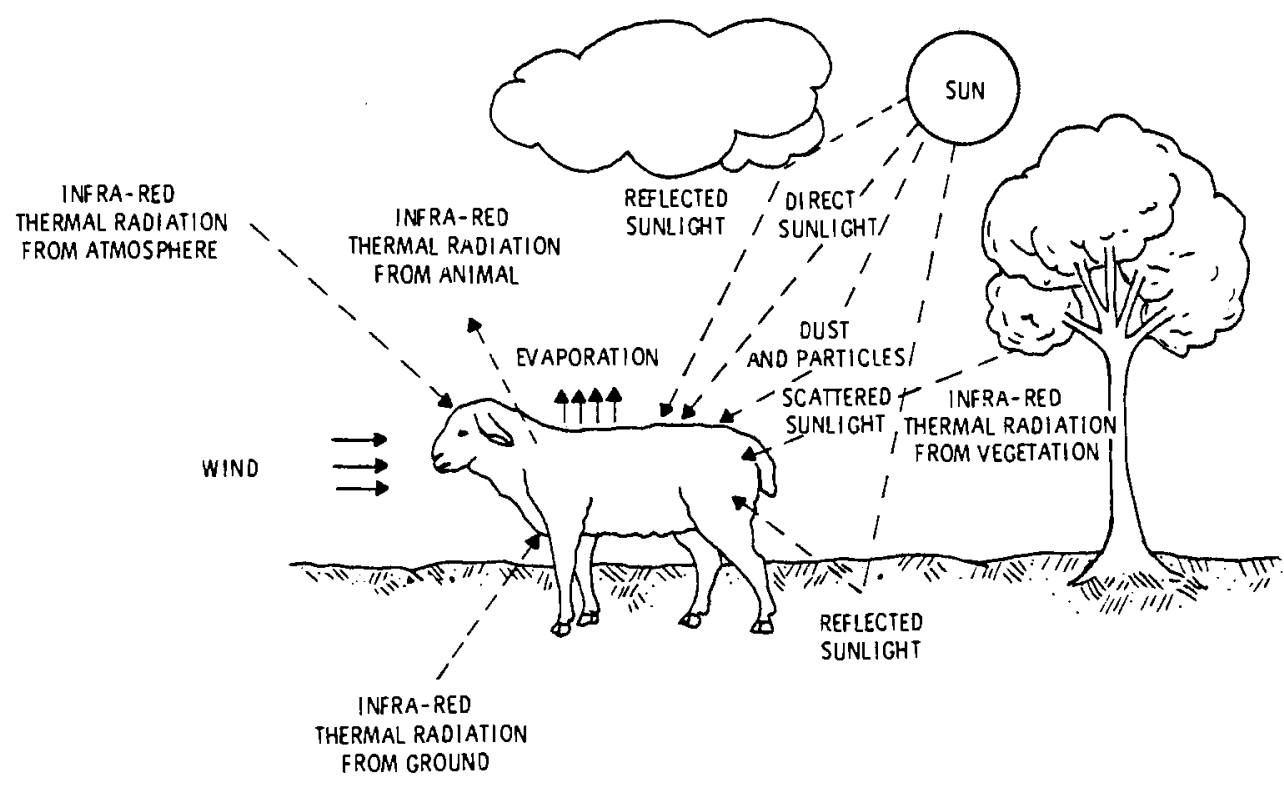

FIGURE 3.3. The Streams of Energy Flow to and From an Organism in Its Natural Environment. Figure from Gates (1963). 
From equation 3.3, the environment and space requirements (the "climate space") in which the animal can survive can be constructed. This climate space consists of the radiation absorbed, air temperature, and wind speed. The climate spaces of large and small birds and mammals have been developed by Porter and Gates (1969). Applying the model to the "cold-blooded" lizard, shrew, pig, sheep, etc. and hypothetical animals, generalizations can be made about the effects of changes in the climate space of these species.

\subsubsection{Temperature}

Higher temperatures tend to increase metabolism and the mean temperature in poikilotherms, and increase sweating and other heat loss mechanisms in homeotherms. According to Porter and Gates (1969), homeotherms without fur or feathers cannot tolerate large ranges in temperature. Large cold and warm-blooded animals are better adapted to lower temperatures while smaller animals can survive higher temperature maxima, although they require more radiation or a higher metabolic rate at lower temperatures.

The persistent temperature increase near an energy center from heat and moisture releases to the atmosphere will cause those animals living near the boundary of their climate spaces to avoid higher air temperatures by migrating or by other behaviors which alter the temperature stress, such as burrowing. They can avoid the radiation boundary by seeking shade, or they can lose excess heat by sweating or by heat conduction into the substrate. An example of this latter method would be pigs wallowing in mud.

Clouds and cooling tower plumes will tend to lessen the radiation absorbed at the boundary of the climate space. Under these conditions species that presently thrive near the extreme will have more competition from other species in proportion to the space and time persistence of sky cover.

\subsubsection{Precipitation and Moisture}

The increase in atmospheric moisture caused by power-generating facilities of the order discussed in this report is a small fraction of that which exists in the summer daytime during the growing season in the United States. 
Therefore the decreased saturation deficit will only slightly decrease the latent heat transfers of sweating and respiration.

A multiple regression study of cottontail rabbit populations in regions of enhanced precipitation and other weather elements in IIlinois (Havera, 1973) showed that cottontail harvests were associated with total precipitation during the May-August period becuase of the effect on vegetation. However the study was complicated because of the kinds of agricultural crops and variation of Illinois farmland put into production as the prices for cash grain crops fluctuated.

Cooper and Jolly (1969) note that organisms in general respond to changed moisture balances as individual species, not as communities. They also observe that extinction of large and small mammals is unlikely from worldwide temperature and moisture changes of the same magnitude as local changes foreseen near large energy centers.

\subsubsection{Fog, Dew and Hail}

The greatest effect of fog on animals will be the reduction in visibility. The boundary stresses of the climate space will be reduced unless there is excessive heat loss by species not adapted to cold drizzle. The increase in fog and dew offers more opportunity for invertebrate populations needing liquid water in their life cycles to be introduced to the region.

Increased hail and thunderstorms would frighten animals and cause physical damage to them and the vegetation in their food chains. Convective storms in small watersheds are associated with increased floods and erosion, thereby changing the habitat.

\subsubsection{Effects on Livestock Animals and Their Agricultural Implications}

In CIAP-5 (1975), Johnson, et al. discuss the effects of environment changes on beef, swine, dairy and poultry production. Adverse environments are generally overcome by breeding, shelter design, and management practice. Their interpretations are made from temperature and humidity experiments. For beef cattle there seem to be no adverse effects from atmospheric changes by large energy centers published in this report. Swine, however, are more temperature sensitive than cattie. Amick and Purcell (1964), quoted by McQuigg (1975) show that "feed per hundred pounds of hogs produced decreases 
as temperature increases to $60^{\circ} \mathrm{F}\left(16^{\circ} \mathrm{C}\right)$, then increases as temperature continues to increase." Smaller pigs grow better at slightly higher temperatures. Charts showing relationships like these are given in CIAP-5, and can be used for planning livestock management near large energy facilities.

Dairy production, measured by milk yield, is species dependent but generally is optimum near $10^{\circ} \mathrm{C}$. Male poultry grows best at $16^{\circ} \mathrm{C}$. Charts showing these relationships are also given in CIAP-5.

\subsection{Effects on Humans and Human Activities}

An energy balance for humans similar to that for animals has been developed by Gates (1963) as quoted by Landsberg (1972). A climate space diagram for humans can be developed. Human subjects generally state they are "comfortable" when there is no visible evidence of sweat and when skin temperature is about $32^{\circ} \mathrm{C}$ (Monteith, 1973). "When the heat load on his body is increased, e.g., by exercise or exposrue to radiation, or when the temperature of the environment is increased, a small amount of excess heat can be dissipated by a rise in skin temperature involving a faster circulation of blood in the peripheral tissue. When the temperature gradient in this tissue becomes too small to conduct metabolic heat out of the body, sweat is released rapidly from glands a few millimeters below the surface of the skin. Depending on the nature of the environment and of clothing, sweat may evaporate without appearing at the skin surface (insensible perspiration), or may wet part of the body oniy, or may cover the whole body. When the rate of evaporation from any area is less than the rate at which sweat is produced there, the sweat trickles over the surface of the skin or is lost by dripping, a wasteful process because the water lost from the body plays no part in relieving heat stress.

Heat stress effects include prickly heat (plugging of sweat glands), fainting (deficient blood flow to the brain because of enhanced flow to the peripheral areas), fatigue, and nausea from depletion of salts. Severe sweat loss and a body temperature increase to $40^{\circ} \mathrm{C}$ causes failure of circulatory functions resulting in heat stroke and death (Landsberg, 1969). Infants, the elderly, and others with poor blood circulation and individuals not acclimated to hot weather are most apt to suffer heat stroke. 
McQuigg (1975) presents several abstracts of studies of weather and human disease. Sudden changes in weather, particularly atmospheric cooling, are associated with respiratory and other diseases. Warm air influxes increase the unrest of schizophrenic patients. However, these are not major effects of energy centers, and in fact the moderating effect of these facilities on the local climate, similar to areas near large bodies of water, could reduce these human effects.

Severe heat waves, particularly in large cities, have been associated with mortality increases up to $20 \%$ for people with heart disease, diabetic respiratory disease, hypertension and disease of the blood. However, heat releases from the energy center to the deep mixing layer of unstable summer atmosphere should contribute little to additional heat wave effects near. these facilities.

\subsubsection{Human Comfort Indices}

There are several ways to quantify heat stress on humans. The wet bulb temperature is one way to express heat stress on a body, since it is directly related to the ability of the body to cool through evaporation of sweat. When the wet bulb globe temperature (WBGT) ${ }^{(a)}$ is greater than or equal to $31^{\circ} \mathrm{C}$, the United States Marines are required to suspend training (Landsberg, 1969).

Hendrick (1969) derived an index of outdoor weather comfort from the American Society of Heating and Ventilating Engineers indoor comfort chart, adding wind speed and solar heat load to express summer comfort index sensations ranging from -5 (uncomfortably cool) to 0 (ideal) to +15 (very oppressive). More elaborate schemes developed by Gagge, from laboratory studies, and Lee, based on measures of relative strain on humans imposed by the atmospheric environment, are described by Landsberg.

The Temperature-Humidity Index (THI) was discussed in the previous chapter. This human comfort indicator is based on temperature $\left({ }^{\circ} \mathrm{F}\right)$ averaged

\footnotetext{
(a) The Wet BuTb Globe Temperature (WBGT) is given by:

WBGT $=0.2$ dry globe temperature +0.1 dry bulb temperature +0.7 wet bulb temperature.
} 
with relative humidity (\%) to give a number indicating human comfort. Almost everyone is uncomfortable when the THI is above 80 , and environmental conditions giving a THI above 90 are considered a physical danger zone. The heat and moisture emissions from large energy centers will increase the THI by only one unit, thus discomfort will not increase noticeably beyond natural THI. An exception to this might occur when warm fog or haze caused by the energy center persists locally.

Indices relating comfort with respect to cold generally combine temperature with wind speed to produce a wind chill index. Landsberg (1972) describes several such indices. Heat and moisture released from energy centers can wet clothing by fog or drizzle which, in cold weather, will reduce its heat insulation properties and chill the human skin.

\subsubsection{Summary of Human Effects}

The physiological effects on humans from large releases of heat and moisture to the atmosphere appear to be very small. Only slight additional discomfort would be noticed either from the increase in heat and moisture on warm days or from an additional wind chill on cold days; the mobility of humans and the ability to adapt to changes in climate and to control them artificially would even cancel these effects.

The psychological effects on humans, and the possible disruption of their activities, from large heat and moisture releases could be more significant than their physiological effects. Some of these more subtle impacts will be addressed in Section 4, Economic Analysis. 


\subsection{ECONOMIC ANALYSIS}

K. A. McGinnis

This task attempts to assign generic monetary values to inadvertent weather modifications. Estimated monetary values were identified through a critical review of the literature and evaluated with regard to economic theory. When such estimates are not available, al ternative methodology for monetary assessment is considered.

As previously postulated, the release of energy from an energy center could modify weather by increased fogging, precipitation, humidity, and vorticity. These impacts are far-reaching on the many human and ecological activities sensitive or vulnerable to potential weather changes. Effects reviewed include transportation interference, aesthetic damage, effects on agriculture and health, property damage and measures of quality of life and life itself.

The significance and degree of these impacts are related not only to whom but to what they impact. The effects will be positive in some cases and negative in others. The monetary assessment of these positive and negative effects of weather modification values the associated costs and benefits in terms of a common unit, dollars, providing a base for comparison with other goods and services.

\subsection{Environmental Economics Theory}

To assign monetary values to weather modification, one must understand weather and changes in weather in the context of economic theory. Weather is an example of a public good. A public good is available to all individuals without cost for consuming it, lacks defined ownership and has no available market price. A public good is one kind of externality or extra market product; heat released to the environment through electricity generation is another extra market product, which also has no identifiable market price. The released heat may cause weather modification which is in turn an externality (namely, a public good). Economic theory concerned with quantifying environmental externalities in monetary terms is that part of natural resource economics called environmental economics. A brief review of environmental economics theory is necessary to further explain the valuing of weather modification. 
A private market good has an inverse relationship between price and quantity demanded; at higher prices there will be a lower quantity demand. Factors influencing individual demand include income, preferences, price or other goods, and expectations.

Supply is the amount of goods that a producer is willing to provide at any price. Price and quantity supplied are positively related; thus, the higher the price the more the producers will be willing to supply. This is because the production costs that govern the ability of the producer to supply at a given price will eventually rise with increased output given a constant scale of production. A private market supply curve does not account for any external cost or benefits. For example, if a steel mill disposes wastes into a river which damage the recreational activities and the mill does not pay for this damage then the costs are not internalized. Payment by the mill could be in the form of pollution controls or compensation to individuals damaged or both. When an externality is internalized the supply curve shifts. It will shift to the right if the externality is a benefit to society; it will shift to the left if it is a cost to society. A supply curve that incorporates all external benefits and costs of production is referred to as the social marginal cost curve.

These benefits and costs in terms of supply and demand are illustrated in Figure 4.1. Also shown is the market equilibrium price, $P$, at quantity, Q. The demand and supply curves intersect and form the equilibrium point. In this case assume the supplied commodity is electricity originating from an energy park. The shape of the supply curve for electricity is hypothetical and in reality may not look like this figure. At the equilibrium point (the margin) the cost of the last unit sold is exactly equal to the price the consumer is willing to pay. Any unit greater than the quantity, $Q$, will not be sold because it cannot be produced for the price, $P$, which is the price that the marginal consumer is willing to pay for the commodity.

The analogous demand curve for an extra market good is based on the willingness to pay concept (WTP); for our purposes, this means the 
population's willingness to pay to avoid weather modifications that are perceived to have negative impacts. The aggregate (WTP) demand curve is the marginal social benefit curve.

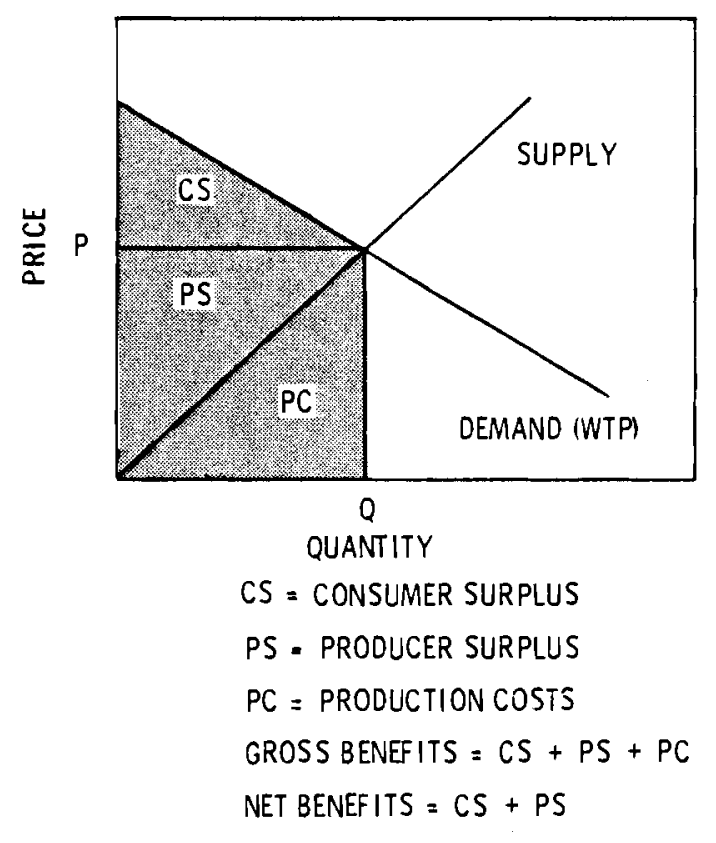

FIGURE 4.1 Components Used in Valuing Private Market Goods

Assume that there are no environmental, aesthetic, health, or other external impacts associated with the production of electricity. Then the gross benefits (in Figure 4.1) to society would be defined as the willingness to pay (WTP) for quantity, $Q$, units of electricity; i.e., the area under the demand curve left of quantity, Q. The net benefits to society are the gross benefits less the production costs, or producer surplus plus consumer surplus included in gross benefits. This is the shaded area in Figure 4.1. The consumer surplus is the amount consumers are willing to pay but do not have to. The producer surplus is the difference between the costs of supplying electricity and what it is sold for. The net benefits, therefore, are distributed on the basis of the respective surpluses to the consumers and producers. 
Many of society's environmental problems today are a result of waste disposal. When more than one product is produced, it is referred to as a joint or multiple production process. In a physical sense, the materials balance approach describes the production and consumption process in terms of conservation of mass. Physical matter cannot be destroyed, therefore it eventually becomes an extra market product for society to dispose of. Waste disposal alternatives are influenced by available technology and existing economic incentives (Seneca, 1974).

When the externality is negative and lowers the perceived quality of a good, then WTP for that good decreases. For example, assume attendance at a football game depends only on the weather. Given the opportunity, the consumer would pay more to watch the game under fair weather conditions than foul weather conditions.

If net benefits are a measure of social welfare when extra market products are internalized, then there will be a shift in the marginal social cost curve and a change in social welfare will result. Theoretically, when the producer is producing an extra market good that is perceived by society to have negative value and if he internalizes the cost for this good, then his supply function shifts to the left and becomes the marginal social cost curve instead of marginal private cost of supplying the commodity. The amount supplied would then decrease $\left(Q_{1}\right.$ to $\left.Q_{2}\right)$ to the point where marginal social benefits and costs are equal (Figure 4.2). The equilibrium point and quantity move to the left and decrease. For example, if electricity generated in a large energy center and transmitted out of the area creates weather modifications with negative impacts to the local population, many of the positive benefits of the elecricity production accrue to people who are not affected by the weather changes. The people not affected by the weather modification are not paying the marginal social cost of electricity unless the external costs resulting from weather modification are internalized.

Estimating the net benefits of electricity generation from an energy center is difficult when considering the many impacts of weather modifications. One must determine all extra market costs and benefits associated with weather modification and incorporate them into the supply curve. 
Examples of these different impacts include effects on recreation, agriculture, forestry, health, aesthetics, transportation, home heating and cooling. Analysis of that scope would probabily require primary data consisting of surveys and interviews. The survey attempts to directly determine the WTP for a certain environmental quality. The worth of the survey lies in accurately revealing consumer preferences and is a major determinant in quality of the assessment. Gathering primary data is beyond the scope of this project. However, the methodology is presented through similar examples of externality assessments to provide a partial overview.

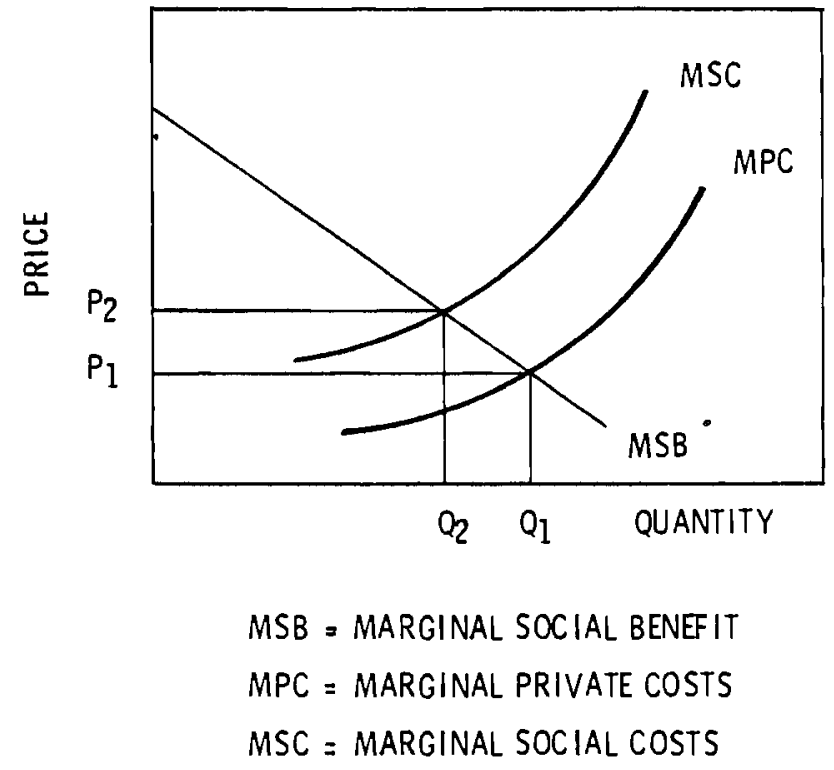

FIGURE 4.2 Incorporation of External Effects

In many instances secondary data can be used to indicate consumer preference for nonmarket goods. This data measures the response to exteralities and tends to provide underestimates of the actual damage. Examples of this would be property value differential as an indicator of the value of a view, measuring material damage due to pollution and human health effects measured by medical expenses incurred and wages and productivity loss. The secondary data in the following sections show the different approaches to valuing weather modifications. 


\subsection{Effects of Fog}

\subsubsection{Effects of Fogging on Air Traffic}

The potential for increased fogging in a local area as a result of heat dissipation to the atmosphere was previously discussed. Obvious potential impacts include interference to both air and ground traffic and psychological effects of reduced visibility, visible plumes, and effects on agriculture and recreation.

Previous studies on the evaluation of fog costs to air traffic have focused on the cost effectiveness of fog dispersion of weather sensitive landing (Federal Aviation Administration (FAA), 1971; Pratt, 1972; Weinstein, 1974). These studies provide a base on which to compare the potential changes in fogging as a result of heat dissipation.

The frequency of fog visibility less than current minimum aircraft landing guidelines (100 ft ceiling and $1200 \mathrm{ft}$ visibility) is estimated at 2 to 3 percent per year (FAA, 1971). The effect of this frequency tends to be compounded by the persistence of fogging conditions. Thus, a flight may be delayed several hours to as much as a day or two (Pratt, 1972). Fogging conditions at the airport cause significant economic damage each year, and any increase in fogging would contribute to the damages.

The most intensive study of fogging effects on air travel was completed by the Federal Aviation Administration in 1ate 1971. This FAA assessment included scheduled aircraft arrivals of first and second class U.S. air carriers, at 41 airports throughout the continental United States and Anchorage, AK. The actual costs are outdated and fail to reflect the drastic escalation of flight costs over the past few years (Weinstein, 1974). However, the worth of this study is not in the precise monetary assessment, but rather as an indication of the relative magnitude of the potential cost of fog disruption. If used as a base in which estimated increases of fog from waste heat are included, the FAA study could be quite helpful in indicating the degree of impact.

The FAA study separated the cost of fog disruption into flight delays, diversions, and cancellations. This approach was based on a procedure 
developed by United Research Incorporation (1962) for an earlier study entitled Economic Data Criteria for Federal Aviation Agency Expenditures. The cost components of fog disruption included interrupted trip expense, in-flight aircraft delay, passenger delay, ferrying expense for repositioned aircraft, cost of subsequent cancellation, passenger revenue loss, duplicate passenger handling, and savings in aircraft operating cost.

Variables included in this analysis were average number of passenger arrivals, direct aircraft operating cost per block hour, and the cost of passenger delays. The first estimates in Table 4.1 were based on previous reports with some adjustments made. These numbers were based on straightforward arithmetic calculations. The next calculation is a difficult but relevant estimate. The cost of passenger delay was computed from the Bureau of the Census data entitled 1967 Transportation Survey (United States Department of Commerce, 1969). Data was averaged on hourly family income of commercial air travellers. Estimates of this type are probably an indication, at best, of minumum impact of passenger delay as a result of flight disruption. As discussed earlier, economic theory suggests that the consumer's WTP that would reveal full social cost of passenger delays as a result of flight disruption could come from statistically estimating demand functions for different modes of travel.

The results of the study showed a large cost variation among airports throughout the U.S. Table 4.1 provides a range with John F. Kennedy International (New York) having the highest cost and Birmingham International (Alabama) the lowest. The cost of passenger delay was highest relative to all other costs, which emphasizes the need for an estimate based on theoretical rationale. The report concluded by recommending an in-depth costbenefit assessment for specific airport environments.

The Pratt (1974) analysis simulated weather sensitive landing at a specific location. This analysis was a cost-benefit comparison of landing techniques with limited visibility at McGuire Air Force Base in New Jersey. The costs were estimated for installation of fog dispersal and landing systems. The benefits and costs, measured in terms of increased efficiency of operating through the reduction of costs, included loss of productive flying 
and opportunity cost for delayed shipment. There was no cost applied to the aircrew because of the fixed salary of military personnel, thus eliminating comparison to civilian airports in terms of passenger delay. It should be noted that consumer surplus does exist for individual military personnel. This analysis developed a procedure for evaluating a specific location and is an example of the detailed type of analys is needed to value inadvertent weather modification resulting in increased fog.

Weinstein (1974) projected the interruption in airport runway operations resulting from fogging conditions. Twenty-five Air Force bases throughout the world were assessed for fog impact to aircraft. Using conservative estimates, the study projected that the traffic at the bases in the U.S. will be adversely affected by the fog 1 to $2 \%$ of the time. Provided in this study was a direct indication of the magnitude of the effect of fog on air traffic.

The various studies reviewed emphasized the economic damages of fog to air traffic. According to the FAA study the cost of fog to an airport is not only related to frequency of fog occurrences, but also to amount of flight disruptions and delays to customers. Because fog costs are not specific to geographic regions the estimation of economic damage from increased fogging is site specific. In order to quantify economic damages in monetary terms a site specific assessment would be required. Pratt's analysis offers an example of possible assessment methodology. However, a monetary assessment should be developed in this analysis for passenger delays. Neither the Pratt nor the Weinstein studies accounted for this cost. The FAA analysis indicated the magnitude of costs for passenger delay, but the approach lacked the conceptual framework. In terms of potential fog from energy centers, further assessments should be considered.

\subsubsection{Effects of Fogging on Ground Travel}

The potential for fogging due to the release of heat could interfere with ground traffic. The fogging impacts reviewed include the effects of accident rates, traffic delays, and a change in traffic patterns. 
Ground traffic interference is site specific; it depends on the location of roads or highways to the site in terms of the meteorological potential for fogging and also the traffic level on the road.

It is not clear that damage would be greater to ground traffic than to air traffic because the damage is site specific. Again, the relative magnitude of expenditures for accidents is no indication of relative or absolute damage. Only by estimating the change in consumer and producer surpluses can we estimate the relative and absolute impacts. The literature does provide some findings that are generic in scope and give some indication of the magnitude of the impact to ground traffic from increased fogging conditions.

A recent study on weather and road accidents by Codling (1974) assessed the economic consequences of weather. However, this analysis was made in England and it is not clear how it will apply to the United States. The conclusions were similar in some aspects to studies analyzing the United States' fogging conditions (Kochmond, 1970).

Codling (1974) reported that fog was estimated to increase injury accidents $16 \%$ when compared to clear weather. However, accidents after dark and those involving pedestrians were reduced significantly. It was also found that accidents involving several vehicles on fast roads increased.

Codling estimated that the average cost of an accident to be $t 1600$ or $\$ 3800$ in 1970 U.S. dollars. Included in this estimate are costs of medical treatment, damage to vehicles and property, administration costs of police and insurance, loss of output suffering, and bereavement. Not included in the average cost per accident were the delays to vehicles not directiy involved in the accident.

In an earlier report by Codling (1971) the effects of thick fog (visibility of 200 meters or less) on traffic flow of accidents were assessed. Based on historical meteorological data (1958-1967), thick fog was found to be relatively infrequent, patchy, localized, and of short duration. Only four week days of fog were analyzed because of sparse data. It was found that traffic flow was reduced on the average of $20 \%$, as a result of fewer people traveling in bad weather. Although accident rates increased 
$16 \%$, many types of accidents decreased. As noted earlier, decreases in pedestrian and after-dark accidents were reported. Further, there was no change found in fatal or serious accidents; this was attributed to decrease in traffic flow. However, slight injury accidents and casualties increased significantly during daylight hours.

A study by Cornell Aeronautics Lab (Kochmond, 1970) on highway fog was directed toward effective fog abatement and vehicle guidance systems. Speed was found to be reduced $4.5 \mathrm{mph}$ during the daylight hours when visibility distance decreased from more than 1,000 ft to approximately $250 \mathrm{ft}$. The ecomomic effects of the reduced speed were not estimated in this study. The probability of over-driving in fog was found to increase as the visibility decreases. The reduction in speed was not enough to reduce over-driving, especially under lower visibility conditions. Further, the Cornell study recommended research on the frequency of lower visibility conditions. It was not found that the net effect of fog was to increase the accident rate. Further, the multi-vehicle accident rate increased when four or more vehicles were involved along with increased fatal injuries. There was no monetary assessment of the fatal injuries or accidents. It is, therefore, not clear what the significance of the Cornell findings is in terms of fog interference to traffic.

This review of literature presented on the travel impacts of fog shows that the evaluations of these impacts were lacking conceptual framework. The economic approach to valuing fog should consider the value of change in traffic patterns and the delay of reduced traffic speed rather than just provide costs for accidents.

\subsubsection{Aesthetic Effect of Fog}

The psychological effects of reduced visibility caused by fog and visible plumes from an energy center or a single power plant is an aesthetic impact. This damage does not directly affect the financial wellbeing of its consumer, but it does influence the consumer's perceived quality of life. Aesthetics are nonexclusive in that their quality can be consumed without decreasing the availability of the goods for others. 
Generally aesthetics are difficult to value without gathering primary data. Genericaliy the valuing of the potential fog from an energy center is not feasible because of the site specific nature of the values.

A study conducted by New Mexico State University (Randa11, 1974) valuing the reduced aesthetics resulting from the Four Corners coal generating plant is a clear example of quantifying the environmental aesthetics. The only damage that was assessed was the reduction in long distance visibility and depth and color perception resulting from air pollutants. Other aesthetic damages included the strip mines and transmission lines. The objective of the study which was to estimate the benefits of abatements of the aesthetic damage by determining the WTP for environmental improvement.

The WTP was determined by bidding games through interview. Criteria for establishing the bidding game was that the situation presented be credible and realistic to the respondents. Freeloading is a problem because a view is nonexclusive. The benefits from abatement will be distributed to all consumers regardless of who pays abatement. Therefore, the bidding was designed to assure the respondent that all consumers will pay in a similar manner, thereby reducing this freeloader problem.

Three levels of environmental quality ranging from maximum environmental damage with little or no abatement to minimal environmental damages. By using yes or no questions the respondents were asked to identify the highest amount of money they were willing to pay to achieve the various environmental quality levels.

Various vehicles of payment were selected to determine the appropriate method for the various affected populations. The population was divided into residents of Indian reservations, other residents, and the tourists and recreationalists. The bidding games included the payment through sales tax, additional electric monthly payments, user fees, and compensation. The sales tax, electricity bill and the user recreation fee games were analyzed further. The nonrespondent rates from the electricity bill game indicated the respondents were offended by the assumption that receptors bear the costs of abateent. Also, compensation games involved situations which were less familiar and possibly not realistic or credible to respondents. 
The benefits of abatement which had taken place prior to 1972 were estimated from the bids to range between $\$ 11$ million and $\$ 15$ million a year. The benefits of complete abatement of emissions were estimated at $\$ 19$ million to $\$ 25$ million annually. These estimates were derived from the various bidding games. These aggregate bids are difficult to relate to because they depend on the level of population. Therefore, Table 2 presents information on the average individual bids at two levels of abatement. Further, the bids were separated into zones which were based on distance from the plant, assuming that the closer locations to the plant perceive greater aesthetic damage. The table bears this out.

TABLE 4.2. Average Bids in Dollars for Emission Control Levels

\begin{tabular}{cc}
$\begin{array}{c}\text { Intermediate } \\
\text { Control }\end{array}$ & $\begin{array}{c}\text { Complete } \\
\text { Control } \\
\text { (Some Emissions) }\end{array}$ \\
\hline
\end{tabular}

Residents Average Bid/Year

Zone 1 \& 2

52.51

82.62

Zone $3 \& 4$

43.72

70.91

Recreationalists Avg. Bid/Day

1.34

2.10

This study suggests that if fogging or visible plumes cause aesthetic environmental damage through obstruction of a view, then it will not be revealed to the market place. In order to determine the costs to society of the potential aesthetic impact from the thermal heat, further analysis is needed. However, the Four Corners assessment provided an example of the available assessment methodology and emphasized the monetary significance of a view.

Traffic interference and aesthetic impacts have been briefly reviewed. These are only a few examples of fogging effects. Additionally fog impacts agriculture, forestry, and recreation. A composite cost benefit assessment would consider all effects of increased fog. 


\subsection{Values of Precipitation, Humidity, Temperature}

Additional postulated weather modifications resulting from waste heat release include increased precipitation and humidity, changes in precipitation distribution and temperature.

\subsubsection{Agricultural Effects}

A short review of the literature follows to provide examples of current methodologies. However, this review is limited in scope and is not a composite of cost/benefit analyses.

Consider, for example, the total impacts of weather modification to the agricultural industry. For each there would be a private market supply and demand curve similar to those shown in Figure 4.1. If the costs and benefits of weather modifications are incorporated into the marginal social cost curve, the supply curve will shift to the right if weather modifications create benefits, and to the left if it is a cost. As discussed in the previous section, the changes in weather have many effects on agricultural yield, all of which need to be incorporated into the supply function. Valuing these impacts of weather modification is difficult and all encompassing. For example, increased rainfall may increase wheat yields but hamper the alfalfa hay harvest, thereby decreasing income from hay. In this situation there would be an increase in economic welfare for society only if the net benefits to wheat producers from weather modifications are greater than the net loss to alphalfa producers and they are compensated for their losses. However, questions of equity and compensation to alfalfa producers would also be important societal considerations and could not be ignored. Previous related studies that value weather modification in terms of agricultural impacts include Shaul (1975), Schmity (1975), Mayo (1975), and Development and Resource Corporation (1975).

\subsubsection{Recreational Effects}

Another example of a weather sensitive activity is recreation. An assessment by Gibbs (1973) provides some insight on valuing the influence of weather elements on recreation activity. Rainfall and temperature are identified as having an inverse relationship to use of selected 
recreation sites. Typically, rainfall has a major bearing on outdoor recreation. Temperature was also associated with the number of visiting recreationists, al though not necessarily significant with regard to energy center effects on weather.

An additional assessment by Gibbs (1973) was directed towards the measurement of the economic value of outdoor recreation for policy decisions. By placing economic values on recreation activities, alternative developments can be compared to determine the desirability of making an investment. The optimal fee levels, based on demand, could also be estimated in advance.

\subsubsection{Health Effects}

Health impacts resulting from changes in the macro-climate were assessed by estimating costs of health services and direct statistical estimates of health costs (Anderson 1975). Results of the estimates are hypothetical based on causal interpretation of regression relationships. But it was interpreted that an increase in $1 \mathrm{a} . \mathrm{m}$. humidity of one percentage point is associated with an increase in the total mortality rate of 0.285 per 10,000 people. Of further interest, a decrease of one day per year of $90^{\circ} \mathrm{F}$ maximum temperature was associated with an increase in total mortality rate of 0.082 per 10,000 people.

Health costs were divided into monetary costs of health care and the loss of output or time. Health care costs include the costs of physicians and hospital services and medication and were estimated from the regression results discussed above. The assessment's only conclusion was that health effects of weather modification need further investigation.

\subsubsection{General Quality of Life Effects}

Effects of weather conditions on the perceived quality of life were measured by Hoch (1974). Hoch's assessment supported the hypothes is that higher wages compensate for "bad" climate. Factors contributing to higher wages for a bad climate include additional heating/cooling expenses for housing, transportation, types of clothing, possible medical expenses, and also the nonmarket good of climate preference. 
The primary goal of Hoch's analysis was to estimate the climatic effects on real income. Twenty-five occupations were considered in three samples. The results concluded that the summer temperatures were the strongest variables. Also precipitation, wind velocity, and winter temperatures were often statistically significant.

An average summer temperature around $74^{\circ} \mathrm{F}$ is optimal, given an average amount of precipitation. Optimal summer temperatures are inversely related to precipitation, that is, an increase in precipitation decreases the optimal temperature. Geographically this would mean the climatic quality of the arid west would improve with precipitation, but the south would improve with less precipitation. The analysis of effects of changes in the weather on welfare were significant. In one case, an average temperature decline of $2.25^{\circ} \mathrm{C}$ and a $20 \%$ decline in precipitation were associated with a real income decrease of approximately $2 \%$.

\subsubsection{Effects of Tornado Damage}

An increase in the probability of a disaster such as a tornado endangers both property and human lives. Based on data compiled at the National Climatic Center, an average 655 tornadoes were reported annually in the United States during the period 1953 through 1971. These tornadoes produced an average property damage of $\$ 200$ million and caused an average of 18 deaths, and 200 injuries each year (Baldwin, 1973). These costs are related to geographic location, tornado strength, and type of man-made structures.

The methodology of evaluating a human life is relevant when considering a disastrous tornado. Various approaches are available for placing monetary values on a human life. A short review of two representative assessments follows.

Dubbin and Lutka (1946) measured the value of a life in terms of the present value of foregone earnings. Dubbin and Lutka's work as actuaries for Metropolitan Life Insurance Company has been used extensively in legal a proceedings. 
A different approach was used by Mishan (1971). The Mishan approach incorporated the compensating variation method which is the maximum amount people would be willing to pay to avoid a hazard (tornado) given a probability of physical injury or death from the hazard if it were to occur. This assessment is a more appropriate approach because it estimates a 11 costs and benefits.

\subsection{Summary of Economic Effects}

A brief theoretical statement was made which defined benefits and costs within a partial analysis framework. It was demonstrated how this framework is used to assess the effects of environmental impacts and how inadvertant weather modification should be analyzed within this conceptual framework.

Several empirical studies which related climatological indexes and factors to economic indicators and activity were reviewed. The purpose of the review was to evaluate the existing work with regard to (1) theoretical and methodological bases and (2) the availability of empirically derived estimates functions that could be used in a generic sense to evaluate the effects of inadvertant weather modifications.

None of the studies reviewed, with the exception of Randall and Gibbs, approached the problem from the point of view that willingness-to-pay was the appropriate measure of valuing a particular impact. Most studies used a basic expenditure approach which revealed only the amount that was paid, a minimum estimate of value.

All of the studies except Coding (1974) were site specific in nature. Therefore, bold assumptions would have to be made to generalize the results. Cross-sectional or pooled data (if they exist) would have to be used for estimating general functional forms relating inadvertant weather modification to economic impacts. 


\section{REFERENCES}

Amick, R. J. and J. C. Purce11, 1964, "Influence of Temperature on Food Conversion by Swine." J. of Farm Economics 46:1227-1231.

Anderson, Robert J., Jr., Lester Lave, Mark V. Pauly, 1975, "Health Costs of Changing Macroclimates, "Economic and Social Measures of Biological and Climatic Change: CIAP Monograph 6, DOT-TST-75-56, Prepared for the Department of Transportation Climatic Impact Assessment Program, Office of the Secretary of Transportation, Washington, D.C.

Arakawa, H., 1957, "Three Great Famines in Japan." Weather 12:211-217.

Austin, P. M. and R. A. Houze, Jr., 1972, "Analysis of the Structure of Precipitation Patterns in New England." J. App1. Meteor. 11:926-935.

Azevedo, J. and D. L. Morgan, 1974, "Fog Precipitation in Coastal California Forests." Ecology 55:1135-1141.

Baldwin, John L., 1973, Climates of the United States, NOAA, Washington, D.C.

Barber, F.R., A. Martin, J.G. Shepherd and G. Spurr, 1974, "The Persistence of Plumes from Natural Draft Cooling Towers." Atmos. Env. 8:407-418.

Bartels, H. and J.W. Casper, 1975, "Cooling-Tower Experience and the Meteorological Consequences of Thermal Discharges from Nuclear Power Plants in the Federal Republic of Germany." Environmental Effects of Cooling Systems at Nuclear Power Plants, International Atomic Energy Agency, Vienna, 85-98.

Battan, L.J. and R.R. Braham, 1956, "Study of Convective Precipitation Based on Cloud and Radar Observations." J. Meteor. 13:587-591.

Bea 11, Sam E., 1969, "Uses of Waste Heat". Oak Ridge National Laboratory, Oak Ridge, TN.

Bergman, K.H., 1970, On the Dynamic Stability of Convective Atmospheric Vortices. Ph.D. Thesis and Technical Report ECON-68G6-1, University of Washington, Seattle, WA.

Biscoe, P.V., R.K. Scott and J.L. Monteith, 1975, "Barley and its Environment III: Carbon Budget of the Stand," J. Appl. Ecol. 12:259-293.

Bode, L., L.M. Leslie and R.K. Smith, 1975, "A Numerical Study of Boundary Effects on Concentrated Vortices with Application to Tornadoes and Waterspouts." Quart. J.R. Met. Soc. 101:313-324.

Boyack, B.E. and D.W. Kearney, 1973, Plume Behavior and Potential Environmental Effects of Large Dry Cooling Towers. Gulf General Atomic Company, San Diego, CA, $176 \mathrm{pp}$. 
Brennan, P.T., D.E. Seymour, M.J. Butler, M.L. Kramer, M.E. Smith and T.T. Frankenberg, 1976a, "The Observed Rise of Visible Plumes from Hyperbolic Natural Draft Cooling Towers." Atmos. Env. 10:425-431.

Brennan, P.T., M.E. Smith, M.L. Kramer and R.W. Reeves, 1976b, "Behavior of Visible Plumes from Hyperbolic Cooling Towers." Presented at the 38th Annual Meeting, American Power Conference, Chicago, IL.

Briggs, G.A., 1969, Plume Rise. U.S. Atomic Energy Commission, Division of Technological Information.

Briggs, G.A., 1975, "Plume Rise from Multiple Sources." Cooling Tower Environment - 1974, 161-179.

Campbe11, G.S., 1968, "Feasibility of Using Reactor Coolant Water for Microclimate Modification in Irrigated Agriculture." Washington State University, Pullman, WA.

Campbe11, G.S., 1966, "Modeling Wheat Production." Unpublished Lecture Notes, Washington State University, Pullman, WA.

Changnon, S.A. and J.C. Nei11, 1968, "A Mesoscale Study of Corn-Weather Response on Cash-Grain Farms." J.Appl. Meteor. 7:94-104.

Changnon, S.A., Jr., and F.A. Huff, 1973, "Enhancement of Severe Weather by the St. Louis Urban-Industrial Complex. Conference on Severe Local Storms, 8th, Denver, C0, Oct 15-17, 1973, Preprints, Boston, Amer. Meteor. Soc., p. 122-129.

CIAP Monograph 5 Part 2 - Climatic Effects [Impacts of Climatic Effects on the Biosphere]. 1975, prepared for Department of Transportation C1imatic Impact Assessment program. Available as PB 247-726. National Technical Information Service, Springfield, VA 22151.

Codling, P.J., 1971, "Thick Fog and Its Effect on Traffic Flow and Accidents," Road Research Laboratory, Department of the Environment, RRL Report LR 397, Accident Analysis Section, Crowthorne, Berkshire, England.

Codling, P.J., 1974, "Weather and Road Accidents, "Climatic Resources and Economic Activity, Newton Abbot, pp. 205-222.

Coligado, M.C. and D.M. Brown, 1975, "Response of Corn (Zea Mays L.) in the Pre-Tassel Initiation Period to Temperature and Photoperiod." Agric. Meteor. 14:357-367.

Cooper, C.F., and W.C. Jolly, 1979, Ecological Effects of Weather Modification: A Problem Analysis. National Technical Information Service PB 185767.

Czapski, U, 1968, "Possible Effects of Thermal Discharges to the Atmosphere." Proceedings Fifth Annual Environmental Health Research Symposium, New York State Dept. of Health, New York, NY. 
Daubenmire, R., 1956, "Climate as a Determinant of Vegetation Distribution in Eastern Washington and Northern Idaho." Ecological Monographs 26:131154.

Daubenmire, R.F., 1974, Plants and Environment: A Textbook of Plant Autecology. Third edition, John Wiley, New York, NY, 422 pp.

Dettwiller, J.W. and S.A. Changnon, Jr., 1976, "Possible Urban Effects on Maximum Daily Rainfall at Paris, St. Louis and Chicago." J. Appl. Meteor. 15:517-519.

Development and Resource Corporation, 1975, "Economic Consequences of Projected Temperature Changes in Climatically Sensitive Wheat-Growing Areas of the Canadian Prairies," ... CIAP Monograph 6, Final Report, DOT-TST-75-56, Prepared for Department of Transportation CTimatic Impact Assessment Program, Office of the Secretary of Transportation, Washington, D.C.

Dubbin, Louis I. and Alfred J. Lotka, 1946, The Money Value of a Man, Ronald Revised Edition.

Edmonds, P.R., H.R. Roffman and R.C. Maxwe11, 1975, "Some Terrestrial Considerations Associated with Cooling Tower Systems for Electrical Power Generation." In: Cooling Tower Environment - 1974, Hanna and Pell (ed.) ERDA Symposium Series; CONF. 740-302, NTIS, Springfield, VA 22161.

EG\&G, Inc., 1971, Potential Environmental Modification Produced by Large Evaporative Cooling Towers. Environment Services Operation, Boulder, CO, Jan 1971, for the Water Quality Office, EPA, Program No. 16130 DNH 01/71, Contract No. 14-12-542.

Elliott, R.D. and E.L. Hovind, 1964, "The Water Balance of Orographic Clouds." J.Appl. Meteor. 3:235-239.

Federal Aviation Administration, 1971, Potential Economic Benefits of Fog Dispersa 1 in the Terminal Area, Part I: Estimating Procedure, (Final Report), Report No. FAA-RD-7T-44-T, Prepared for the Department of Transportation, Washington, D.C. Potential Economic Benefits of Fog Dispersal in the Terminal Area, Part II: Findings, (Final Report), Report No. FAA-RD-71-44-11, Prepared for the Department of Transportation, Federal Aviation Administration, Systems Research and Development Service, Washington, D.C.

Fritschen, Leo J. and Paul Doraiswamy, 1973, "Dew: An Addition to the Hydrologic Balance of Douglas Fir." Water.

Gates, David M., 1963, "The Energy Environment in Which We Live," Amer. Sci., $51: 327-348$.

Gates, David M., 1965, "Energy, Plants and Ecology." Ecology 46:1-13.

Gibbs, Kenneth C., 1973, A Measure of Outdoor Recreational Usage, University of Florida, Gainesville, FL. 
Glaser, A.H., 1975, Tornado Studies. Final Report, A\&M Project 129- Reference 57-3F, Dept. of Oceanography and Meteorology, College Station, TX.

Graham, H.E., 1955, "Fire Whirlwinds." Bul1. Amer. Meteor. Soc. 36:99-103.

Hane, C.E. and R. Drake, 1975, Atmospheric Effects of Nuclear Energy Centers Monthly Progress Report, H.W. Hoffman and I. Spiewak, (eds.), Oak Ridge Nationa 1 Laboratory, 7-11.

Hanks, R.J., 1974, "Model for Predicting Plant Yield as Influenced by Water Use." Agron. J. 66:660-665.

Hanna, Steven R. and Searle D. Swisher, ;07;. "Meteorological Effects of the Heat and Moisture Produced by Man." Nuclear Safety 12:114-122.

Hanna, S.R., 1972, "Rise and Condensation of Large Cooling Tower Plumes." J. Appl. Meteor. 11:793-799.

Hanna, S.R. and F.A. Gifford, 1974, "Meteorological Effects." In: Evaluation of Nuclear Energy Centers, Vol. 2 - Appendices, WASH-1288, 73-75, 1974.

Hanna, S.R. and F.A. Gifford, 1975, "Meteorological Effects of Energy Dissipation at Large Power Parks." Bu11. Amer. Meteor. Soc. 56:1069-1076.

Havera, Stephen P., 1973, "The Relationship of Illinois Weather and Agriculture to the Eastern Cottontail Rabbit." Technical Report No. 4, I1linois Precipitation Enhancement Program, Phase 1. Illinois State Water Survey.

Hegarty, T.W., 1973, "Effects of Total Solar Radiation and Temperature on Vegetative Growth in the East of Scotland." J. Appl. Ecol. 10:145-156.

Hendrick, Robert L., 1959, "An Outdoor Weather-Comfort Index for the Summer Season in Hartford, Connecticut." Bu11. Amer. Meteor. Soc. 12:620-623.

Hi11, G., 1974, "Factors Controlling the Size and Spacing of Cumulus Clouds as Revealed by Numerical Experiments." J.Atmos. Sci. 31:646-673.

Hoch, Irving and Judith Drake, 1974, "Wages, Climate, and the Quality of Life," Journal of Environmental Economics and Management 1: 268-295.

Hoddinott, M.H.0., 1960, "Funnel Cloud at Chester, 28 July 1959." The Meteorological Magazine 89(1053):124-125.

Huda, A.K. Samsul, B.P. Ghildyal, V.S. Tomar and R.C. Jain, 1975, "Contribution of Climatic Variables Predicting Rice Yield." Agric. Meteor. 14:71-86.

Huff, F.A. and S.A. Changnon, 1973, "Precipitation Modification by Major Urban Areas." Bul1. Amer. Meteor. Soc. 54:1220-1232.

Idso, S.B., 1974, "Tornado or Dust Devi1: The Enigma of Desert Whirlwinds." American Scientist 62:530-541. 
Ingram, R.S., 1973, Arizona "Eddy" Tornadoes. NOAA Tech. Memo. MWS WR 91, U.S. Dept. of Commerce, Western Region, Salt Lake City, UT.

Johns, R.W., R. J. Folwe11, R.T. Dailey, and M.E. Wirth, 1971, "Agricultural Alternatives for Utilizing Off-Peak Electrical Energy and Cooling Water." Department of Agricultural Economics, Washington State University, Pullman, WA.

Kaima1, J.C. and J.A. Businger, 1970, "Case Studies of a Convective Plume and a Dust Devi1." J.App1. Meteor. 9:612-620.

Kessler, E., 1969, "On the Distribution and Continuity of Water Substance in Atmospheric Circulation." Meteor. Monogr. 10, No. 32, 84 pp.

Kochmond, Warren C. and Kenneth Perchonok, 1970, Highway Fog, National Cooperative Highway Research Program Report 95, Highway Research Board, Division of Engineering, National Research Council, National Academy of Sciences National Academy of Engineers, Cornell Aeronautical Laboratory, Buffalo, NY.

Koenig, L.R. and C.M. Bhumralkar, 1974, "On Possible Undesirable Atmospheric Effects of Heat Rejection from Large Electric Power Centers." R-1628-RC, Rand, $40 \mathrm{pp}$.

Konstantinov, A.R., L.I. Sakaly and L.S. Daigot, 1974, "The Signficance of the Components of Heat and Water Balances in the Formation of Micro- and Local Climate." Proceedings of the Symposium on Physical and Dynamic Climatology 1974, WMO No. 347, Leningrad, 400 pp.

Kramer, M.L., M.E. Smith, M.J. Butler, D.E. Seymour and T.T. Frankenberg, 1976, "Cooling Towers and the Environment" J. Air Poll. Control, 26:582584.

Landsberg, H.E., 1962, "City Air -- Better or Worse." Symposium: Air Over Cities, U.S. Public Health Service, Taft Sanitary Engineering Center, Cincinnati, $\mathrm{OH}$, Technical Report A62-65, 122 pp.

Landsberg, H.E., 1969, Weather and Health. Anchor Books, Doubleday and

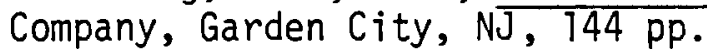

Landsberg, H.E., 1972, "The Assessment of Human Bioclimate, a Limited Review of Physical Parameters." WMO Technical Note No. 123. World Meteorological Organization, No. 331, Geneva.

LeBTanc, L.L. and K.C. Brundidge, 1969, "A Numerical Experiment in Predicting Stratus Clouds." J. App1. Meteor. 8:177-189.

Lee, S.L. and L.M. Hellman, 1974, "Heat and Mass Transfer in Fire Research." Advances in Heat Transfer Vol. 10, Acad. Press, New York, NY, 219-284. in the Planetary Boundary Layer." J. Atmos. Sci. 30:1077-1091. 
Leslie, L.M. B.R. Morton and R.K. Smith, 1970, "On Modelling Tornadoes." Quart. J.R. Met. Soc. 544-549.

Linacre, E.T., 1964, "Calculations of the Transpiration Rate and Temperature of a Leaf." Archiv for Meteor., Geophys. and Bioclimatol, Series B, 13:391399.

Lomas, J.E., Schlesinger and J. Lewin, 1974, "Effects of Environmental and Crop Factors on the Evapotranspiration Rate and Water Use Efficiency of Maize." Agric. Meteor. 13:239-251.

Lopez, R.E., 1973, "A Parametric Model of Cumulus Convection." J.Atmos. Sci. 30: 1354-1373.

Ma1kus, J.S., 1963, "Tropical Rain Induced by a Smal1 Natural Heat Source." J. App 1. Meteor. 2:547-556.

Malkus, J.S. and M.E. Stern, 1952, "The Flow of a Stable Atmosphere Over a Heated Island." J. Meteor. 10:30-41.

Markee, E.H., Jr., J.G. Beckerley and K.E. Sanders, 1974, Technical Basis for Interim Regional Tornado Criteria, WASH-1300, U.S. Atomic Energy Commission, Washington, D.C.

Marlatt, W.E., 1967, "The Effect of Weather Modification on Physical Processes in the Microclimate." Ground Level Climatology. R.H. Shaw, ed., AAAS, Washington, D.C., pp. 295-308.

Martin, A., 1974, "The Influence of a Power Station on Climate - A Study of Local Weather Records." Atmos. Env. 8:419-424.

Mather, John R., 1974, Climatology Fundamentals and Application. McGraw Hil1, New York, NY, 412 p.

Mayo, David McMilliam, 1975, "Economic Estimates of the Climatic Induced Changes in the World Wheat Production." ... CIAP Monograph 6, Final Report, DOT-TST 75 56, Prepared for the Department of Transportation, Climatic Impact Assessment Program, Office of the Secretary of Transportation Washington, D.C.

McCree, K.J. and M.E. Keener, 1974, "Effect of Atmospheric Turbidity on the Photosynthetic Rates of Leaves." Agric. Meteor. 13:349-357.

McQuigg, James D., 1975, Economic Impacts of Weather Variability. Atmospheric Science Department, University of Missouri, Columbia under NSF grant No. GI37218X.

McVehi1, G.E., 1971, "Evaluation of Atmospheric Effects for Cooling Towers and Cooling Lakes. Proposed Plant Site Y." Sierra Research Corporation, Environmental Systems Group, Commonwea Tth Edision Company, Boulder, CO, $58 \mathrm{pp}$. 
Mishan, C., 1971, "Evaluation of Life and Limb: A Theoretical Approach," Journal of Political Economy.

Monteith, John L., 1973, Principles of Environmental Physics. American Elsevier Publishing Company, New York, NY, 241 pp.

Moore, D.J., 1975, "Recent Central Electricity Generating Board Research on Environmental Effects of Wet Cooling Towers." Cooling Tower Environment 1974, pp. 205-220.

Morton, B.R., 1966, "Geophysical Vortices." Progress in Aeronautical Sciences Vol. 7, Pergamon Press, 145-194.

Morton, B.R., 1969, "The Physics of Fire Whirls." GFDL Paper 19, Geophysical Fluid Dynamics Laboratory, Monash University, Australia.

Moser, B.C., 1975, "Airborne Sea Salt: Techniques for Experimentation and effects on vegetation," in Cooling Tower Environment-1974, ERDA Symposium Series; CONF-740302, pp. 353-369.

Munn, R.E., 1970, Biometeorological Methods. Academic Press, New York, NY, $336 \mathrm{pp}$.

Murata, Yoshio, 1975, "Estimation and Simulation of Rice Yield from Climatic Factors." Agric. Meteor. 15:117-131.

Namken, L.N., C.I. Wiegand and W.0. Willis, 1974, "Soi1- and Air-Temperature as Limitations to More Efficient Water Use." Agric. Meteor. 14:169-181.

Oak Ridge Staff, 1974, Evaluation of Nuclear Energy Centers, Vol. 2, Appendix 2: Analysis of the Gulf States Utilities River Bend Site for a Nuclear Energy Center. Prepared by Nuclear Energy Center Evaluation Task Force Under the Direction of the Division of Reactor Research and Development.

Parr, R.D., F.G. Taylor and J.J. Beauchamp, 1976, "Sensitivity of Tobacco to Chromium from Mechanical Draft Cooling Tower Drift,: Atmos. Envir., 10:421423.

Porter, Warren P. and David M. Gates, 1969, "Thermodynamic Equilibria of Animals with Environment." Ecol. Mon. 39:227-244.

Petterson, S., 1956, Weather Analysis and Forecasting - Vol. II, Weather and Weather Systems. McGraw-HilT Book Co., Inc., p. 87.

Pratt, Thomas E., 1972, Simulation of Weather Sensitive Landing Aids: A Cost Comparison, A Thesis Presented to the Faculty of the Graduate School at the University of Missouri in partial fulfillment of the Requirements for the 1. Degree of Masters of Science. 
Ramsde11, J.V., R.L. Drake and J.R. Young, 1976, "The Significance of Atmospheric Effects of Heat Rejection from Energy Centers in the Semi Arid Northwest." Presented at the 69th Annual Meeting, Air Pollution Control Association, Portland, OR.

Ramsde11, J.V., 1977, Impact of a Hanford Nuclear Energy Center on Ground Level Fog and Humidity, BNWL-2058, Battelle, Pacific Northwest Laboratories, Richland, WA.

Randa11, Allan, Berry C. Ives, and Clyde Eastman, 1974, "Benefits of Abating Aesthetic Environmental Damage from the Four Corners Power Plant, Fruitland, New Mexico." Agricultural Experiment Station, New Mexico State University, 40 pp., Las Cruces, NM.

Reifsnyder, W.E. and H.W. Lul1, 1965, "Radiant Energy in Relation to Forests." USDA-Forest Service Technical Bulletin No. 1344, 111 pp., Washington, D.C.

Roffman, A., 1975, "Environmental, Economic, and Social Conditions in Selecting a Cooling System for a Steam Electric Generating Plant." In:Cooling Tower Environment - 1974, Hanna and Pel1 (ed.), ERDA Symposium Series; CONF740-302, NTIS, Springfield, VA 22161.

Rosenberg, Norman J., 1974, Microclimate: The Biological Environment. John Wiley, New York, NY, 315 pp.

Rotty, R.M., 1974, Waste Heat Disposal from Nuclear Power Plants. ERL ARL43, NOAA Technical Memorandum, Air Resources Laboratory, Silver Springs, MD, $28 \mathrm{pp}$.

Schlesigner, R.E., 1972, "A Numerical Model of Deep Moist Convection, the Influence of Ambient Conditions and Internal Physical Mechanisms. "Annual Report, 1971, Studies of the Atmosphere Using Aerospace Probings, Vo 1. 1: Theoretical Studies. Space Science and Engineering Center, University of Wisconsin, 149-356.

Schmity, A., S. Anderson, T. Bigg, and A. Anderson, 1975, "Climatic Changes and Agriculture: A Case Study of Wheat," ... CIAP Monograph 6, (Final Report), DOT-TST-75-56, Prepared for the Department of Transportation, Climatic Impact Assessment Program, Office of the Secretary of Transportation, Washington, D.C.

Scott, B.C., 1970, "Raflux - A Numerical Model for Calculating the Long Wave Radiative Transfer in the Troposphere." PNL Annual Report for 1969 to the USAEC-DBER, Pt. 1, Atmos. Sci., 62-68.

Scott, B.C., 1976, A Theoretical Study of the Evolution of Mixed Phase Cumulus Clouds. Ph.D. Dissertation, University of Washington, $269 \mathrm{pp}$.

Screenivasan, P.S., 1974, "Influence of Rainfall on Wheat Varieties at Jalgam and Niphad." Agric. Meteor. 13:267-278. 
Seneca, Joseph J. and Michael K. Taussig, 1974, Environmental Economics, Prentice Hall, Inc., Englewood Cliffs, NJ.

Shaul, B, and William SchuTze, 1975, "Economic Impact of Climatic Change on World Agriculture: Benefit-Cost Analys is for Cotton and Corn," Economic and Social Measures of Biological and Climatic Change: CIAP Monograph 6, Fina T Report - DOT-TST076056, Prepared for the Department of Transportation Climatic Impact Assessment Program, Office of the Secretary of Transportation, Washington, D.C.

Skaggs, Richard H., 1969, "Analysis and Regionalization of the Diurnal Distribution of Tornadoes in the United States," Mon. Wea. Rev., 97: 103- 115.

STinn, W.G.N., 1975, "A Suggested Concept for Dynamic Weather Modification Utilizing Large Atmospheric Heat Releases to Stimulate Cumulonimbus Clouds." PNL Annual Report for 1974 to the USAEC-DBER, Pt. 3, Atmos. Sciences, 253-256.

Simpson, J.S., and V. Wiggert, 1969, "Models of Precipitating Cumulus Towers." Mon. Wea. Rev. 97:471-489.

Smith, L.P., 1974, "The Influence of Temperature and Sunshine on the AlphaAcid Content of Hops," Agric. Meteor., 13:375-382.

Soong, S., 1974, "Numerical Simulation of Warm Rain Development in an Axisymetric Cloud Model." J.Atmos. Sci. 31:1262-1285.

Spurr, G., 1974, "Meteorology and Cooling Tower Operation." Atmos. Envir. 8: $321-324$.

Spurr, G. and R.A. Scriven, 1975, "United Kingdom Experience of the Physical Behavior of Heated Effluents in the Atmosphere and in Various Types of Aquatic Systems." Environmental Effects of Cooling Systems at Nuclear Power Plants, International Atomic Energy Agency, Vienna, 227-248.

Stone, W.A., D.E. Jenne, and J.M. Thorp, 1972, Climatography of the Hanford Area. BNWL-1605, UC-53, Battelle, Pacific Northwest Laboratories, Richland, WA.

Stout, G.E., 1961, "Some Observations of Cloud Initiation in Industrial Areas." Symposium, Air Over Cities, SEC Tech. Report A62-5, 147-153.

Taylor, D.F. and D.T. Williams, 1968, "Severe Storm Features of a Wildfire." Agric. Meteor. $5: 311-318$.

Taylor, R.J., S.T. Evans, N.K. King, E.T. Stephens, D.R. Packham and R.G. Vines, 1973, "Convective Activity Above a Large Scale Brushfire." J. Appl. Meteor. 12:1144-1150.

Tanner, C.B., 1968, "Evaporation of Water from Plants and Soil," In: Water Deficits and Plant Growth, T.L. Kazlowski, ed., Academic Press, New York. 
United Research, Inc., Economic Criteria for Federal Aviation Agency Expenditures, Cambridge, MA, June 1962.

United States Department of Commerce, 1969, 1967 Transportation Survey, Bureau of the Census, Washington, D.C.

United States Weather Bureau, 1952, Mean Number of Thunderstorm Days in the United States. Technical Paper No. 19, prepared by Climatological Services Division, Asheville, NC, 24 pp.

Vukovich, F.M., J.W. Dunn III and B.W. Crissman, 1976, "A Theoretical Study of the St. Louis Heat Island: The Wind and Temperature Distribution."

J. Appl. Meteor. 15:417-440.

Wallach, Daniel, 1975, "The Effect of Environmental Factors on the Growth of a Natural Pasture," Agric. Meteor., 15:231-244.

Weinstein, A.I. and L.G. Davis, 1968, A Parameterized Numerical Model of Cumulus Convection. Rpt. 11, NSF GA-777, 43 pp.

Weinstein, A.I., 1970, "A Numerical Model of Cumulus Dynamics and Microphysics," J. Atmos. Sci. 27:246-255.

Weinstein, Alan I., 1974, Projected Interruptions in Airport Runway Operations Due to Fog, AFCRL-TR-75-0978 (Air Force Surveys in Geophysics, No. 307), Meterorology Laboratory Project 7605, Air Force Cambridge Research Laboratories, Hanscom AFB, Massachusetts.

Witherspoon, 1972. Beneficial Use of Waste Reaction Heat from a Forced Draft Cooling Tower for Heated Enclosures at Hanford. Master's Thesis, University of Washington, Seattle, WA.

Whittaker, R.H., 1962, "Ecological Impacts of Weather Modification." Grand Level Climatology, R.H. Shaw (ed.), AAAS, Washington D.C., pp. 367384 .

Young, K.C., 1974, "A Numerical Simulation of Wintertime, Orographic Precipitation: Part II. Comparison of Natural and AgI-Seeded Conditions." J. Atmos. Sci. 31:1749-1767. 


\section{APPENDIX A}

LIST OF SYMBOLS 


\section{APPENDIX A}

\section{LIST OF SYMBOLS}

$C_{p}=$ specific heat at constant pressure

$D=$ drop diameter

$E=$ collection efficiency

$\mathrm{e}_{\mathrm{s}}=$ saturation vapor pressure

$\dot{h}=$ rate of energy release

$L=$ latent heat of vaporization

$M=$ mass of hydrometeor (falling precipitation water, $\mathrm{g} \mathrm{m}^{-3}$ )

$M_{f}=$ final hydrometeor water content (after leaving the plume)

$M_{0}=$ initial hydrometeor water content (before entering the plume)

$m=$ mass of air

$m_{v}=$ molecular weight of water

$\mathrm{N}<\mathrm{D}>\mathrm{dD}$ the concentration of rain drops with diameters between $D$ and $D \pm \Delta D$

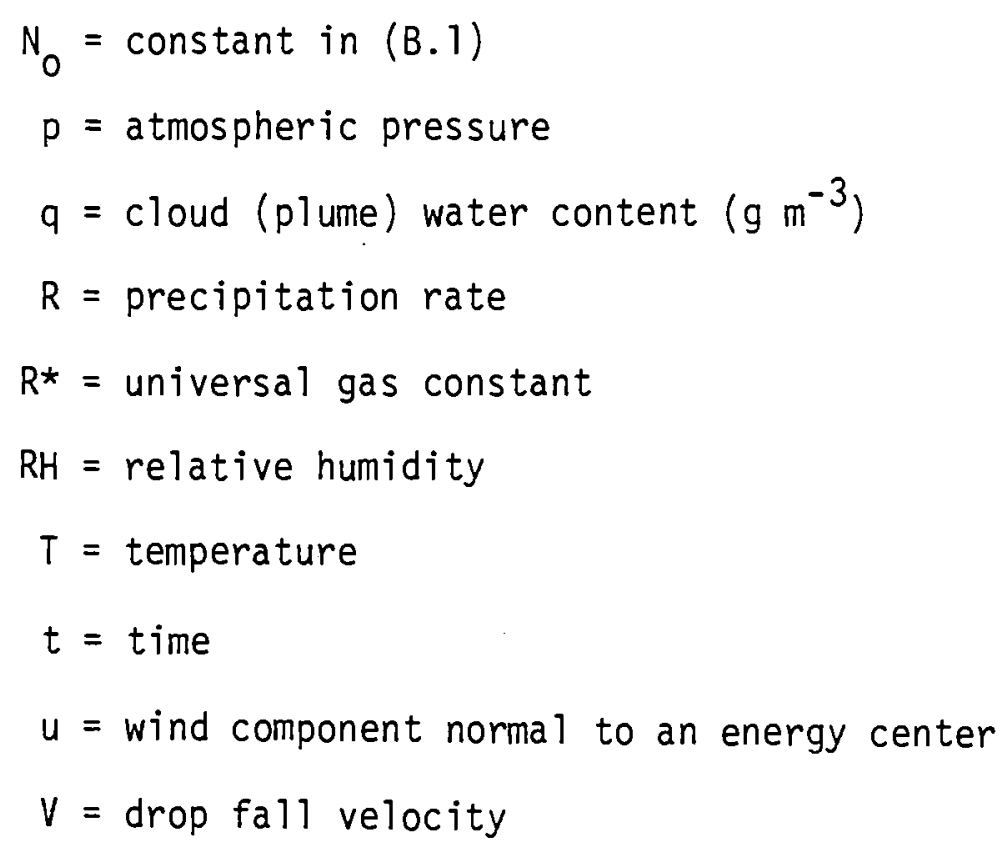




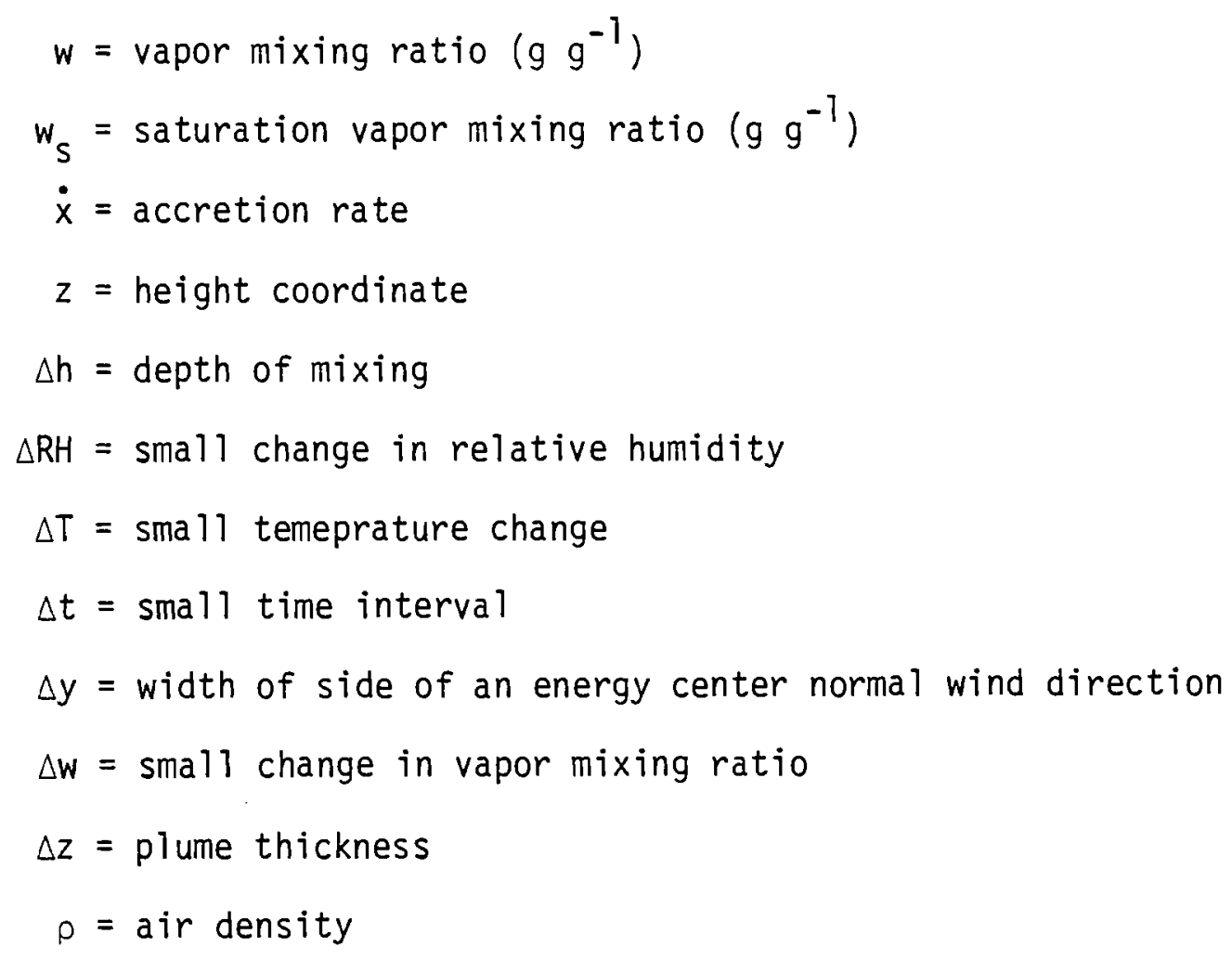


APPENDIX B

INCREASE IN P.RECIPITATION DUE TO

SEDIMENTATION THROUGH A PLUME OF THICKNESS $\Delta Z$ 


\section{APPENDIX B}

\section{INCREASE IN PRECIPITATION DUE TO}

\section{SEDIMENTATION THROUGH A PLUME OF THICKNESS $\Delta z$}

The total water mass accreted by a spectrum of rain drops passing through a uniform cloud is given by

$$
\frac{d M}{d t}=\int_{0}^{\infty} \dot{x} \quad N<D>d D
$$

From Kessler (1969), the righthand side of (B.I) can be expressed as

$$
\frac{d M}{d t}=6.96 \times 10^{-4} E_{0} q M^{7 / 8} .
$$

Rewriting the lefthand side of (B.I) as

$$
\frac{d M}{d t}=\frac{d M}{d z} \frac{d z}{d t}
$$

where $\frac{d z}{d t}=V$, the drop fall velocity, we obtain

$$
\frac{d M}{d z}=\frac{6.96 \times 10^{-4} E N_{0} q M^{7 / 8}}{v} .
$$

Again using Kessler's (1969) empirical expression for drop fall velocity $\left(V=38.3 \mathrm{~N}_{0}^{-1 / 8} \mathrm{M}^{1 / 8}\right)$ and integrating (B.4), we obtain

$$
M_{f}=\left[M_{0}^{1 / 4}+\frac{6.96 \times 10^{-4} E N_{0}^{1 / 4} q}{153} \Delta z\right]^{4} \text {. }
$$

The final precipitation rate, $R$, can be obtained from (Kessler, 1969)

$$
R=18.35 \mathrm{M}^{9 / 8} \mathrm{~mm} \mathrm{hr}^{-1} \text {. }
$$

For our calculations we have used $q=0.5 \mathrm{~g} \mathrm{~m}^{-3}, \mathrm{~N}_{0}=10^{7} \mathrm{~m}^{4}$ and $E=0.7$. 
$\bullet$

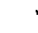


APPENDIX C

DEFINITIONS

If

II. 


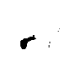

$\bullet$ 
Aerosol Number Concentration

Aerosol Size Distribution

Albedo

Ambient Rotation

Atmospheric Lapse Rate

Autecology

Capping Inversion

Climate Space

Cloud Street

Concentrated Convective Vortices

Conduction

Convection

Energy Center
Number of aerosol particles per unit volume.

Distribution of aerosol particles by size range. The distributions in moisture and continental air masses are different.

The fraction of the incoming solar energy reflected back to space by the earth and its atmosphere.

Rotation of the air prior to coming under the influence of an external force such as a large addition of energy.

Variation of temperature with height in the atmosphere.

Study of the interactions between an individual and its environment.

A layer of warm air that lies over cooler air. The density stratification that results tends to suppress vertical motions.

Conceptual combination of the conditions necessary for an organism's survival. The space is bounded by environmental factors such as temperature and humidity as well as physical considerations of volumes, etc.

A line of convective (cumulus) clouds.

Small scale atmospheric phenomena such as dust devils, waterspouts and tornadoes in which the air rotates rapidly.

Energy transfer by physical contact in a stationary medium.

Energy transfer by moving medium.

A group of 10 to 40 power plants located on a common site. Supporting facilities for the power plants may also be included. 
Evaporative Cooling

Forced Lifting

Frontal Precipitation

Heat Island

Homeotherms

Isopleth

Latent Heat

Lifting Condensation Level (LCL)

Low Level Buoyancy

MWe

Natural Draft Cooling Tower
The use of the evaporation of water to dissipate excess energy and maintain a low temperature. Examples of evaporative cooling systems are cooling ponds, cooling towers and once through cooling using river, lake or sea water.

Upward displacement of air as it moves over terrain or a more dense air mass.

Precipitation that occurs at the intersection of two air masses of different densities as the less dense air mass is lifted.

A region of warm air created by a release of energy or a change in thermal properties of the surface, or both.

Warm blooded animals.

A line connecting points of equal value.

The energy required to vaporize a liquid (water) and stored within the. vapor while in a gaseous state.

Height at which condensation occurs. in rising air.

An unstable atmospheric condition in which air rises because it is less dense than the surrounding air. The buoyancy can be caused by warming or the addition of moisture.

Megawatt of electrical power, generally refers to the visible output of a generating facility.

A cooling system in which the induced busy area of the air resulting from evaporation of water and warming drives the circulation. These towers are generally several hundred feet high. 
Orographic Precipitation

Orographic Systems

Photosynthesis

Poikilotherms

Radiant Energy

Sensible Heat

Solar Energy Flux

Stratiform Layer

Subsidence

Synoptic Scale Extratropical Cyclone

Thermal Power Plant

Thermal Radiation

Vorticity

Wet-Bulb Temperature
Precipitation that occurs as air is lifted over topographic features.

Weather systems in which the precipitation is caused by airflow over topographic features.

The process by which radiant energy is convected to chemical energy in plants.

Cold blooded animals.

See Thermal Radiation.

The energy used to increase temperature.

The amount of solar energy received per unit area per unit time.

A layer of clouds that occur in stable air in which there is relatively little vertical motion. These layers are characterized by uniform gray coloration.

Slow downwind movement of air in the center of a high pressure region.

A large scale weather system with a characteristic diameter of $1000 \mathrm{~km}$.

A power plant in which thermal energy is convected into electrical energy. The thermal energy may be derived from a number of sources including nuclear or fossil fuels.

Energy in the form of electromagnetic waves emitted from a body proportional to the fourth power of its temperature.

The tendency of a fluid to rotate.

The temperature determined by a thermometer cooled by evaporation of water from wick surrounding the bulb. 


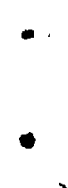

,

$-$

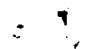


No. of

Copies

\section{OFFSITE}

Albert $P$. Kenneke

Office of Policy Evaluation Nuclear Regulatory Commission Washington, DC 20555

Robert B. Minogue Office of Standards Development Nuclear Regulatory Commission Washington, DC 20555

Roger J. Mattson

Office of Standards Development Nuclear Regulatory Commission Washington, DC 20555

I. Craig Roberts

Office of Standards Development Nuclear Regulatory Commission Washington, DC 20555

Edward E. Held Office of Standards Development Nuclear Regulatory Commission Washington, DC 20555

John B. Martin

Office of Nuclear Material

Safety and Safeguards

Nuclear Regulatory Commission

Washington, DC 20555

Richard B. Chitwood

Office of Nuclear Material

Safety and Safeguards

Nuclear Regulatory Commission

Washington, DC 20555

Bernard C. Rusche

Office of Nuclear Reactor

Regulations

Nuclear Regulatory Commission

Washington, DC 20555
No. of

Copies

Edson G. Case

Office of Nuclear Reactor Regulations

Nuclear Regulatory Commission Washington, DC 20555

Darrell G. Eisenhut

Office of Nuclear Reactor Regulations

Nuclear Regulatory Commission

Washington, DC 2.0555

Brian K. Grimes

Office of Nuclear Reactor Regulations

Nuclear Regulatroy Commission Washington, DC 20555

Harold R. Denton

Office of Nuclear Reactor Regulations

Nuclear Regulatory Commission Washington, DC 20555

Daniel R. Muller

Office of Nuclear Reactor Regulations

Nuclear Regulatory Commission Washington, DC 20555

Malcolm L. Ernst

Office of Nuclear Reactor Regulations

Nuclear Regulatory Commission Washington, DC 20555

Ronald L. Ballard

Office of Nuclear Reactor

Regulations

Nuclear Regulatory Commission Washington, DC 20555

B. Joe Youngblood

Office of INuclear Reactor

Regulations

Nuclear Regulatory Commission Washington, DC 20555 
No. of

Copies

Voss A. Moore

Office of Nuclear Reactor Regulations

Nuclear Regulatory Commission

Washington, DC 20555

George W. Knighton

Office of Nuclear Reactor

Regulations

Nuclear Regulatory Commission

Washington, DC 20555

William H. Regan, Jr.

Office of Nuclear Reactor

Regulations

Nuclear Regulatory Commission

Washington, DC 20555

William P. Gammill

Office of Nuclear Reactor

Regulations

Nuclear Regulatory Commission

Washington, DC 20555

Lewis C. HuTman

Office of Nuclear Reactor

Regulations

Nuclear Regulatory Commission

Washington, DC 20555

Earl H. Markee, Jr.

Office of Nuclear Reactor

Regulations

Nuclear Regulatory Commission

Washington, DC 20555

Frank G. Lowman

Office of Nuclear Reactor

Regulations

Nuclear Regulatory Commission

Washington, DC 20555

Jared J. Davis

Office of Nuclear Reactor

Regulations

Nuclear Regulatory Commission

Washington, DC 20555
No. of

Copies

Robert A. Gilbert

Office of Nuclear Reactor Regulations

Nuclear Regulatory Commission

Washington, DC 20555

25 Jan A. Norris

Office of Nuclear Reactor

Regulations

Nuclear Regulatory Commission

Washington, DC 20555

A.A. Churm

ERDA Chicago Patent Group

9800 S. Cass Ave.

Argonne, IL 60439

Laura Henning

Electric Power Research Institute P.0. Box 10412

Palo Alto, CA 94304

2 Theodore Beresovski, Chief

Advanced Concepts

Energy Research and Development Administration

Mail Stop F-309

Washington, DC 20545

27 ERDA Technical Information Center

Energy Facility Site Evaluation Councit

820 East Fifth Avenue

Olympia, WA 98504

W.K. Woods

Oregon State Energy Office

528 Cottage N.E.

Salem, OR 97310

D. Eisenberg

Oak Ridge National Laboratory

P.0. Box Y

Oak Ridge, TN 37830 
No. of

Copies

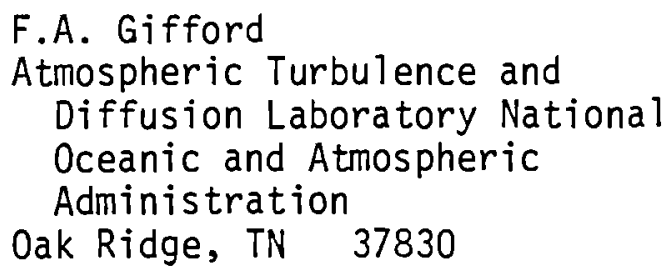

Oak Ridge, TN 37830

\section{ONSITE}

1 ERDA Richland Operations Office

36 Battelle-Northwest

E.C. Christopherson

J.G. Droppo

D.L. Elliott

R.F. Foster

J.J. Fuquay

H. Harty (5)

K.A. McGinnis

M.M. Orgill

J.V. Ramsde11 (10)

D.S. Renné

W.F. Sandusky

B.C. Scott

R.D. Widrig

K.E. Yandon

J.R. Young

Technical Information (5)

Technical Publications (3) 


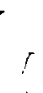
$-4$ 